\title{
Products consisting of materials based on renewable resources: Drivers of purchase intention, consumers' information needs and target groups
}

\author{
Dissertation \\ zur Erlangung des Doktorgrades \\ der Wirtschaftswissenschaftlichen Fakultät \\ der Georg-August-Universität Göttingen \\ (Dr. rer. pol.)
}

\author{
vorgelegt von \\ Victoria-Sophie Osburg \\ geboren in Göttingen
}

Göttingen, 2015 
Erstbetreuer:

Weitere Betreuer:
Prof. Dr. Waldemar Toporowski

Prof. Dr. Lutz M. Kolbe

Prof. Dr. Margarete Boos

Tag der mündlichen Prüfung: 13.05.2015 
This thesis is dedicated to my parents.

Thank you for your endless love and support. 


\section{Acknowledgements}

Above all, I am thankful for the constant and reliable support provided by my supervisor, Prof. Dr. Waldemar Toporowski. He gave me the freedom to pursue the projects I was interested in and gave me his advice at crucial points. I thank Prof. Dr. Lutz Kolbe and Prof. Dr. Margarete Boos for being my second and third examiners and for encouraging me to engage in this interdisciplinary work. Additionally, I am grateful for the support that I have received from Prof. Dr. Jutta Geldermann and I thank Prof. Dr. Matthias Schumann for his feedback. I owe special thanks to PD Dr. Micha Strack who provided great encouragement and support since supervising my Bachelor thesis.

I am grateful for the financial support that I have received from the German Research Foundation (DFG; Deutsche Forschungsgemeinschaft). It was a great experience belonging to the DFG Research Training Group 1703 'Resource Efficiency in Interorganizational Networks - Planning Methods to Utilize Renewable Resources'. Working together with its members and my colleagues from the Chair of Retailing required creative thinking and led to common projects and helpful suggestions for improving this thesis. Even though many colleagues supported me, I particularly thank Shanna Appelhanz for our remarkable collaborations and Laura Teuber for various discussions about material characteristics. While visiting the University of Auckland Business School, I also received valuable feedback from the members of its marketing department, especially from Dr. Denise Maria Conroy.

Beyond that, my deepest thank goes to my family and friends for encouraging me and simply being around in all phases of my doctorate. I particularly thank my parents, Betina and Dr. Bernward Osburg, for their love, trust and support not only during my doctorate but also in all stages of my life. 


\section{Contents}

List of Tables $\quad$ IV

List of Figures $\quad$ V

List of Abbreviations $\quad$ VI

1 Introduction 1

1.1 Relevance of consumer acceptance of products based on renewable resources 1

1.1.1 The necessity for material utilizations of renewable resources . . . . 1

1.1.2 Traditional and innovative materials based on renewable resources . 2

1.1.3 Related consumer research . . . . . . . . . . . . . . . . 3

1.2 Framework and objectives . . . . . . . . . . . . . . . . 4

1.2.1 Research Training Group 1703 'Resource Efficiency in Interorganizational Networks' . . . . . . . . . . . . . . . . . . . 4

1.2.2 Cascading utilization . . . . . . . . . . . . . . 5

1.2.3 The B2C perspective and objectives of the project . . . . . . . . 6

1.3 Outline of the projects . . . . . . . . . . . . . . 8

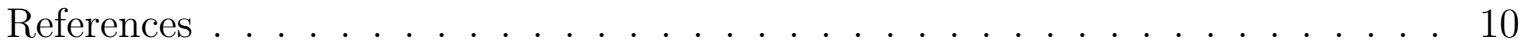

2 An empirical investigation of wood product information valued by young $\begin{array}{lr}\text { consumers (Paper 1) } & 16\end{array}$

2.1 Introduction . . . . . . . . . . . . . . . . . . . 17

2.2 Current state of research . . . . . . . . . . . . . . . . . . . . . 19

2.2.1 Retrieval of product information at the point of sale . . . . . . . . 19

2.2.2 Relevance of product information for the purchase decision . . . . . 19

2.2.3 Provision of wood product information to consumers . . . . . . . . 20

2.3 Methods . . . . . . . . . . . . . . . . . . . . . 21

2.3.1 Procedure and participants . . . . . . . . . . . . . 21

2.3.2 Selection of wood product information . . . . . . . . . . . . 22

2.3 .3 Measures . . . . . . . . . . . . . . . . . . 23

2.3 .4 Data analyses . . . . . . . . . . . . . . . . 23

2.4 Results . . . . . . . . . . . . . . . . . . . . 23

2.4.1 Relevance of product information items and a comparison to other drivers of the purchase decision . . . . . . . . . . . . . 23

2.4.2 Consumer segments and their information demand . . . . . . . . 25

2.4.3 Young consumers' information retrieval preference . . . . . . . . . . 26

2.5 Discussion and managerial implications . . . . . . . . . . . . . . . . 27

2.6 Limitations and suggestions for future research . . . . . . . . . . . . . . 29

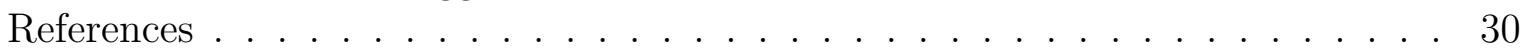

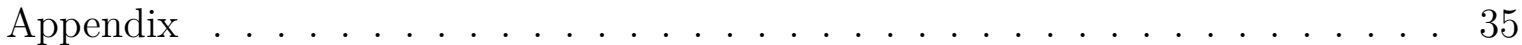

3 Consumer acceptance of Wood-Polymer Composites: a conjoint analytical approach with a focus on innovative and environmentally concerned $\begin{array}{lr}\text { consumers (Paper 2) } & 36\end{array}$

3.1 Introduction . . . . . . . . . . . . . . . . . 37

3.2 Literature Review . . . . . . . . . . . . . . . . . . . . . . 37

3.2.1 Consumers' green purchasing behavior . . . . . . . . . . . . . 37

3.2.2 Consumer acceptance of WPC products . . . . . . . . . . . . . 38 
3.2.3 Important consumer segments for WPC products . . . . . . . . . . 40

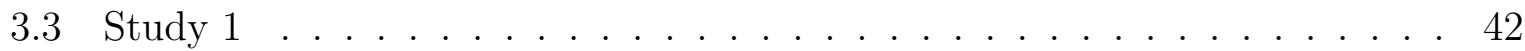

3.3 .1 Methods . . . . . . . . . . . . . . . . . . . 42

3.3.2 Results............................ . . . 44

3.3.3 Discussion . . . . . . . . . . . . . . . . . 46

3.4 Study $2 \ldots \ldots \ldots \ldots \ldots \ldots \ldots$

3.4 Methods . . . . . . . . . . . . . . . . 46

3.4 Results . . . . . . . . . . . . . . . . . . 47

3.4 .3 Discussion . . . . . . . . . . . . . . . . 50

3.5 General Discussion . . . . . . . . . . . . . . . . 50

3.5.1 Practical implications . . . . . . . . . . . . . . . 52

3.5.2 Limitations and suggestions for future research . . . . . . . . . . . 52

3.6 Conclusions . . . . . . . . . . . . . . . . . . . . 53

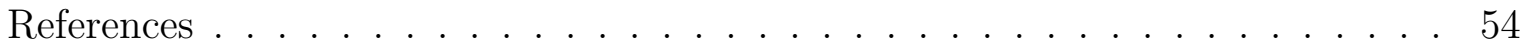

4 An empirical investigation of the determinants influencing consumers' planned choices of eco-innovative materials (Paper 3) 59

4.1 Eco-innovative materials facilitating efficient resource utilization . . . . . . 60

4.2 Literature review . . . . . . . . . . . . . . . . . . . 60

4.2.1 WPCs and their acceptance by consumers . . . . . . . . . . . 60

4.2.2 Predicting eco-friendly consumption based on the Theory of Planned

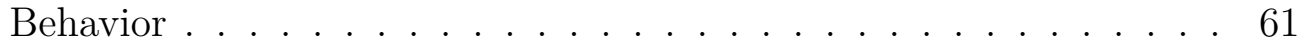

4.3 Methods . . . . . . . . . . . . . . . . . . . . 63

4.3.1 Participants and procedure . . . . . . . . . . . 63

4.3 .2 Measures . . . . . . . . . . . . . . . . . . . 64

4.3 .3 Data analyses . . . . . . . . . . . . . . . . 65

4.4 Results . . . . . . . . . . . . . . . . . . . 66

4.4 Descriptive statistics . . . . . . . . . . . . . . . 66

4.4.2 Test of the proposed TPB model . . . . . . . . . . . . . 66

4.5 Discussion . . . . . . . . . . . . . . . . . . . 68

4.6 Conclusions . . . . . . . . . . . . . . . . . . . . . 71

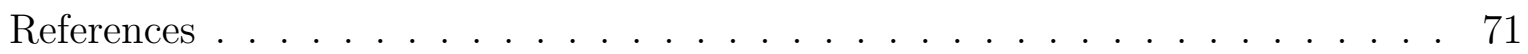

Appendix A . . . . . . . . . . . . . . . . . . 76

Appendix B . . . . . . . . . . . . . . . . . . . 77

$\begin{array}{lll}5 & \text { General discussion and conclusion } & \mathbf{7 8}\end{array}$

5.1 Main results and implications . . . . . . . . . . . . . . . . . 78

5.2 Limitations and future research . . . . . . . . . . . . . . . . 81

5.3 Conclusions . . . . . . . . . . . . . . . . . . . . . . 82

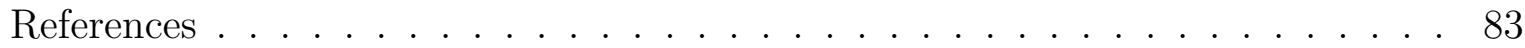

References (complete thesis) VII 


\section{List of Tables}

1 Summary of the three papers presented in Chapter 2 to $4 \ldots \ldots$

2 Sample statistics . . . . . . . . . . . . . . . . . . 22

3 List of the presented product information, means and SD for information relevance and explanation requirement . . . . . . . . . . . . . . 24

4 Comparison of the ipsatized product information means within the four segments . . . . . . . . . . . . . . . . . . 27

5 Attributes and levels of the CBCA (Study 1 and 2) . . . . . . . . . 43

$6 \quad$ Results of the logistic regression (Study 1) . . . . . . . . . . . . 45

7 Results of the logistic regression (Study 2) . . . . . . . . . . . . . 49

8 Attributes and levels of the CBCA . . . . . . . . . . . 65

9 Means and standard deviations of the TPB items . . . . . . . . . . 66

10 Standardized path coefficients and significance levels of the measurement model ... . . . . . . . . . . . . . . . . . 67

11 Correlation matrix of the latent variables . . . . . . . . . . . . . 67

12 Standardized path coefficients and significance levels of the structural model 68

13 Research questions and related findings . . . . . . . . . . . . . . . . 79 


\section{List of Figures}

1 Cascading utilization and conventional use (according to Fraanje, 1997) . . 6

2 Main objectives and the relation of the papers . . . . . . . . . 8

3 Varimax rotated PCA plot . . . . . . . . . . . . . . 25

4 Scatterplot of the four identified segments . . . . . . . . . . . . 26

$5 \quad$ Universal value structure $($ Schwartz, 1992) . . . . . . . . . . . . . . . 41

6 Predicted probability for product choice depending on Environmental Con-

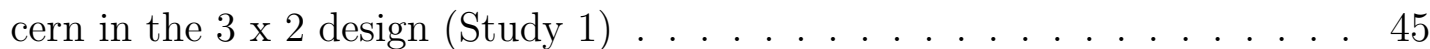

$7 \quad$ Positioning of EC and RIS in the Value Circumplex (Study 2) . . . . . . . 48

8 Predicted probability for product choice in the $3 \times 2$ design (Study 2) . . . 48

$9 \quad$ Predicted probability for product choice depending on Environmental Concern and Innovativeness in the $3 \times 2$ design (Study 2) . . . . . . . . . . 50

10 The Theory of Planned Behavior (Ajzen, 1991) . . . . . . . . . . . . 62

11 The final TPB model . . . . . . . . . . . . . . . . . . 68 


\section{List of Abbreviations}

CBCA Choice-based conjoint analysis

CI Confidence Interval

EC Environmental Concern

FMCG Fast Moving Consumer Goods

ID Identifier

LCA Life Cycle Assessment

NFT Need for Touch

PBC Perceived Behavioral Control

POS Point of Sale

QR Quick Response

RIS Roehrich's Innovativeness Scale

RQ Research Question

SN Subjective norm

TPB Theory of Planned Behavior

TRA Theory of Reasoned Action

WPC Wood-Polymer Composite

WTP Willingness to Pay 


\section{Introduction}

This project is about consumer acceptance of products consisting of materials that are based on renewable resources. Therefore, making a distinction between traditional and innovative materials is essential, as both are examined by different research questions. When considering traditional materials based on renewable resources, it is important to ensure consumer trust in case of critical media reports, e.g., illegal timber felling or use of tropical wood. In this regard, providing consumers with valued information is argued to be a promising marketing tool (e.g., Gleim et al., 2013; Gracia \& Zeballos, 2005; Ortega et al., 2011; Ubilava \& Foster, 2009). However, for innovative materials based on renewable resources, little is known about whether they are accepted by consumers; and therefore an assessment of consumers' intention to buy innovative materials based on renewable resources must be the starting point, followed by an analysis of the determinants of consumers' choices. To better address the market, the identification of target groups is essential for both, traditional and innovative materials that are based on renewable resources.

The introductory section begins by highlighting the relevance of consumer acceptance for products that are based on renewable resources (section 1.1). It is followed by background information about the frame of the project and the deduction of research questions that are addressed in the following chapters (sections 1.2). Finally, an overview is given connecting the three papers in the main chapters (section 1.3).

\subsection{Relevance of consumer acceptance of products based on re- newable resources}

To highlight the relevance of the topic, the necessity for an increasing and efficient use of renewable resources is argued (section 1.1.1). The differentiation between traditional and innovative materials that are based on renewable resources is introduced by using the example of wood (section 1.1.2). This is followed by a brief overview of research regarding green consumer behavior (section 1.1.3).

\subsubsection{The necessity for material utilizations of renewable resources}

The rapidly increasing world population size and efforts to improve or maintain economic growth have resulted in a continuously growing resource demand and irresponsible resource utilizations. Resources are not only demanded by developed countries, but also by emergent ones, as they seem to pave the way for a better life. Besides a competition for finite resources, environmental problems also emerge. Among these are influences on the climate, ecosystem processes and biodiversity (Brown et al., 2011). To address these challenges, efficient and responsible resource utilizations are required.

The utilization of renewable resources ${ }^{1}$ appears to be promising for several reasons. As suggested by the term 'renewable', these resources provide an alternative raw material base to limited fossil fuels. While renewable resources help to ensure raw material supply, the limitation of fossil fuels challenges many industries such as polymer production (Keenan

\footnotetext{
${ }^{1}$ This project builds on Leible et al. (2001) who define renewable resources as all those substances that originate from plants or animals and that are not used for nutritional or feeding purposes, but for chemical, technical and energetic objectives. Specifically, this project relies on the definition of renewable resources in a narrower sense which only refers to biomass originating from plants.
} 
et al., 2004). An increasing utilization of renewable resources appears to be promising in particular to those countries with a high oil consumption and low production rate such as Germany (Central Intelligence Agency, 2014). Renewable resources result in a lower dependence on the often politically unstable, oil-exporting countries, and provide a more secure raw material supply. Furthermore, renewable resources have the potential for economic benefits. Since it has to be acknowledged that peak oil, i.e., the global maximum conventional oil output, has been reached, corresponding resource prices continuously rise (Chapman, 2014; Lloyd \& Subbarao, 2009). Assuming that potential uses will be explored and production will improve, renewable resources may constitute a cheaper choice from a long-term perspective (Verbruggen \& Al Marchohi, 2010). Ecological benefits also emerge as renewable resources are generally more environmentally compatible than competing resources. Compared to most fossil fuel-based products, renewable resource products such as the $\mathrm{CO}_{2}$-neutral renewable raw materials of wood, have higher energy and greenhouse gas savings (Fraanje, 1997; Kim \& Song, 2014; nova-Institut, 2010). Additionally, a material use of renewable resources positively affects biodiversity because of the variety of niche crops that are cultivated for diverse fields of application (nova-Institut, 2010). Finally, social benefits are identifiable for material utilizations because of job creation and preservation. Material usages of renewable resources have a five to ten times higher employment rate compared to energetic utilizations (nova-Institut, 2010).

Despite the benefits associated with a material utilization of renewable resources, the main challenge that exists is the huge competition between different forms of land usage (Godfray et al., 2010). The cultivation of renewable resources for a material use competes with cultivations for food production or energy purposes. To overcome this problem and to satisfy the demand, efficient resource utilization is important. This implies a material utilization of primary (e.g., solid wood) and secondary processed materials (e.g., sawmill by-products, waste wood) prior to a conversion into energy as it is described by the principle of cascading utilization (section 1.2.2). Nevertheless, for the success of efficient material utilizations of renewable resources, products consisting of these materials must affect the market. For this reason, this project examines consumer acceptance of products consisting of materials that are based on renewable resources.

\subsubsection{Traditional and innovative materials based on renewable resources}

A discussion of material utilizations of renewable resources has to consider that nature provides an enormous variety of different raw materials (Leible et al., 2001). They are typically distinguished with respect to either their agricultural or forestry origin (novaInstitut, 2012). While there is a huge amount of different plants and components being used from agricultural raw materials (e.g., fats and oils, carbohydrates such as sugar, starch and natural fibers, proteins), wood is primarily used in the sawmilling industry, for the production of engineered wood (e.g., particleboards, Wood-Polymer Composites) and wood fiber (e.g., paper pulp, mechanical pulp, waste paper) (nova-Institut, 2010, 2012). Nevertheless, especially for Germany, the relevance of wood is highlighted by the fact that quantitatively, it is the most important renewable resource (Leible et al., 2001). Woods predominance in relation to agricultural commodities is clearly recognizable when comparing the utilizations of renewable resources in the year 2008: Of the 89.3 million tonnes of renewable resources that have been used in Germany, $48 \%$ was materially and $36 \%$ energetically used wood; while only $4 \%$ were material and $12 \%$ energetically-utilized agricultural commodities (nova-Institut, 2012). Given the importance of this resource, wood-based materials will now be considered. 
Products consisting of wood-based materials can be distinguished according to the utilization of primary (e.g., solid wood), or secondary processed wood (e.g., sawmill byproducts, waste wood). While solid wood is a traditional material, secondary processed wood-based materials differ with respect to their innovativeness. Many materials based on wood by-products such as particleboards and recycled pulp are long-known, others have only recently been developed (Ghanbari et al., 2014). An example of the latter are Wood-Polymer Composites (WPCs) which consist of up to more than $80 \%$ of wood byproducts, plastics and additives (Klyosov, 2007). WPCs aim at combining the material advantages of both of their main components, i.e., wood and plastics (Schwendemann, 2008). To further improve the material properties, additives are included such as UV stabilizers, biocides and flame retardants (Ashori, 2008; Satov, 2008). North America is still the largest WPC producer with 1.100.000 tonnes being produced in 2012, followed by China with about 900.000 tonnes and the greatest production growth rate of $25 \%$ per annum (Carus et al., 2014; Eder \& Carus, 2013). 260.000 tonnes of WPCs were produced in the EU in 2012, of which $67 \%$ have been used for decking, $24 \%$ in the automotive industry, followed by siding and fencing, technical applications, furniture, and consumer goods (Carus et al., 2014). As traditional applications such as decking have reached the maturity stage in the European WPC market, a growth of the WPC production is forecasted for furniture, consumer goods, and other WPC construction applications (Carus et al., 2014; Eder \& Carus, 2013). Hence, the time is ripe to conduct consumer research addressing the acceptance of innovative wood-based materials in addition to traditional ones.

\subsubsection{Related consumer research}

The question of consumer acceptance of products consisting of renewable resources falls within the scope of research about 'green' consumer behavior. A large and growing body of literature has focused on consumers' intention to buy eco-friendly Fast Moving Consumer Goods (FMCG), in particular organic food (e.g., Bernard \& Bernard, 2009; Marette et al., 2012; Nocella et al., 2012; Onozaka \& McFadden, 2011; Vermeir \& Verbeke, 2008; Yue et al., 2009). Consumer acceptance of other products such as detergents and cosmetics (e.g., Lin \& Huang, 2012; Luchs et al., 2010), as well as recycled and remanufactured goods (e.g., Essoussi \& Linton, 2010; Michaud \& Llerena, 2011), has also been examined. Current attention relates to different forms of eco-friendly behavior, including the implementation of recycling (e.g., Chan \& Bishop, 2013; Park \& Ha, 2012; Rhodes et al., 2014; Wan et al., 2014), eco-tourism (e.g., Han et al., 2010; Kim et al., 2013) and sustainable transportation (e.g., Donald et al., 2014; Groot \& Steg, 2007; Jansson et al., 2011; Wiedmann et al., 2011). In recent years, an increasing amount of studies have also been published about consumers' adoption of green energy (e.g., Diaz-Rainey \& Ashton, 2011; Hartmann \& Apaolaza-Ibáñez, 2012; Litvine \& Wüstenhagen, 2011; Ozaki, 2011; Read et al., 2013; Scarpa \& Willis, 2010).

It is apparent that fewer studies consider consumer acceptance of durable goods, which differ in many respects from FMCG and other investigated services. Some research addressed consumer acceptance of wood-based products (e.g., Aguilar \& Vlosky, 2007; Cai \& Aguilar, 2013; Hansmann et al., 2006; Husted et al., 2014; Kalafatis et al., 1999; Ozanne \& Vlosky, 2003; Thompson et al., 2010; Veisten, 2007), but most of these studies solely investigated the effects of certifications informing consumers about sustainable forest management. Additionally, certifications are considered as a tool to ensure consumers' trust in wood-based products as consumers are concerned about environmental and social issues 
in relation to forest management (e.g., Aguilar \& Cai, 2010; Cai \& Aguilar, 2013). Nevertheless, consumer research about FMCG indicates that detailed information is superior to mere certification labels (Ortega et al., 2011; Ubilava \& Foster, 2009); so far, however, no study has been carried out about consumers' preferences for detailed wood product information. Furthermore, it must be acknowledged that the vast majority of consumer studies focus on traditional materials such as solid wood and particleboards, so that there is very limited understanding of consumer acceptance of innovative wood-based materials such as WPCs (Jonsson et al., 2008; Weinfurter \& Eder, 2009).

The variety of products and services being investigated suggest a broad range of factors that have been examined as driving consumer acceptance. Most attention has been drawn to (environmental) attitudes (e.g., Chan \& Bishop, 2013; Diaz-Rainey \& Ashton, 2011; Donald et al., 2014; Hartmann \& Apaolaza-Ibáñez, 2012; Kim et al., 2013; Ozaki, 2011; Read et al., 2013; Rhodes et al., 2014; Tikir \& Lehmann, 2011; Vermeir \& Verbeke, 2008), values (e.g., Jansson et al., 2011; Lin \& Huang, 2012; Nordlund \& Garvill, 2002; Tikir \& Lehmann, 2011; Urien \& Kilbourne, 2011; Vermeir \& Verbeke, 2008) and sociodemographic characteristics (e.g., do Paço \& Raposo, 2009; Park et al., 2012; Thompson et al., 2010). The value consumers ascribe to environmental product attributes or ecofriendly services is often assessed by the willingness to pay (WTP) a surcharge compared to a conventional alternative (e.g., Aguilar \& Vlosky, 2007; Cai \& Aguilar, 2013; Marette et al., 2012; Michaud \& Llerena, 2011; Scarpa \& Willis, 2010; Yue et al., 2009). To better target environmentally conscious consumers and to address other consumer groups with their specific preferences, segmentation is a commonly used approach (e.g., do Paço \& Raposo, 2009; Gleim et al., 2013; Ozanne \& Vlosky, 2003; Thompson et al., 2010; Wiedmann et al., 2011). Additionally, the investigations build on different theoretical backgrounds with the Theory of Planned Behavior (Ajzen, 1991) and the Value-Belief-Norm Theory (Stern, 2000; Stern et al., 1999) as the most prominent ones.

Above all, a considerable amount of literature indicates consumers' preference for ecofriendly products. Nevertheless, the market share of green products is still lower than it is suggested by consumers' stated preferences (Gleim et al., 2013; Lin \& Huang, 2012; Rex \& Baumann, 2007; Tseng \& Hung, 2013). Because of this, research about factors ensuring and increasing consumer acceptance of green products is still needed. Additionally, studies about eco-innovations are required as eco-innovations have high development costs and high risks in entering the market.

\subsection{Framework and objectives}

The general frame of the project is illustrated by introducing the Research Training Group 1703 in which this project was developed (section 1.2.1), and by referring to the principle of cascading utilization (section 1.2.2). Later, the main questions addressed in this project are presented (section 1.2.3).

\subsubsection{Research Training Group 1703 'Resource Efficiency in Interorganiza- tional Networks'}

The Research Training Group 1703 aims at identifying and improving methods that support an efficient utilization of renewable resources in value-generating networks. As this involves several material utilizations of renewable resources prior to an energetic one, all related process steps, emerging products and supporting systems must be considered to 
maximize the overall aim of resource efficiency in interorganizational networks. Because of this, the study and research program of the Research Training Group represents an interdisciplinary approach and is subdivided into three areas:

- Topical Group A: Material sciences - the classification and modification of renewable resources and their by-products for use in industrial networks

- Topical Group B: Planning of production and supply chains for renewable resources

- Topical Group C: Governance, coordination and distribution

The targets of study are lignocellulosic materials, with a focus on wood particle and wood fiber-based panel materials, wood pulp, and also the innovative WPCs. The present project, with its focus on consumer acceptance of products made from renewable resources, is part of the topical group $\mathrm{C}$ and covers the area of $\mathrm{B} 2 \mathrm{C}$ marketing. Its topic is essentially related to the other projects, as consumer acceptance is a prerequisite for the success of products and production processes that foster a more efficient utilization of renewable resources. For example, communication treatments can be identified that help to enhance consumer acceptance. Additionally, consumer preferences concerning the investigated materials are analyzed, thereby providing important feedback for the topical group A. As consumers' valued information is also studied, the topical group B receives indications of the amount and characteristics of information that should be delivered to consumers, therefore helping to design a traceability information system.

The Research Training Group started in April 2012 and is funded by the German Research Foundation (DFG; Deutsche Forschungsgemeinschaft). The principle of cascading utilization represents its central theme, which is elaborated in the following section.

\subsubsection{Cascading utilization}

Cascading utilization is defined as 'the sequential exploitation of the full potential of a resource during its use' (Fraanje, 1997, p. 22). According to the principle, resource quality decreases with every use, just as in its analogy of a (mountain) river: The water falls from one step to another with diminishing forces until reaching the lowest level (Connelly \& Koshland, 1997; Fraanje, 1997; Sirkin \& ten Houten, 1994). In the context of renewable resources, resource quality refers to the degree to which original functional properties exist, e.g., strength and durability (Fraanje, 1997). A simplified illustration of cascading utilization relies on two parameters (Sirkin \& ten Houten, 1994): resource quality $(Q)$ and utilization time $(T)$. Following the approach described by Fraanje (1997) and illustrated in Figure 1, cascading utilization involves:

- high resource quality $(Q)$ of the first application

- maximization of i) the life time of every application $(\Delta T)$ and ii) the overall life time $\left(\sum \Delta T\right)$

- minimization of the quality loss between consecutive applications $(\Delta Q)$.

Figure 1 visualizes the principle exemplified for wood (Fraanje, 1997): Products consisting of solid wood require the highest resource quality, for example, as needed for the production of solid wood bookshelves. Subsequent to the product's utilization phase, another use of the renewable resource with a lower resource quality might follow. Flake boards can be made out of the old solid wood boards and be used to produce new bookshelves. 


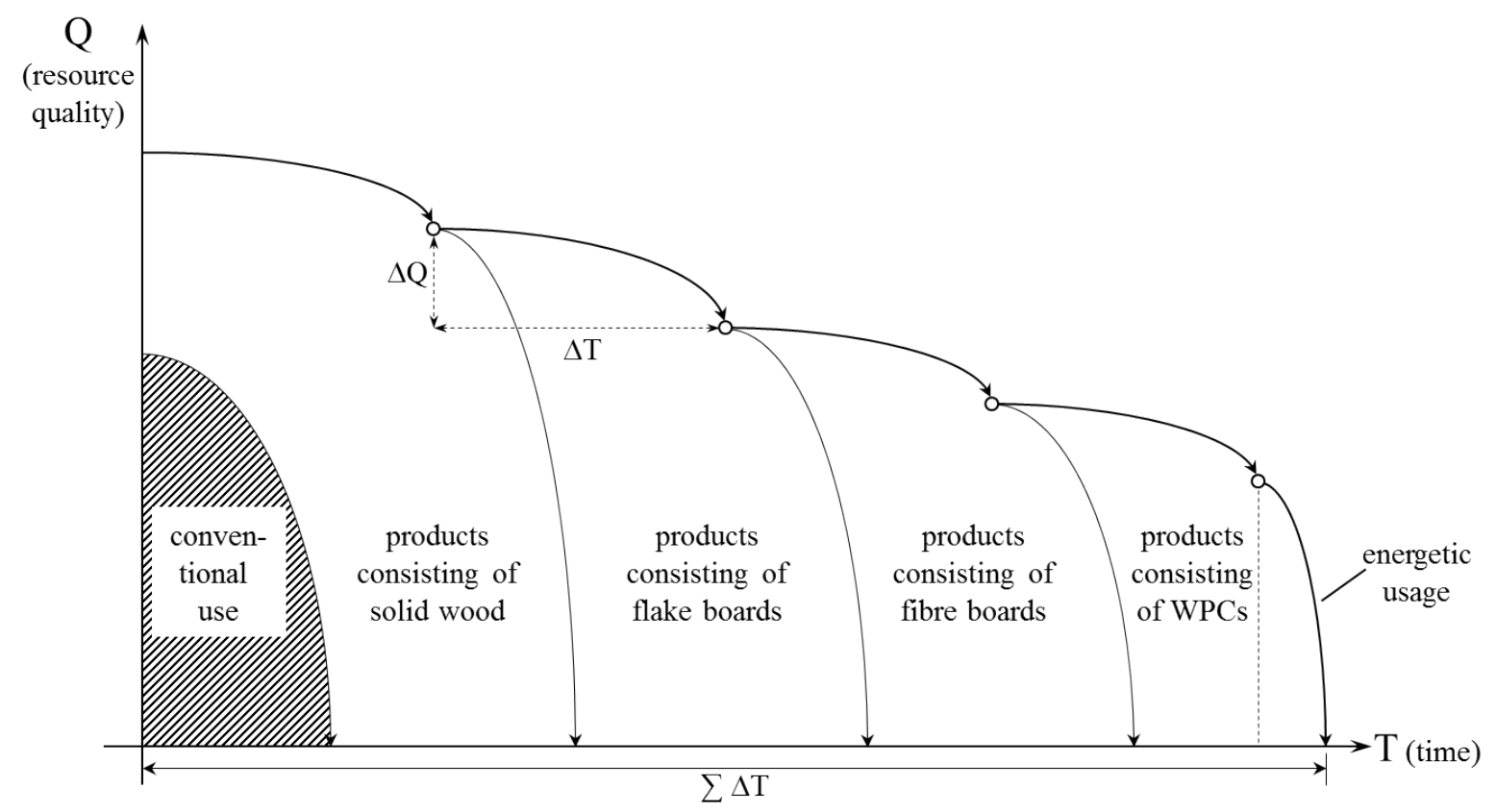

Figure 1: Cascading utilization and conventional use (according to Fraanje, 1997)

This procedure can be continued for the whole cascade. Above all, wood by-products arising during the various production steps can also be used in a material way, e.g., for the production of particleboards or WPCs. This reduces the usage of virgin natural resources and the amount of wood waste which has also a positive influence on the environmental impact of the timber sector (Eshun et al., 2012). It is essential to identify the best potential use in the beginning, as otherwise too much log would be given away. However, contrary to the principle of cascading utilization, renewable resources are usually only used once in a material way, and beyond that only for applications requiring a rather low resource quality. This impedes tapping the full potential of cascading utilization by expanding the resources' overall lifetime $\sum \Delta \mathrm{T}$. For instance, the possible lifetime of pine wood can be expanded from 75 years to more than 350 years (Fraanje, 1997). Above all, this principle also does not impair energetic utilizations, as the energetic use of the raw material is just belated (nova-Institut, 2010).

Considering Figure 1, a diverse range of wood-based materials exist. A successful implementation of cascading utilization implies that consumers accept as many materials that can be produced during the cascading steps as possible. Because of this, the project has to address important research gaps concerning consumer acceptance of materials that do not only belong to the first (i.e., solid wood), but also to subsequent steps of the cascading utilization of wood (i.e., particleboards, WPCs).

\subsubsection{The B2C perspective and objectives of the project}

Based on the previous considerations, consumer acceptance of products made from renewable resources has to be ensured not only for materials requiring a high resource quality, but also for those emerging at subsequent steps of the cascade. As many wood-based materials exist for a long time, while others have just been developed, different research questions arise for both of these cases. Focusing on traditional wood-based materials, including primary (e.g., solid wood) and secondary (e.g., particleboards) processed mate- 
rials, the vast majority of consumer studies investigated consumers' value of environmental attributes by considering certifications. Because of the huge amount of certification labels being available, consumers seem to be confused about the different meanings and are starting to question the sustainability of forest management (e.g., Aguilar \& Cai, 2010; Borin et al., 2011; Cai \& Aguilar, 2013). Additionally, consumers encounter difficulties in processing the information that these labels provide (Ortega et al., 2011). Studies carried out in the food industry suggest that consumers prefer detailed product information over mere certification labels (Ortega et al., 2011; Ubilava \& Foster, 2009), and that detailed information increases product trust and purchase intention (Chen et al., 2008; Clemens, 2003; Gracia \& Zeballos, 2005; Ortega et al., 2011; Ubilava \& Foster, 2009). However, it is not yet clear whether consumers also value an access to wood product information and specifically, which information they prefer. Additionally, it has to be considered that the valued product information may vary among consumer segments (Dimara \& Skuras, 2003; Verbeke, 2005, 2008). Young consumers especially seek detailed product information and use this information precisely (Cole \& Balasubramanian, 1993; Kanchanapibul et al., 2014; Klein \& Ford, 2003), therefore young consumers represent an interesting sample for initial investigations. This leads to the following research questions (RQ):

RQ1a: Which young consumer groups value the provision of wood product information?

RQ1b: What information is relevant for the identified consumer segments and is therefore evaluated by young consumers as increasing their product trust and purchase intention?

While many studies have investigated factors determining consumer acceptance of traditional wood-based materials, only a few studies have addressed innovative wood-based materials facilitating efficient resource utilizations (Jonsson et al., 2008; Weinfurter \& Eder, 2009). As a starting point, consumers' intention to buy products consisting of ecoinnovative materials such as WPCs must be assessed. As WPCs can substitute both of their components, consumer acceptance should be examined in relation to full plastics and the traditional solid wood. While consumer segments with a high environmental orientation or innovativeness trait typically prefer eco-innovations (Jansson, 2011; Lin \& Huang, 2012), it is questioned whether the environmentally conscious consumers accept WPCs, as this segment might overvalue the synthetic component they usually reject (Eyerer et al., 2010; Petrescu et al., 2010). Hence, for the marketing of these materials it is essential to identify which consumer segments value WPC products.

RQ2a: To what extent do consumers accept innovative wood-based materials in comparison to competing materials?

RQ2b: Which consumer segments especially accept innovative wood-based materials?

Having assessed consumer acceptance of innovative wood-based materials, an investigation of factors that enhance consumers' purchases can follow. Literature indicates that it requires a considerable marketing effort to convince consumers of the advantages new materials have over the traditional solid wood material (Singh, 2010). It is important to identify consumers' perceived advantages of new products and materials and afterwards use them in product related communications (Henard \& Szymanski, 2001). Therefore, the following research question is formulated:

RQ3: Which factors drive consumer acceptance of innovative wood-based materials? 


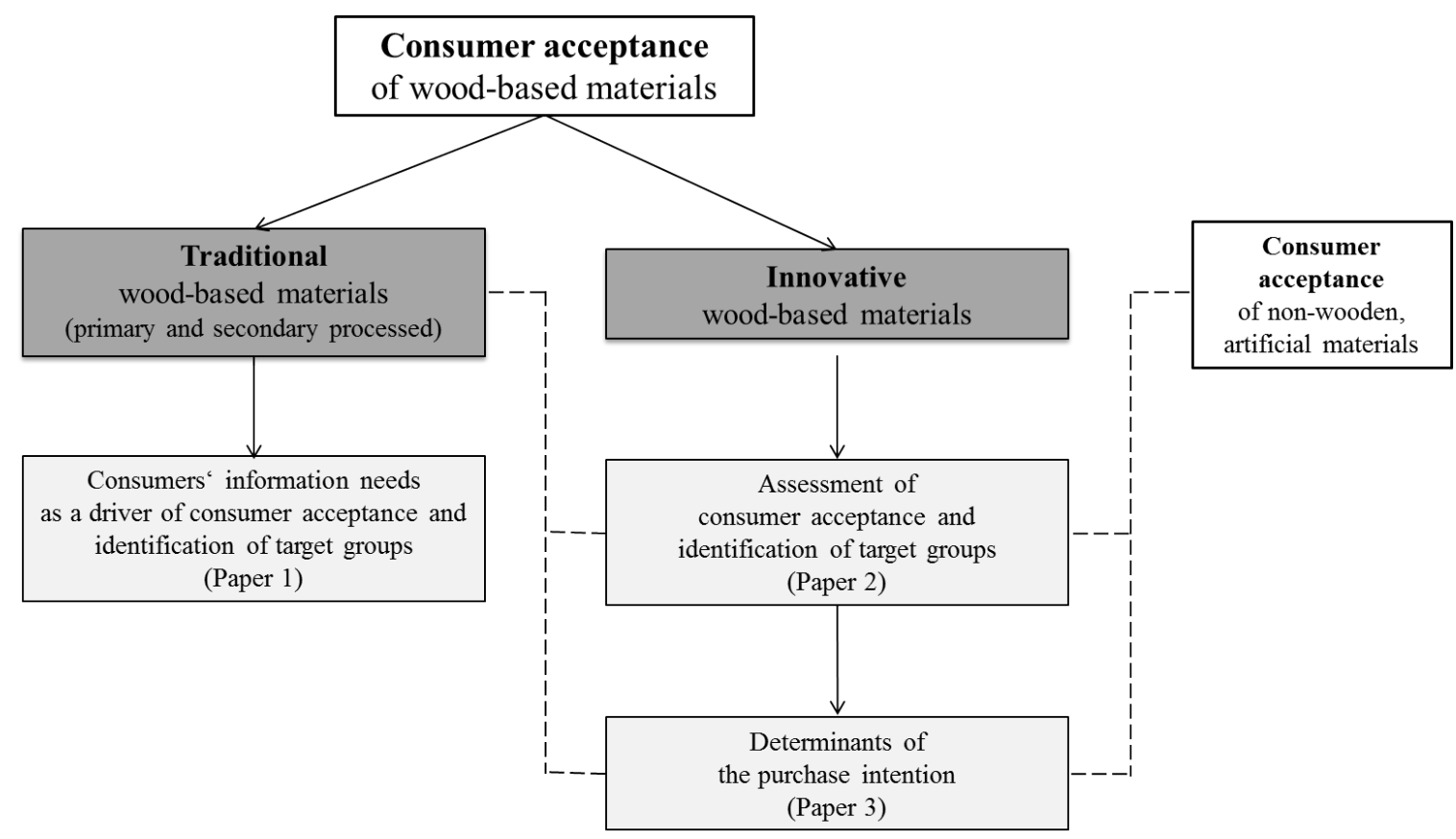

Figure 2: Main objectives and the relation of the papers

Figure 2 shows the relationship of the project's main objectives reflecting the presented research questions. The objectives can be divided into three areas which will be addressed in separate papers that are provided in the following chapters. The dashed line indicates the connections of Paper 2 and 3, which focus on eco-innovative materials, with studies on traditional wood-based materials and the importance to also assess new materials in relation to all competing ones, i.e., artificial materials.

\subsection{Outline of the projects}

Following the introduction, this work is divided into four parts. Chapter 2 through 4 are structured as three independent papers which address the research questions that were presented in the previous section. Table 1 gives an overview of the objectives, methods, results and contributions of all papers. For a detailed, comparative discussion of the papers see Chapter 5.

Chapter 2 presents the paper An empirical investigation of wood product information valued by young consumers, which is coauthored by Shanna Appelhanz, Waldemar Toporowski and Matthias Schumann. This paper aims to identify consumer groups that value the provision of information for traditional wood-based products. Additionally, it reveals how the preferred information varies among the identified consumer segments.

The paper Consumer acceptance of Wood-Polymer Composites: a conjoint analytical approach with a focus on innovative and environmentally concerned consumers, which is coauthored by Micha Strack and Waldemar Toporowski, is presented in Chapter 3. The main objective is an assessment of consumers' choices of innovative wood-based materials (WPCs) in relation to a traditional wood-based material (solid wood) and a traditional environmentally hazardous material (full plastics). Furthermore, the choices of WPC products are analyzed for two segments whose acceptance is expected to deviate from the acceptance of the average consumer, i.e., innovative and eco-friendly consumers. 


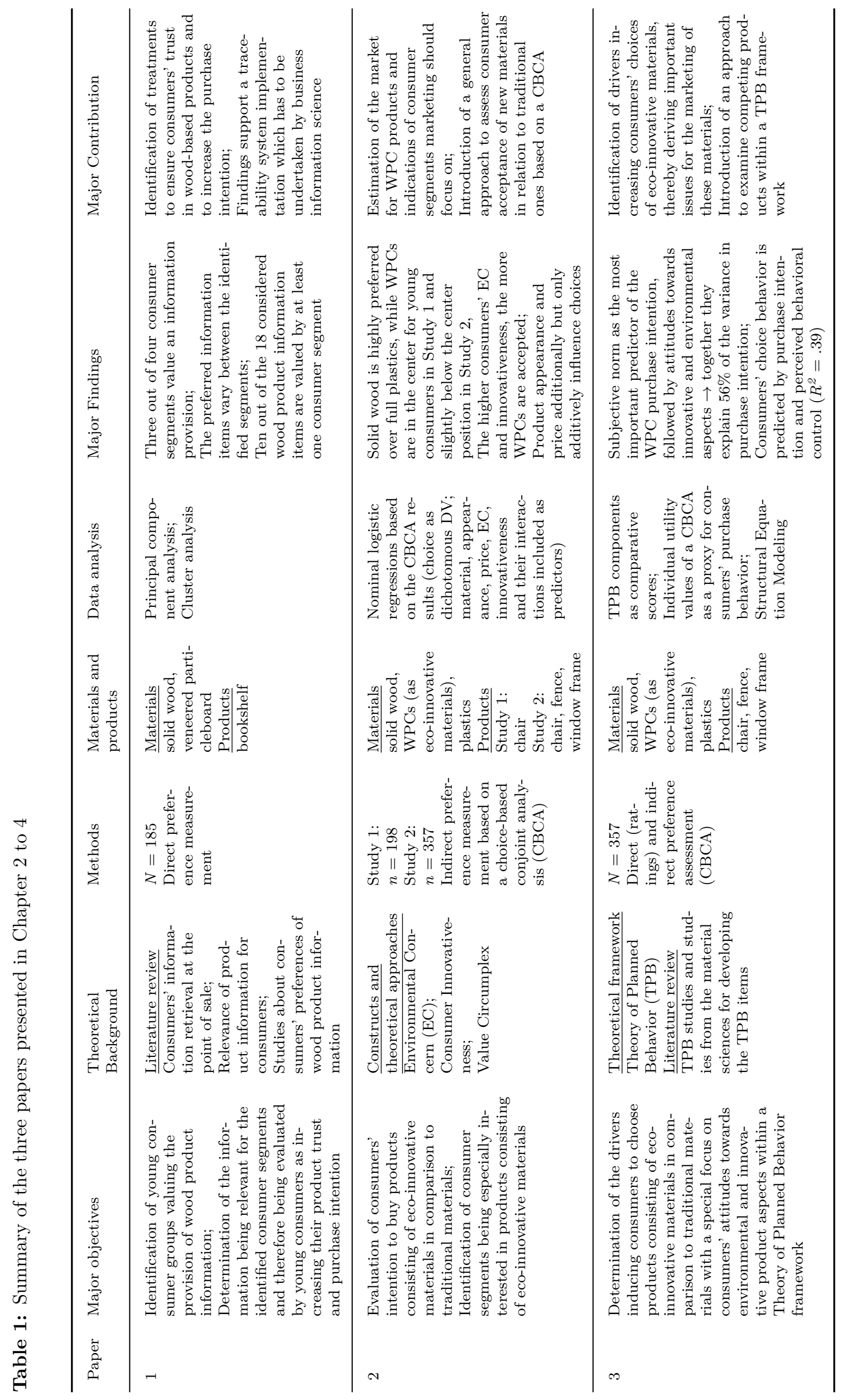


Chapter 4 includes the paper An empirical investigation of the determinants influencing consumers' planned choices of eco-innovative materials. As this paper aims at obtaining an insightful investigation of factors influencing consumers' choices of WPC products, the Theory of Planned Behavior (Ajzen, 1991) is selected as a framework, allowing a deep understanding of various drivers in consumers' reasoned choices. To consider the materials that WPCs compete, all components of the Theory of Planned Behavior are tested as comparative scores against wood and plastics.

The final chapter draws upon the entire thesis, tying up the various contributions to research and practical implications provided by the three papers. The comparative discussion also indicates areas for future research that might help to broaden the understanding of consumer acceptance of environmentally-friendly products and resource efficient materials. Finally, this section is followed by concluding remarks.

\section{References}

Aguilar, F. X., \& Cai, Z. (2010). Conjoint effect of environmental labeling, disclosure of forest of origin and price on consumer preferences for wood products in the US and UK. Ecological Economics, 70, 308-316.

Aguilar, F. X., \& Vlosky, R. P. (2007). Consumer willingness to pay price premiums for environmentally certified wood products in the U.S. Forest Policy and Economics, 9, 1100-1112.

Ajzen, I. (1991). The theory of planned behavior. Organizational Behavior and Human Decision Processes, 50, 179-211.

Ashori, A. (2008). Wood-plastic composites as promising green-composites for automotive industries!. Bioresource Technology, 99, 4661-4667.

Bernard, J. C., \& Bernard, D. J. (2009). What is it about organic milk? An experimental analysis. American Journal of Agricultural Economics, 91, 826-836.

Borin, N., Cerf, D. C., \& Krishnan, R. (2011). Consumer effects of environmental impact in product labeling. Journal of Consumer Marketing, 28, 76-86.

Brown, J. H., Burnside, W. R., Davidson, J. P. D., Dunn, W., Hamilton, M. J., Nekola, J. C., ... Zuo, W. (2011). Energetic limits to economic growth. BioScience, 61, 19-26.

Cai, Z., \& Aguilar, F. X. (2013). Meta-analysis of consumer's willingness-to-pay premiums for certified wood products. Journal of Forest Economics, 1, 15-31.

Carus, M., Eder, A., Dammer, L., Korte, H., Scholz, L., Essel, R., \& Breitmayer, E. (2014). Wood-plastic composites (WPC) and natural fibre composites (NFC): European and global markets and future trends (Version 2014-03). Hürth: nova-Institut GmbH.

Central Intelligence Agency (2014). The World Factbook. Retrieved November 24, 2014, from http://cs.fit.edu/ ryan/factbook/factbook/index.html

Chan, L., \& Bishop, B. (2013). A moral basis for recycling: Extending the theory of planned behaviour. Journal of Environmental Psychology, 36, 96-102.

Chapman, I. (2014). The end of peak oil? Why this topic is still relevant despite recent denials. Energy Policy, 64, 93-101. 
Chen, R.-S., Chen, C.-C., Yeh, K. C., Chen, Y.-C., \& Kuo, C.-W. (2008). Using RFID technology in food produce traceability. WSEAS Transactions on Information Science and Applications, 11, 1551-1560.

Clemens, R. (2003). Meat traceability and consumer assurance in Japan. MATRIC Briefing Paper 03-MBP 5, Midwest Agribusiness Trade Research and Information Center, Iowa State University.

Cole, C. A., \& Balasubramanian, S. K. (1993). Age differences in consumers' search for information: Public policy implications. Journal of Consumer Research, 20, 157-169.

Connelly, L., \& Koshland, C. P. (1997). Two aspects of consumption: Using an energy-based measure of degradation to advance the theory and implementation of industrial ecology. Resources, Conservation and Recycling, 19, 199-217.

Diaz-Rainey, I., \& Ashton, J. K. (2011). Profiling potential green electricity tariff adopters: Green consumerism as an environmental policy tool? Business Strategy and the Environment, 20, 456-470.

Dimara, E., \& Skuras, D. (2003). Consumer evaluations of product certification, geographic association and traceability in Greece. European Journal of Marketing, 37, 690-705.

Donald, I., Cooper, S., \& Conchie, S. (2014). An extended theory of planned behavior model of the psychological factors affecting commuters' transport mode use. Journal of Environmental Psychology, 40, 39-48.

do Paço, A. M. F., \& Raposo, M. L. B. (2009). "Green" segmentation: An application to the Portuguese consumer market. Marketing Intelligence 63 Planning, 27, 364-379.

Eder, A., \& Carus, M. (2013). Global trends in Wood-Plastic Composites (WPC). Bioplastics, 4, 16-17.

Eshun, J. F., Potting, J., \& Leemans, R. (2012). Wood waste minimization in the timber sector of Ghana: A systems approach to reduce environmental impact. Journal of Cleaner Production, 26, 67-78.

Essoussi, L. H., \& Linton, J. D. (2010). New or recycled products: How much are consumers willing to pay? Journal of Consumer Marketing, 27, 458-468.

Eyerer, P., Beilharz, F., Hübner, C., Kupfer, T., \& Ulrich, C. (2010). Opportunities and (in particular) risks of use (utilization phase) of plastic structural components. In P. Eyerer (Ed.), Polymers - Opportunities and risks I: General environmental aspects (pp. 363-389). Berlin: Springer.

Fraanje, P. J. (1997). Cascading of pine wood. Resource, Conservation and Recycling, 19, $21-28$.

Ghanbari, A., Madhoushi, M., \& Ashori, A. (2014). Wood Plastic Composite Panels: Influence of the species, formulation variables and blending process on the density and withdrawal strength of fasteners. Journal of Polymers and the Environment, 22, 260-266.

Gleim, M. R., Smith, J. S., Andrews, D., \& Cronin, J. J. (2013). Against the green: A multimethod examination of the barriers to green consumption. Journal of Retailing, 89, 44-61.

Godfray, H. C. J., Beddington, J. R., Crute, I. R., Haddad, L., Lawrence, D., Muir, J. F., . . . Toulmin, C. (2010). Food security. The challenge of feeding 9 billion people. Science, $327,812-818$. 
Gracia, A., \& Zeballos, G. (2005). Attitudes of retailers and consumers toward the EU traceability and labeling system for beef. Journal of Food Distribution Research, 36, 45-56.

Groot, J. I. M. de, \& Steg, L. (2007). General beliefs and the theory of planned behavior: The role of environmental concerns in the TPB. Journal of Applied Social Psychology, 37, $1817-1836$.

Han, H., Hsu, L.-T., \& Sheu, C. (2010). Application of the theory of planned behavior to green hotel choice: Testing the effect of environmental friendly activities. Tourism Management, $31,325-334$.

Hansmann, R., Koellner, T., \& Scholz, R. W. (2006). Influence of consumers' socioecological and economic orientations on preferences for wood products with sustainability labels. Forest Policy and Economics, 8, 239-250.

Hartmann, P., \& Apaolaza-Ibáñez, V. (2012). Consumer attitude and purchase intention toward green energy brands: The roles of psychological benefits and environmental concern. Journal of Business Research, 65, 1254-1263.

Henard, D. H., \& Szymanski, D. M. (2001). Why some new products are more successful than others. Journal of Marketing Research, 38, 362-375.

Husted, B. W., Russo, M. V., Meza, C. E. B., \& Tilleman, S. G. (2014). An exploratory study of environmental attitudes and the willingness to pay for environmental certification in Mexico. Journal of Business Research, 67, 891-899.

Jansson, J. (2011). Consumer eco-innovation adoption: Assessing attitudinal factors and perceived product characteristics. Business Strategy and the Environment, 20, 192-210.

Jansson, J., Marell, A., \& Nordlund, A. (2011). Exploring consumer adoption of a high involvement eco-innovation using value-belief-norm theory. Journal of Consumer Behaviour, 10, $51-60$.

Jonsson, O., Lindberg, S., Roos, A., Hugosson, M., \& Lindström, M. (2008). Consumer perceptions and preferences on solid wood, wood-based panels, and composites: A repertory grid study. Wood and Fiber Science, 40, 663-678.

Kalafatis, S. P., Pollard, M., East, R., \& Tsogas, M. H. (1999). Green marketing and Ajzen's theory of planned behaviour a cross-market examination. Journal of Consumer Marketing, $16,441-460$.

Kanchanapibul, M., Lacka, E., Wang, X., \& Chan, H. K. (2014). An empirical investigation of green purchase behaviour among the young generation. Journal of Cleaner Production, $66,528-536$.

Keenan, T. M., Tanenbaum, S. W., Stipanovic, A. J., \& Nakas, J. P. (2004). Production and characterization of Poly- $\beta$-hydroxyalkanoate Copolymers from Burkholderia cepacia utilizing Xylose and Levulinic acid. Biotechnology Progress, 20, 1697-1704.

Kim, M. H., \& Song, H. B. (2014). Analysis of the global warming potential for wood waste recycling systems. Journal of Cleaner Production, 69, 199-207.

Kim, Y. J., Njite, D., \& Hancer, M. (2013). Anticipated emotion in consumers' intentions to select eco-friendly restaurants: Augmenting the theory of planned behavior. International Journal of Hospitality Management, 34, 255-262.

Klein, L. R., \& Ford, G. T. (2003). Consumer search for information in the digital age: An empirical study of prepurchase search for automobiles. Journal of Interactive Marketing, 17, 29-49. 
Klyosov, A. A. (2007). Wood-Plastic Composites. Hoboken, NJ: John Wiley \& Sons, Inc.

Leible, L., Kälber, S., \& Nieke, E. (2001). Nachwachsende Rohstoffe - eine Zwischenbilanz [Renewable resources - an interim result]. In A. Grundwald (Ed.), Jahrbuch des Instituts für Technikfolgenabschätzung und Systemanalyse (ITAS) 1999/2000 [Annual book of the Institute for Technology Assessment and Systems Analysis (ITAS) 1999/2000] (pp. 25-41). Eggenstein: Wilhelm Stober GmbH.

Lin, P.-C., \& Huang, Y.-H. (2012). The influence factors on choice behavior regarding green products based on the theory of consumption values. Journal of Cleaner Production, 22, $11-18$.

Litvine, D., \& Wüstenhagen, R. (2011). Helping "light green" consumers walk the talk: Results of a behavioural intervention survey in the Swiss electricity market. Ecological Economics, $70,462-474$.

Lloyd, B., \& Subbarao, S. (2009). Development challenges under the Clean Development Mechanism (CDM) - Can renewable energy initiatives be put in place before peak oil? Energy Policy, 3, 237-245.

Luchs, M. G., Naylor, R. W., Irwin, J. R., \& Raghunathan, R. (2010). The sustainability liability: Potential negative effects of ethicality on product preference. Journal of Marketing, $74,18-31$.

Marette, S., Messean, A., \& Millet, G. (2012). Consumers' willingness to pay for eco-friendly apples under different labels: Evidences from a lab experiment. Food Policy, 37, 151-161.

Michaud, C., \& Llerena, D. (2011). Green consumer behaviour: An experimental analysis of willingness to pay for remanufactured products. Business Strategy and the Environment, 20, 408-420.

Nocella, G., Boecker, A., Hubbard, L., \& Scarpa, R. (2012). Eliciting consumer preferences for certified animal-friendly foods: Can elements of the theory of planned behavior improve choice experiment analysis? Psychology \& Marketing, 29, 850-868.

Nordlund, A. M., \& Garvill, J. (2002). Value Structures behind Proenvironmental Behavior. Environment and Behavior, 34, 740-756.

nova-Institut (2010). Entwicklung von Förderinstrumenten für die stoffliche Nutzung von nachwachsenden Rohstoffen in Deutschland (Kurzfassung) [The development of instruments to support the material use of renewable raw materials in Germany (Summary)]. Hürth: nova-Institut für politische und ökologische Innovation GmbH.

nova-Institut (2012). Stoffliche Nutzung von Biomasse. Basisdaten für Deutschland, Europa und die Welt [Material use of biomass. Basic data for Germany, Europe and the world]. Retrieved June 18, 2013, from http://www.nova-institut.de/download/Stoffliche_Nutzun g_von_Biomasse_nova

Onozaka, Y., \& McFadden, D. (2011). Does local labeling complement or compete with other sustainable labels? A conjoint analysis of direct and joint values for fresh produce claims. American Journal of Agricultural Economics, 93, 693-706.

Ortega, D. L., Wang, H. H., Wu, L., \& Olynk, N. J. (2011). Modeling heterogeneity in consumer preferences for select food safety attributes in China. Food Policy, 36, 318-324.

Ozaki, R. (2011). Adopting sustainable innovation: What makes consumers sign up to green electricity? Business Strategy and the Environment, 20, 1-17. 
Ozanne, L. K., \& Vlosky, R. P. (2003). Certification from the U.S. consumer perspective: A comparison from 1995 and 2000. Forest Products Journal, 53, 13-21.

Park, J., \& Ha, S. (2012). Understanding pro-environmental behavior: A comparison of sustainable consumers and apathetic consumers. International Journal of Retail $\mathcal{E}$ Distribution Management, 40, 388-403.

Park, S.-J., Choi, S., \& Kim, E.-J. (2012). The relationships between socio-demographic variables and concerns about environmental sustainability. Corporate Social Responsibility and Environmental Management, 19, 343-354.

Petrescu, I., Ispas, C., \& Mohora, C. (2010). Risk assessment in the implementation of composite materials (Proceedings in Manufacturing Systems No. 5). Retrieved August 10, 2013, from http://icmas.eu/recenzare2010/248-Petrescu.doc

Read, D. L., Brown, R. F., Thorsteinsson, E. B., Morgan, M., \& Price, I. (2013). The theory of planned behaviour as a model for predicting public opposition to wind farm developments. Journal of Environmental Psychology, 36, 70-76.

Rex, E., \& Baumann, H. (2007). Beyond ecolabels: What green marketing can learn from conventional marketing. Journal of Cleaner Production, 15, 567-576.

Rhodes, R. E., Beauchamp, M. R., Conner, M., Bruijn, G.-J. de, Kaushal, N., \& LatimerCheung, A. (2014). Prediction of depot-based specialty recycling behavior using an extended Theory of Planned Behavior. Environment and Behavior, 1-23.

Satov, D. V. (2008). Additives for wood-polymer composites. In K. Oksman Niska, K. \& M. Sain (Eds.), Wood-polymer composites (pp. 23-40). Cambridge: Woodhead Publishing Limited.

Scarpa, R., \& Willis, K. (2010). Willingness-to-pay for renewable energy: Primary and discretionary choice of British households' for micro-generation technologies. Energy Economics, 32, 129-136.

Schwendemann, D. (2008). Manufacturing technologies for Wood-Polymer Composites. In K. Oksman Niska, \& M. Sain (Eds.), Wood-polymer composites (pp. 72-100). Cambridge: Woodhead Publishing Limited.

Singh, S. C. (2010). Strategies to make the manufacturing processes more environment friendly. Management Insight, VI, 49-58.

Sirkin, T., \& ten Houten, M. (1994). The cascade chain. A theory and tool for achieving resource sustainability with applications for product design. Resources, Conservation and Recycling, 10, 213-277.

Stern, P. C. (2000). New environmental theories: toward a coherent theory of environmentally significant behaviour. Journal of Social Issues, 56, 407-424.

Stern, P. C., Dietz, T., Abel, T., Guagnano, G. A., \& Kalof, L. (1999). A value-belief-norm theory of support for social movements: The case of environmentalism. Human Ecology Review, 6, 81-97.

Thompson, D. W., Anderson, R. C., Hansen, E. N., \& Kahle, L. R. (2010). Green segmentation and environmental certification: Insights from forest products. Business Strategy and the Environment, 19, 319-334.

Tikir, A., \& Lehmann, B. (2011). Climate change, theory of planned behavior and values: A structural equation model with mediation analysis. A letter. Climate Change, 104, 389-402. 
Tseng, S.-C., \& Hung, S.-W. (2013). A framework identifying the gaps between customers' expectations and their perceptions in green products. Journal of Cleaner Production, 59, $174-184$

Ubilava, D., \& Foster, K. (2009). Quality certification vs. product traceability: Consumer preferences for informational attributes of pork in Georgia. Food Policy, 34, 305-310.

Urien, B., \& Kilbourne, W. (2011). Generativity and self-enhancement values in eco-friendly behavioral intentions and environmentally responsible consumption behavior. Psychology Es Marketing, 28, 69-90.

Veisten, K. (2007). Willingness to pay for eco-labelled wood furniture: Choice-based conjoint analysis versus open-ended contingent valuation. Journal of Forest Economics, 13, 29-48.

Verbeke, W. (2005). Agriculture and the food industry in the information age. European Review of Agricultural Economics, 32, 347-368.

Verbeke, W. (2008). Impact of communication on consumers' food choices. Proceedings of the Nutrition Society, 67, 281-288.

Verbruggen, A., \& Al Marchohi, M. (2010). Views on peak oil and its relation to climate change policy. Energy Policy, 38, 5572-5581.

Vermeir, I., \& Verbeke, W. (2008). Sustainable food consumption among young adults in Belgium: Theory of planned behaviour and the role of confidence and values. Ecological Economics, 64, 542-553.

Wan, C., Shen, G. Q., \& Yu, A. (2014). The moderating effect of perceived policy effectiveness on recycling intention. Journal of Environmental Psychology, 37, 55-60.

Weinfurter, S., \& Eder, A. (2009). Consumer perceptions of innovative wood-polymer composite decking with a focus on environmental aspects. Lenzinger Berichte, 87, 168-178.

Wiedmann, K.-P., Hennigs, N., Pankalla, L., Kassubek, M., \& Seegebarth, B. (2011). Adoption barriers and resistance to sustainable solutions in the automotive sector. Journal of Business Research, 64, 1201-1206.

Yue, C., Alfnes, F., \& Jensen, H. H. (2009). Discounting spotted apples: Investigating consumers' willingness to accept cosmetic damage in an organic product. Journal of Agricultural and Applied Economics, 41, 29-46. 


\title{
2 An empirical investigation of wood product infor- mation valued by young consumers (Paper 1)
}

This paper is accepted for publication in the Journal of Cleaner Production, Special Volume on Resource Efficiency and Cascading Utilisation of Renewable Materials (Osburg, Appelhanz, Toporowski \& Schumann), doi: 10.1016/j.jclepro.2015.01.068. A subsequent article proposing a traceability information system for the capturing, processing and provision of wood product information, followed by an investigation of its economic feasibility has also been accepted for publication in the Special Volume (Appelhanz, Osburg, Toporowski \& Schumann).

\begin{abstract}
Recent media reports regarding wood products question the trustworthiness of wood origin declaration, the sustainability of production methods and the product quality. In light of this question, it becomes important to ensure consumer trust in wood and woodbased products. Current research indicates that providing product information enhances product trust and purchase intentions, while young consumers in particular seek detailed product information. However, it is necessary to determine which wood product information young consumers strongly value because providing a high amount leads to information overload. As information needs may vary between different consumer segments, the present work aims at identifying segments of young consumers and their preferred wood product information. The importance of different wood product information items concerning the purchase decision was investigated with a German-language online survey $(N=185$, age range 18-30). A cluster analysis revealed four consumer segments. Thereof, three segments (an environmentally oriented, an environmentally and quality oriented, and a quality oriented segment) valued the provision of wood product information. The preferred information types differed among the three segments. Overall, this paper provides insights into young consumers' preferences for wood product information and the consumer segments on which marketing should focus.
\end{abstract}

Keywords

Wood product, Product information, Young consumers, Consumer segments, Marketing 


\section{$2.1 \quad$ Introduction}

Critical media reports on illegal timber felling, calls for boycotts of tropical wood products, marketing of cheap wood imitations consisting of paper or plastic sheet, and production processes with serious environmental impacts have increasingly occurred over the past several years. For example, news articles refer to non-reversible logging in rainforests (Vidal, 2013), the associated threat to biodiversity (Barnes, 2012) and consumer concern about fake wood (McKeough, 2014). Several consumer campaigns indicate that potential buyers care about these issues. Examples include the development of the buying guide 'Rainforest-Safe Kids Books' and a successful prevention of constructing the world's largest chip mill in a rain forest (Walker et al., 2013).

As a result, consumers' perception of wood as an eco-friendly raw material may be threatened. For instance, consumers are concerned about sustainability of forest management (Aguilar \& Cai, 2010). In addition to being worried about environmental issues such as resource depletion or the utilization of tropical timber, consumers also consider social issues, e.g., maintenance of workers' rights (Aguilar \& Cai, 2010; Cai \& Aguilar, $2013 \mathrm{~b})$. A trend involving consumers questioning the eco-friendliness of wood is dangerous because wood products usually possess high environmental friendliness, as wood is a $\mathrm{CO}_{2}$-neutral renewable raw material which can also foster the realization of cascading utilization (Fraanje, 1997; Kim \& Song, 2014). A cascading utilization of wood implies that the timing of $\mathrm{CO}_{2}$ emissions is postponed into the future through multiple material uses (Fraanje, 1997). To realize a more efficient resource utilization, it is also important not only to use virgin material but also by-products and waste materials. An example is given by the furniture industry (Tsoumis, 2009): While solid wood boards are created primarily from forest wood, co-products (sawmill by-products), secondary wood (recovered from waste wood) and wood from forest thinning are used for the production of wood-based panels such as particleboards. When considering that wood furniture can be reused again after a long utilization phase, wood can be used up to 350 years before it is used for combustion (Fraanje, 1997). Nevertheless, these benefits will not be fully exploited without consumer acceptance of wood-based products.

To increase consumer trust in both wood itself and products made from wood, additional measures are needed. For a long time, certification was a commonly used approach to regain trust and enhance the purchasing disposition of sensitized consumers. Certifications are based on the assumption that consumers prefer to purchase wood products originating from sustainable managed forests (Anderson \& Hansen, 2004). The most important European certification schemes are the Forest Stewardship Council (FSC) and the Program for the Endorsement of Forest Certification Schemes (PEFC) (Cai \& Aguilar, 2013b; Roos \& Nyrud, 2008; Yamamoto et al., 2014). In addition to certifying the forestland, these schemes also include a chain of custody certification, i.e., the traceability of the wood products to the forest of origin (Cai \& Aguilar, 2013b; Yamamoto et al., 2014). Nevertheless, consumers seem to be confused by the high quantity and variety of certification labels they are confronted with every day, so that it becomes difficult to capture their meanings (Borin et al., 2011). In recent years, studies in the Business-to-Consumer (B2C) sector examined whether a precise provision of product information is a promising alternative to certification labels of Fast-Moving Consumer Goods (FMCG), using the example of the food industry. These investigations show that consumers have higher product trust and purchase intentions when detailed product information is available (Chen et al., 2008; Clemens, 2003; Gracia \& Zeballos, 2005; Ortega et al., 2011; Ubilava \& Foster, 2009). The 
provision of the information has even been identified as a strategy to overcome purchase barriers of green products (Gleim et al., 2013) and is partially demand driven, with an increasingly growing request being reported (Dimara \& Skuras, 2003; Hobbs, 2003; Salaün \& Flores, 2001). However, simple access to information is important because consumers' uncertainties seldom induce potential buyers to actively search for product information (Verbeke, 2008). Overall, the provision of product information seems to be particularly promising for young consumers as they seek longer and more for detailed product information and use this information precisely (Cole \& Balasubramanian, 1993; Klein \& Ford, 2003; Kanchanapibul et al., 2014). Hence, those consumers aged between 18 and 30 are particularly interesting (Kanchanapibul et al., 2014). These consumers are currently described as the most educated ones, being thirsty for knowledge and having grown up in a technological environment (Yeaton, 2008). The technologically well informed suggest that the information search behavior of potential young consumers specifically relies on information and communication technology. Additionally, these consumers become increasingly active in the marketplace and are therefore an important generation for marketing research (Noble et al., 2009). Because of this, young consumers appear to be an interesting target group for initial investigations.

While recent studies indicate that consumers value access to FMCG product information, research in the wood industry is still needed. The provision of product information is also discussed as an important marketing tool for durable goods and premium products (Clemens, 2003; da Silva et al., 2010). Nevertheless, it has been noted that providing a huge number of product information items might result in an information overload; it therefore becomes necessary to identify the items consumers especially value (Kehagia et al., 2007; Pieniak et al., 2013; Salaün \& Flores, 2001; Verbeke, 2005, 2008). As the information consumers demand might vary between consumer segments, the valued information items also should be determined for different target groups (Dimara \& Skuras, 2003; Verbeke, 2005, 2008). Because of this and the suitability of the young generation for an initial examination, this study aims to identify young consumers' wood product information preferences by identifying different consumer segments and their valued information items. Specifically, the following research questions are addressed:

- Which young consumer groups value the provision of wood product information?

- What information is relevant for the identified consumer segments and is therefore evaluated by young consumers as increasing their product trust and purchase intention?

The rest of this article is organized as follows: Section 2 refers to solutions enabling consumers to retrieve product information at the point of sale (POS), consumer studies concerning FMCG product information and first approaches regarding durable goods in the wood sector. The next section describes the methods of an online survey investigating young consumers' preferences for wood product information in Germany. Section 4 presents the obtained results for the identified consumer segments and their information preferences. The paper concludes with a discussion of marketing implications concerning how to address the different consumer segments and topics for further research. 


\subsection{Current state of research}

\subsubsection{Retrieval of product information at the point of sale}

Existing consumer studies on the provision of detailed product information focused on FMCG and were carried out in the food sector (e.g., Clemens, 2003; Dimara \& Skuras, 2003; Gellynck \& Verbeke, 2001; Gracia \& Zeballos, 2005; Hobbs et al., 2005; Kehagia et al., 2007; Ortega et al., 2011; Pieniak et al., 2013; Ubilava \& Foster, 2009). Overall, these studies indicate that consumers associate access to product information with quality and safety assurance (Clemens, 2003; Dimara \& Skuras, 2003; Hobbs et al., 2005), particularly when the information is provided in pre-purchase processes at the POS (Hobbs et al., 2005).

Consumers' information retrieval at the POS can be supported by technological applications. These help to overcome problems such as limited space or the static nature of information that has been printed on packaging (GS1, 2009). Additionally, these approaches help to minimize the threat of an information overload and to provide different consumer segments with their preferred information. Consumers' information access at the POS can be classified into two commonly used approaches (da Silva et al., 2010). First, consumers can enter an identifier (ID; e.g., ID-numbers or a number-letter combination), e.g., by using a kiosk machine or Internet-enabled mobile device such as a smartphone (Chen et al., 2008). When accessing the information with a smartphone, the consumer first must call up the associated mobile website before entering the ID. In contrast, the ID can be directly typed into the input form of the website when using a kiosk machine. Second, instead of entering a long HTTP URL and/or ID, an identification medium such as a bar code (e.g., Quick Response (QR) code) with an encoded HTTP URL (address of the mobile website with the desired product information) is scanned with the built-in mobile device camera (mobile tagging) of a smartphone or Internet-enabled 2D QR-code reader provided by the retailer. Scanning results in a faster and more precise information retrieval that no longer requires manual entry of HTTP URL and/or ID, which is a timeconsuming and error-prone task. Of the various types of bar codes, QR-codes are the most important and widely distributed mobile tagging technology because of their high reading speed, high accuracy, and superior functionalities (Kan et al., 2009). QR scanning allows consumers to retrieve product information at the POS in a convenient way. However, as this is a newer approach for consumers to access product information at the POS compared with entering an ID, e.g., an URL, utilization barriers might exist. Nevertheless, both information retrieval approaches could be valuable for young consumers, as they often rely on technology to obtain further information and as they perceive technology as a tool that improves their lifestyles (Kanchanapibul et al., 2014).

\subsubsection{Relevance of product information for the purchase decision}

The previously explained access to product information could create or increase product trust (Chen et al., 2008; Clemens, 2003). Therefore, the extent of information depth is essential as it influences credibility (O'Brien \& Teisl, 2004). Expanding the information spectrum seems to be especially promising when skepticism exists on the part of consumers (e.g., due to health or environmental crises related to the product or production methods); however, the threat of an information overload always should be considered. Another benefit of providing consumers with product information in pre-purchase processes is that this information can be regarded as an indicator of credence attributes 
(Hobbs et al., 2005). A few decades ago, indicators such as product price and appearance were sufficient to imply credence attributes such as product quality, but these indicators increasingly lose reliability (Salaün \& Flores, 2001). However, it can be assumed that individual, situational and product-specific factors might influence the relevance of product information. In this context, purchase involvement appears an important concept that can be defined as the personal relevance of a buying decision (e.g., Petty \& Cacioppo, 1986; Smith \& Bristor, 1994). This motivational factor can vary across consumers, with high involvement resulting in deeper search behavior and a utilization of more information sources (Rijnsoever et al., 2012; Smith \& Bristor, 1994). Because of this, purchase involvement might influence the type and amount of product information being valued.

Despite its advantages, it must be acknowledged that the provision of detailed product information is attended by costs. A few studies examined whether consumers are willing to pay (WTP) for having access to FMCG product information. WTP is commonly defined as a point measure of the maximum price a consumer would pay for one unit of a product (Miller et al., 2011). Overall, these studies report the existence of a WTP for the provision of additional information (Clemens, 2003; Hobbs et al., 2005). The stated WTP for the retrieval of product information is higher than the WTP for product-specific labels such as a mere quality certification label or a label presenting some additional product information (Ortega et al., 2011; Ubilava \& Foster, 2009). The fact that a product-specific label is not valued as much as QR-code- and ID-number-based information retrieval results from consumers' skepticism concerning these types of product labels. This may be due to the complicated verification of the information provided by these labels (Ortega et al., 2011). Additionally, consumers need not compensate alone for the costs resulting from the information provision. Detailed product information might also be valuable in the B2B sector, e.g., by leading to an improvement of production processes or inventory and increasing trust among supply chain participants. Because of this, supply chain members might also be interested in this information, thereby being willing to bear at least some of the resulting costs.

\subsubsection{Provision of wood product information to consumers}

As shown above, several consumer studies investigated the relevance of retrieving FMCG product information. Analyses for durable goods are rare and studies concerning wood products are still missing. The results of FMCG studies concerning consumers' information preferences cannot be simply transferred to durable wood products because the required information is highly dependent on the considered product type (Giraud \& Halawany, 2006).

However, a few studies in the wood sector already have considered the influences of providing consumers with a small number of selected wood product information items. Most of the existing studies refer to environmental effects of the wood product. Therein, the value consumers set on environmental issues is primarily assessed by the WTP for sustainable forest management certification. Overall, the existing research provides evidence that consumers value forest certification in diverse countries and are therefore willing to pay a price premium (e.g., Aguilar \& Vlosky, 2007; Anderson \& Hansen, 2004; Cai \& Aguilar, 2013b; Hansmann et al., 2006; Husted et al., 2014; Veisten, 2007; Yamamoto et al., 2014). Interestingly, consumers favored detailed eco-labels over simple eco-seals by ascribing a higher credibility to the former, thereby indicating consumers' preferences for more detailed product information (Teisl, 2003). Thus far, however, there has been 
little discussion of the consequences of providing consumers with further wood product information. Some studies indicate that disclosure of wood origin influences consumer preferences (e.g., Aguilar \& Cai, 2010; Bigsby \& Ozanne, 2002; Cai \& Aguilar, 2013a; Veisten, 2007). Detailed material information also affected consumer acceptance of wood products (e.g., Anderson \& Hansen, 2004; Bumgardner \& Bowe, 2002; Roos \& Nyrud, 2008; Scholz \& Decker, 2007).

When considering providing consumers with detailed product information, two decisions must be made (Salaün \& Flores, 2001): First, the information that should be accessible to consumers should be selected. Second, the information retrieval approach and the addressed consumers must be determined. Concerning the first issue, it should be noted that the observable tendency to convey increasingly more and detailed information bears the risk of an information overload (Verbeke, 2005, 2008; Salaün \& Flores, 2001). This might lead to consumers being confused, disinterested or bored (Verbeke, 2008). Therefore, the type of information that consumers may request must be studied (Kehagia et al., 2007; Pieniak et al., 2013). Regarding the second issue, an approach that enables consumers to retrieve this information must be specified. Because of possible negative effects such as information overload, it is further suggested that different market segments be identified and that these segments be provided only with the specific information they demand (Dimara \& Skuras, 2003; Verbeke, 2005, 2008). As consumers do not understand and correctly evaluate all information (Salaün \& Flores, 2001), each information item must be examined to determine if further explanation is needed.

To the best of our knowledge, investigations considering consumers' evaluations of a wide range of wood product information are still missing. Therefore, we conducted a study to investigate which consumer segments should be addressed and which wood product information items are valued by these segments.

\subsection{Methods}

\subsubsection{Procedure and participants}

An online survey using Sawtooth Software was conducted to assess young consumers' wood product information demand and to identify different consumer segments. Flyers inviting participation in the online survey were distributed at several residence halls and in surrounding areas of four German cities (Darmstadt, Frankfurt am Main, Goettingen, Muenster) from August until December 2013. Participants were additionally recruited through announcements in Internet platforms for students and do-it-yourselfers. As motivation for participation, respondents who completed the survey were automatically entered in a prize draw for two vouchers, each worth 15 Euro.

In the beginning of the survey, respondents were introduced to the two commonly used approaches to retrieve product information. Thereby, the differences between QR-codebased and ID-number-based information retrieval were explained. The assessment of product information items valued by young consumers was based on participants imagining a purchase situation. To match the expected characteristics of the convenience sample of participants, we chose ready-to-assemble furniture as the product category. Specifically, participants were presented with two bookshelves available at a large furniture retailer that is frequently consulted by young consumers and consumers with a low-to-medium budget. Two products were introduced: a bookshelf made of solid wood (beech wood) 
Table 2: Sample statistics

\begin{tabular}{lcc}
\hline & Frequency & Percent \\
\hline Gender of respondent & & \\
Male & 87 & 47.02 \\
Female & 98 & 52.97 \\
Age of respondent & & \\
$18-21$ & 46 & 24.86 \\
$22-25$ & 59 & 31.89 \\
$26-30$ & 50 & 27.03 \\
Profession of respondent & & \\
University student & 170 & 91.89 \\
Employee & 10 & 5.41 \\
Other & 5 & 2.70 \\
\hline
\end{tabular}

and a bookshelf consisting of veneered particleboards (beech veneer). In addition, we chose bookshelf as the product category because Germany is one of the most important markets for wood furniture (Scholz \& Decker, 2007). The online survey was pretested with 10 academicians and slightly modified in response to their comments.

In total, 205 persons participated of whom 20 participants had to be excluded. This was necessary as three showed missing answers and 17 were not within the age range of 18-30, which was selected according to the age scope for young consumers as defined by Kanchanapibul et al. (2014). Table 2 shows the respondent characteristics for the sample, which comprised 185 respondents. Gender was distributed nearly equally (47\% were male) and mean age was 23.49 years $(S D=2.89)$. A majority of $91.9 \%$ were university students. Hence, the results may be generalized only to younger, well-educated people.

\subsubsection{Selection of wood product information}

The main objective of the survey was to investigate the relevance of different wood product information. A literature search was conducted to identify product information items that should be examined in the present study. The information was selected based on the following criteria. First, we chose information which either had a significant effect in consumer studies on FMCG product information or whose delivery to consumers was successful in practice (Clemens, 2003; Folinas et al., 2006; Gadema \& Oglethorpe, 2011; Hobbs et al., 2005; Kehagia et al., 2007; Pieniak et al., 2013; Ubilava \& Foster, 2009; Upham et al., 2011; Vanclay et al., 2011). Second, we included information that predicted consumer acceptance of wood-based products in previous studies (e.g., Aguilar \& Cai, 2010; Anderson \& Hansen, 2004; Bigsby \& Ozanne, 2002; Bumgardner \& Bowe, 2002; Cai \& Aguilar, 2013a; Gold \& Rubik, 2009; Jonsson et al., 2008; Kalafatis et al., 1999; Macias \& Knowles, 2011; O'Brien \& Teisl, 2004; Park et al., 2012; Roos \& Nyrud, 2008; Salazar \& Meil, 2009; Scholz \& Decker, 2007; Veisten, 2007; Weinfurter \& Eder, 2009). Finally, we considered information whose influence on consumers' attitudes towards sustainable products is discussed in the current literature (Achabou \& Dekhili, 2013; Essoussi \& Linton, 2010; Fenning \& Gershenzon, 2002; Thompson et al., 2005; Tseng \& Hung, 2013). This procedure led to a total of 18 wood product information items (e.g., country, carbon footprint, type of wood, date of wood harvest), 16 information items for the beech wood and two additional items for the beech veneer product (Appendix). The obtained wood product information items were assigned to one of four categories based on their information content: origin, environmental impact, material and illustration of the supply chain. 


\subsubsection{Measures}

The online survey comprised questions about respondents' evaluation of the product information items and their explanation requirements as well as participants' information retrieval preference.

Product information relevance. Participants evaluated the relevance of the considered product information with regard to their purchase decision. To measure the importance of this information, two questions were assessed separately for each information item and the two product variants: Participants rated the influence on product trust ('The following information would increase my trust in the product.') and purchase intention ('If I had the following information, I would be more likely to buy the product.'). Responses were made on 5-point scales ranging from 1 (does not apply at all) to 5 (fully applies). Items and product sequence were presented in random order.

Additional measures. Participants indicated whether product information items must be further explained to be intelligible. Respondents also rated as how relevant they assess eight additional factors (quality, appearance, price, brand, durability, warranty, certification, environmental impact) related to the purchase decision compared to the product information. Again, responses were made on 5-point scales.

Additionally, respondents were asked if they were familiar with QR-code- and ID-numberbased information retrieval prior to their participation and which of the two approaches they preferred. Finally, socio-demographic characteristics were assessed.

\subsubsection{Data analyses}

Data analyses began with descriptive statistics related to young consumers' preferences concerning information retrieval. The two ratings of the product information relevance (product trust and purchase intention) were averaged per information item (Cronbach's $\alpha$ $=.89$ ); the associated dependent variable was named product information relevance. For further analyses, product information relevance was ipsatized across the 16 information items to eliminate the amount of acquiescence; i.e., each respondent's mean across all items was subtracted from each product information relevance score. Ipsatized scores allow identifying which product information items are specifically relevant for a single respondent. In the next step, we wanted to uncover common dimensions underlying the 16 product information items. A principal component analysis (PCA) of the ipsatized product information relevance of the 16 items was conducted, and the resulting dimensions were saved (factor scores). To identify segments of consumers in the resulting space, a hierarchical cluster analysis (Ward's method) was carried out on the factor scores. Finally, the revealed segments were described by their product information profile.

\subsection{Results}

\subsubsection{Relevance of product information items and a comparison to other drivers of the purchase decision}

Table 3 documents the means for the product information items. Participants demanded information referring to origin (mainly country and region), environmental impact and material. Two information items of the material category were the most important, namely type of wood $(M=4.04, S D=0.97)$ and health effects of additives $(M=4.09$, 
Table 3: List of the presented product information, means and SD for information relevance and explanation requirement (if assessed)

\begin{tabular}{|c|c|c|c|c|c|}
\hline & & \multicolumn{2}{|c|}{$\begin{array}{l}\text { Information } \\
\text { relevance }\end{array}$} & \multicolumn{2}{|c|}{$\begin{array}{l}\text { Explanation } \\
\text { requirement }\end{array}$} \\
\hline & & Mean & $\mathrm{SD}$ & Mean & $\mathrm{SD}$ \\
\hline \multicolumn{6}{|l|}{ Origin } \\
\hline 1 & Country* & 3.56 & 1.20 & 2.81 & 1.37 \\
\hline 2 & Region* & 3.45 & 1.18 & 2.86 & 1.33 \\
\hline 3 & Name of the company* & 2.80 & 1.15 & 2.63 & 1.38 \\
\hline 4 & Plantation or forest* & 3.33 & 1.29 & 2.82 & 1.36 \\
\hline 5 & Picture of the plantation or forest & 2.23 & 1.08 & - & - \\
\hline 6 & Comments of the forest/plantation owners & 2.66 & 1.03 & - & - \\
\hline \multicolumn{6}{|c|}{ Environmental impact } \\
\hline 7 & Sustainable forest/plantation management* & 3.94 & 1.12 & 3.19 & 1.40 \\
\hline 8 & Carbon footprint* & 3.47 & 1.20 & 3.69 & 1.30 \\
\hline veneer 1 & Portion of recycling ${ }^{*}$ & 3.81 & 1.01 & 3.36 & 1.27 \\
\hline \multicolumn{6}{|l|}{ Material } \\
\hline 9 & Type of wood* & 4.04 & 0.97 & 2.98 & 1.37 \\
\hline 10 & Material composition* & 3.94 & 0.92 & 3.38 & 1.23 \\
\hline 11 & Additives* & 3.94 & 0.99 & 3.85 & 1.08 \\
\hline 12 & Health effects of additives* & 4.09 & 0.97 & 3.86 & 1.16 \\
\hline 13 & Comments of the producers & 3.01 & 1.09 & - & - \\
\hline veneer 2 & Composition of the veneer* & 3.82 & 0.92 & 3.23 & 1.26 \\
\hline \multicolumn{6}{|c|}{ Illustration of the Supply Chain } \\
\hline 14 & Involved companies* & 2.81 & 1.12 & 2.63 & 1.27 \\
\hline 15 & Date of wood harvest* & 2.08 & 1.02 & 2.10 & 1.27 \\
\hline 16 & Date specification (processing)* & 2.13 & 1.00 & 2.19 & 1.32 \\
\hline
\end{tabular}

* For this information, participants also evaluated whether further explanation was required.

$S D=0.97)$. However, the environmental and material information items were also evaluated as being in need of an explanation. This refers in particular to carbon footprint $(M=3.69, S D=1.30)$, additives $(M=3.85, S D=1.08)$ and health effects of additives $(M=3.86, S D=1.16)$ items. With the exception of the country and region information, product information items in the origin and supply chain categories were assessed neither as being particularly relevant nor in need of explanation.

Overall, the list of product information (total $M=3.17, S D=1.06$ ) reached a medium relevance concerning the purchase decision. Compared with other purchase decision drivers, i.e., appearance $(M=4.59, S D=0.62)$, quality $(M=4.57, S D=0.65)$, durability $(M=4.39, S D=0.73)$, price $(M=4.31, S D=0.80)$, environmental impact $(M=$ $3.65, S D=1.06)$, warranty $(M=3.48, S D=1.10)$, certification $(M=3.30, S D=1.05)$ and brand $(M=2.33, S D=1.21)$, the list of product information showed a lower relevance than did most of the other aspects.

The PCA of the 16 ipsatized items led to five components with eigenvalues over Kaiser's criterion of 1, but the scree plot suggested the extraction of two components. Figure 3 illustrates the varimax rotated component plot by showing the correlations of all product information items with the two extracted components. Component 1 differentiates between 


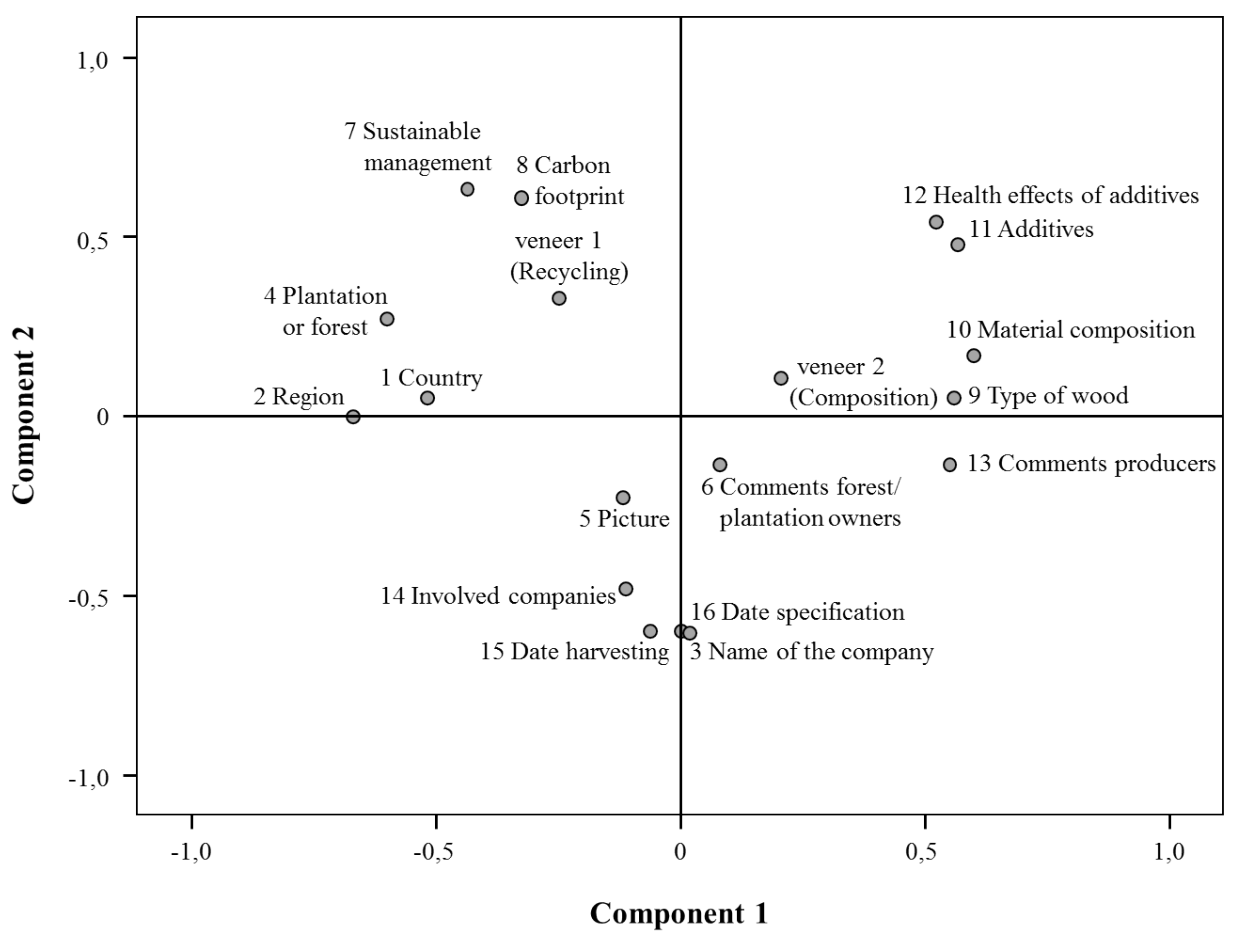

Figure 3: Varimax rotated PCA plot

material (i.e., material composition, type of wood, comments of the forest/plantation owners) and commonly used origin information (i.e., country, region, plantation or forest). Component 2 distinguishes between environmental information (i.e., sustainable forest/plantation management, carbon footprint, portion of recycling) and all supply chain as well as further origin information (i.e., name of the company, picture of the plantation or forest). The latter information is primarily demanded by respondents who differentiate only slightly among the considered items (i.e., date of wood harvest, date specification (processing), name of the company). This is shown by the within-subject SD across the 16 information items, which assessed the discrimination each participant had performed. The correlation of this discrimination performance with the components of Figure 3 is $r=.28$ with the first and $r=.54$ with the second component. Hence, respondents located in the lower left area of the component plot only slightly discriminated the considered product information items.

\subsubsection{Consumer segments and their information demand}

A hierarchical cluster analysis on the respondents was performed using the two extracted components. Figure 4 provides the results obtained from Ward's method leading to a fourcluster solution: an environmentally oriented $(n=54)$, an environmentally and quality oriented $(n=40)$, a quality oriented $(n=31)$, and an unmotivated $(n=60)$ segment. Individuals belonging to the environmentally oriented segment are located in the upper left area of Figure 4, thereby demonstrating high values on component 2, which are related to environmental issues of the product. Members of the quality oriented segment show high values on component 1 , suggesting that they mainly demand information about the product's material. Additionally, the environmentally and quality oriented segment takes an intermediate position between both segments. The wording of the latter so-called unmotivated segment points to the low discrimination performance (within subjects, $S D \leq 1.00$ ) found in that segment. The segments did not differ concerning age (means range between 


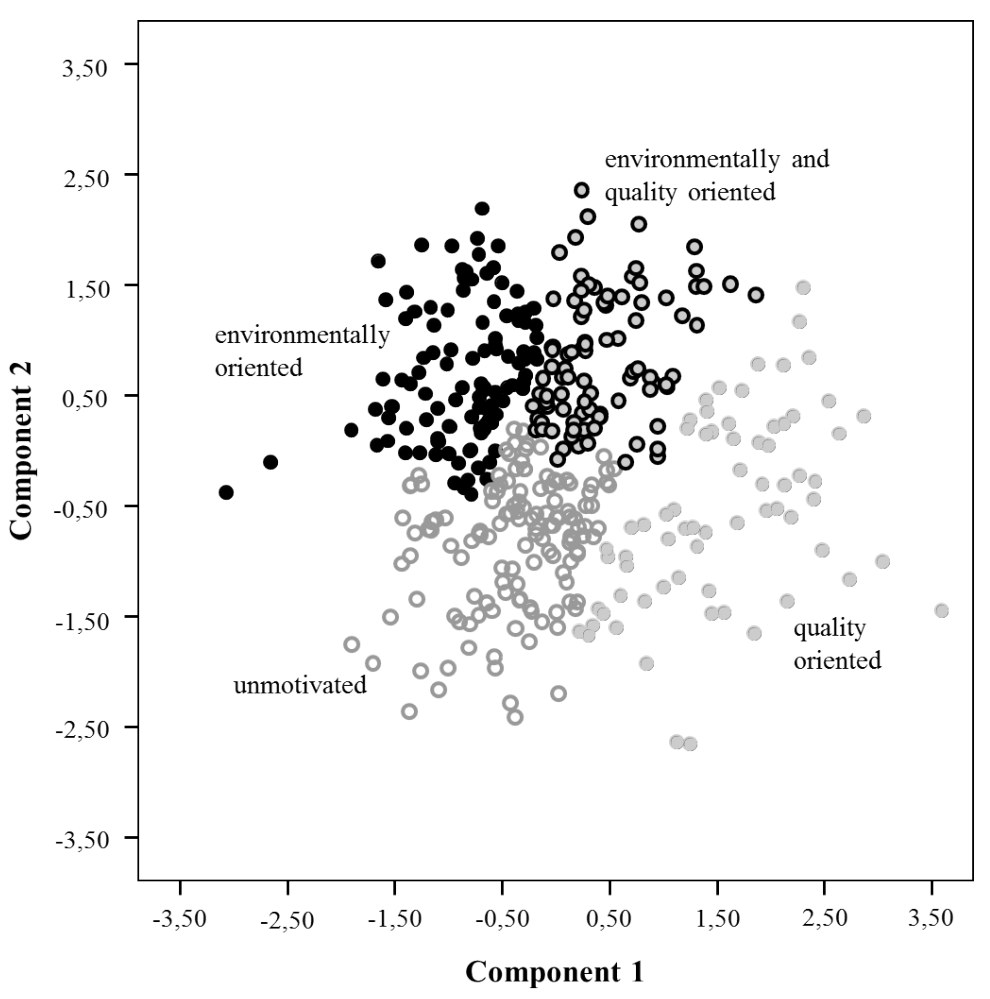

Figure 4: Scatterplot of the four identified segments

$23.36(S D=3.01)$ and $23.76(S D=2.92))$, and neither age, gender nor their interaction could predict segment membership.

Table 4 presents the ipsatized means for the product information separately for each segment. One product information item (health effects of additives) is valued by the three segments with a high discrimination performance. Additionally, the environmentally oriented segment asks for all information items referring to the environmental impact and one item revealing the product's origin. For this segment, information about sustainable forest/plantation management $(M=1.28)$, carbon footprint $(M=.92)$ and health effects of additives $(M=.90)$ are particularly relevant. In contrast, the quality oriented segment solely values the retrieval of material information. Except for the information item presenting the comments of the producers $(M=.85)$, the means of all material information items exceed 1.25, with type of wood being the most relevant $(M=1.55)$. Several information items related to the product's material and environmental impact are relevant for the environmentally and quality oriented segment. This segment values information that is preferred by the environmentally oriented (e.g., sustainable forest/plantation management $(M=1.17)$ and portion of recycling $(M=.86))$ as well as the quality oriented segment (e.g., additives $(M=1.20)$ and type of wood $(M=1.11))$. As can be expected, the 'unmotivated' segment did not show a clear preference for specific information. In total, ten product information items were relevant for at least one of the three discriminating segments.

\subsubsection{Young consumers' information retrieval preference}

$5.9 \%$ of the subjects had no knowledge about QR-codes and $40.0 \%$ no knowledge about ID-numbers prior to their participation. More participants knew QR-codes than knew ID-numbers from hearsay (QR: 63.8\%, ID: 49.2\%) or used them regularly (QR: $30.3 \%$, 
Table 4: Comparison of the ipsatized product information means within the four segments (preferred information is highlighted)

\begin{tabular}{|c|c|c|c|c|c|}
\hline & & \multicolumn{4}{|c|}{ Consumer segments } \\
\hline & & $\begin{array}{c}\text { environ- } \\
\text { mentally } \\
\text { orientend } \\
(29 \%)\end{array}$ & $\begin{array}{l}\text { environ- } \\
\text { mentally } \\
\text { and } \\
\text { quality } \\
\text { oriented } \\
(22 \%)\end{array}$ & $\begin{array}{c}\text { quality } \\
\text { oriented } \\
(17 \%)\end{array}$ & $\begin{array}{c}\text { unmoti- } \\
\text { vated } \\
(32 \%)\end{array}$ \\
\hline \multicolumn{6}{|l|}{ Origin } \\
\hline 1 & Country & .85 & .13 & -.28 & .37 \\
\hline 2 & Region & .76 & -.10 & -.67 & .45 \\
\hline 3 & Name of the company & -.79 & -.82 & -.07 & -.01 \\
\hline 4 & Plantation or forest & .83 & -.10 & -.91 & .14 \\
\hline 5 & Picture of the plantation or forest & -1.11 & -1.14 & -1.11 & -.71 \\
\hline 6 & Comments of the forest/plantation owners & -.87 & -.50 & -.45 & -.39 \\
\hline \multicolumn{6}{|c|}{ Environmental impact } \\
\hline 7 & Sustainable forest/plantation management & 1.28 & 1.17 & -.28 & .45 \\
\hline 8 & Carbon footprint & .92 & .55 & -.55 & -.12 \\
\hline veneer 1 & Portion of recycling & .86 & .86 & .46 & .25 \\
\hline \multicolumn{6}{|l|}{ Material } \\
\hline 9 & Type of wood & .48 & 1.11 & 1.55 & .56 \\
\hline 10 & Material composition & .36 & 1.09 & 1.39 & .48 \\
\hline 11 & Additives & .63 & 1.20 & 1.26 & .22 \\
\hline 12 & Health effects of additives & .90 & 1.35 & 1.44 & .24 \\
\hline 13 & Comments of the producers & -.76 & -.07 & .85 & -.36 \\
\hline veneer 2 & Composition of the veneer & .35 & .75 & 1.26 & .40 \\
\hline \multicolumn{6}{|c|}{ Illustration of the Supply Chain } \\
\hline 14 & Involved companies & -.51 & -.77 & -.36 & -.09 \\
\hline 15 & Date of wood harvest & -1.52 & -1.59 & -.95 & -.62 \\
\hline 16 & Date specification (processing) & -1.44 & -1.52 & -.86 & -.62 \\
\hline
\end{tabular}

ID: $10.8 \%$ ). Hence, $66.5 \%$ preferred information retrieval by means of QR-codes, while only $22.2 \%$ favored ID-numbers.

\subsection{Discussion and managerial implications}

To the best of our knowledge, this is the first study investigating if young consumers (and especially which consumer segments) require detailed wood product information. The present work reveals that wood product information has medium relevance with regard to purchase decision and a lower relevance compared with most other considered factors determining purchase decision (i.e., the product's quality, appearance, durability and price). This might be partially attributable to the fact that one of the identified segments, the so-called 'unmotivated' segment, does not particularly value the product information delivery. Nonetheless, the provision is recommended because the respondents indicated that the information items lead to an increase in consumers' product trust and purchase intentions. Additionally, providing information about the environmental impact can influence the market success of products consisting of eco-friendly and $\mathrm{CO}_{2}$ neutral materials, as the efforts for realizing resource efficiency will fail without achieving consumer acceptance. 
The present study identifies four consumer segments, of which three must be examined in more detail. Only the so-called unmotivated segment can be neglected, as it did not exhibit any information prioritization. Possibly, this segment might partially be ascribed to the method, as self-administered surveys bear a risk of including a proportion of participants showing a lack of motivation (Couper, 2000). Nevertheless, it suggests that in POS situations, a portion of consumers will not be interested in product information. The three other segments differed with respect to the wood product information that was deemed relevant, resulting in environmentally oriented, environmentally and quality oriented, and quality oriented segments. As supposed by Salaün and Flores (2001), respondents indicated that most of the information items require further explication and/or reference values to facilitate intelligibility. While five to six information items were emphasized per segment, ten out of the 18 investigated information items were determined to be important after consideration of overlaps, thereby partially being in line with previous studies solely investigating a very limited number of wood product information items (e.g., Aguilar \& Cai, 2010; Cai \& Aguilar, 2013a, 2013b; Scholz \& Decker, 2007). Specifically, the present study reveals that information about origin (country), environmental impact (sustainable forest/plantation management, carbon footprint, portion of recycling), and material (type of wood, material composition, additives, health effects of additives, composition of the veneer, comments of the producers) should be accessible to young consumers when intending to address all three segments. While one segment primarily focused on material information pointing to the product's quality, another one was mainly interested in environmental aspects. Beyond these, a third segment emphasized both types of information content. It must be considered that the environmentally oriented segment valued one product information item referring to the product's origin in addition to environmental information. However, the item revealing wood origin might also convey further environmental information in the sense of whether the wood originates from a tropical rain forest country.

From a marketing perspective, the present study highlights the need to provide young consumers with wood product information. Specifically, the results reveal that ten wood product information items are valued by the three identified consumer segments. The present study suggests that young consumers value product information items presenting environmental and quality information. Therefore, these issues should be highlighted in the promotion of those wood products, which are typically bought by the younger generation (e.g., bookshelves). However, it is not sufficient to state the product information; the information should rather be explained because the participants declared an explanation requirement for most of the information items. Nevertheless, the present findings do not imply that marketing can neglect the 'unmotivated' segment. Taking recourse in the Elaboration Likelihood Model (Petty \& Cacioppo, 1986), the results indicate that three segments use the central path for information processing by being motivated to address the product information items. In contrast, one out of the four segments seems to rely predominately on the peripheral path. As not all consumers are typically motivated for deep information processing, it is comprehensible that this segment was the largest of the four $(32 \%)$. When intending to address the fourth segment, advertising considering more affective cues seems to be required instead of a focus on cognitive components.

The material category was the most influential one in the present study, with health effects of additives being the only information requested by all three segments. The necessity of making health information available was also reported in studies on consumers' preferences for access to FMCG product information (e.g., Kehagia et al., 2007; Pieniak et al., 
2013). Marketing could reduce these health concerns by informing consumers about the effects of additives in general and/or disclosing them for the specific product.

Finally, marketing should engage with the transmission of the information to consumers. This study identifies QR-codes as young consumers' preferred method. Therefore, mobile web portals must be developed to provide product information to customers using QRcodes. An adequate structure seems to be necessary to arouse consumers' interest; while marketing must identify and adapt the relevant information, the design of the system falls into the scope of business information science. Close cooperation with business information science might also help marketers to address better the three segments. Due to the threat of an information overload, each of the segments should be provided with their specific information requirements (Dimara \& Skuras, 2003; Verbeke, 2005, 2008). Business information science should create three information packages that consumers have access to after scanning the product's QR-code. This allows consumers to assign themselves to one of the three information packages. The product information items included in each package should be listed on the first page so that consumers can better understand the differences between environmental, quality as well as environmental, and quality information packages.

\subsection{Limitations and suggestions for future research}

Even though this study significantly contributes to a deeper understanding of providing young consumers with wood product information, leading towards increased product trust and purchase intentions, the following limitations lead to suggestions for future research. First, as the present study comprises young German respondents, the generalizability of the obtained segments and their information preference to the broader population and other cultures must be examined in subsequent studies. It can be assumed that the three identified segments focusing to varying degrees on environmental or quality aspects might also emerge when investigating the broader population, as these issues are of special relevance concerning consumers' evaluation of wood products. Nevertheless, information preference also must be examined for an older and more diverse sample. As most of the respondents were well educated, it is worth investigating whether other consumer groups are interested in dealing with detailed product information to the same degree. Second, the results are based on ready-to-assemble furniture, specifically the investigation of young consumers' information preferences concerning bookshelves. Future studies should determine whether the obtained information preferences also hold true for other product categories. Consumers might value different product information items for other goods, e.g., products of the construction or pulp and paper industries. Additionally, product information items being valued by consumers might also vary within the furniture category. Third, the preference for QR-code- instead of ID-number-based information retrieval might also be partially related to participants' low mean age. Nevertheless, the favoritism of QR-codes is understandable, as scanning barcodes is attended by reduced effort on the part of consumers and a lower error rate than when entering ID-numbers. Finally, the present study does not include the actual purchase relevance for the respondent as well as the respondent's involvement. Future studies could address whether the amount of purchase involvement influences the perceived relevance of the information provision and which product information items are being valued. 
Beyond the limitations of the present study, future research must address two major issues related to the profitability of providing this service and its implementation. On the one hand, the present study suggests that the provision of wood product information may offer an additional service for young consumers, contributing to the strategy of product differentiation and providing competitive advantages. The role of product information as a market leverage instrument needs to be considered in subsequent studies of the economic component. A cost-benefit analysis must clarify if the provision of wood product information is profitable. Before the analysis, the resulting benefits for the companies of providing consumers with detailed wood product information must be examined, e.g., an increase in sales rate and WTP a price premium for the new service. Determining the WTP for a product and the change in sales rate due to the provision of wood product information becomes especially important for young consumers. As suggested by this study, whether they can afford the required surcharge must be investigated. The revealed benefits must be compared with the investment and recurring hardware and software costs for the development of the system. The matter of how number of supply chain participants and the price and sales rate of the product can influence the profitability of the investment also should be examined.

On the other hand, a close collaboration with business information science is essential to implement the findings of this study. Future studies should address whether (and how) current information technology and systems can satisfy young consumers' demands regarding the provision of the identified wood product information. In this context, explanation of terms and/or reference values such as statistics and benchmarking values must be considered so that consumers can better assess the information about a specific product. Simultaneously, marketing research should address the optimal presentation type motivating young consumers to retrieve the information. Concerning the estimation of product information having a medium relevance compared with other factors driving the purchase decision, it would be interesting to assess whether the product information is also influencing the evaluation of these factors. Some of the other factors respondents emphasized most were credence attributes (e.g., product quality, durability). As consumers cannot evaluate such values reliably before purchase, it should be examined whether product information may also function as their indicator, thereby reducing consumers' uncertainties and leading to a further increase in purchase intention.

\section{Acknowledgements}

This research was supported by the German Research Foundation (DFG), grant GRK 1703/1 for the Research Training Group 'Resource Efficiency in Interorganizational Networks - Planning Methods to Utilize Renewable Resources'.

\section{References}

Achabou, M. A., \& Dekhili, S. (2013). Luxury and sustainable development: Is there a match? Journal of Business Research, 66, 1896-1903.

Aguilar, F. X., \& Cai, Z. (2010). Conjoint effect of environmental labeling, disclosure of forest of origin and price on consumer preferences for wood products in the US and UK. Ecological Economics, 70, 308-316.

Aguilar, F. X., \& Vlosky, R. P. (2007). Consumer willingness to pay price premiums for environmentally certified wood products in the U.S. Forest Policy and Economics, 9, 1100-1112. 
Anderson, R. C., \& Hansen, E. N. (2004). The impact of environmental certification on preferences for wood furniture: A conjoint analysis approach. Forest Products Journal, 54, $42-50$.

Barnes, S. (2012, November 10). Saving the orang-utan. The Times Magazine. Retrieved March 10, 2014, from http://www.thetimes.co.uk/tto/magazine/article3590919.ece

Bigsby, H., \& Ozanne, L. K. (2002). The purchase decision: Consumers and environmentally certified wood products. Forest Products Journal, 52, 100-105.

Borin, N., Cerf, D. C., \& Krishnan, R. (2011). Consumer effects of environmental impact in product labeling. Journal of Consumer Marketing, 28, 76-86.

Bumgardner, M. S., \& Bowe, S. A. (2002). Species selection in secondary wood products: Implications for product design and promotion. Wood and Fiber Science, 34, 408-418.

Cai, Z., \& Aguilar, F. X. (2013a). Consumer stated purchasing preferences and corporate social responsibility in the wood products industry: A conjoint analysis in the U.S. and China. Ecological Economics, 95, 118-127.

Cai, Z., \& Aguilar, F. X. (2013b). Meta-analysis of consumer's willingness-to-pay premiums for certified wood products. Journal of Forest Economics, 1, 15-31.

Chen, R.-S., Chen, C.-C., Yeh, K. C., Chen, Y.-C., \& Kuo C.-W. (2008). Using RFID technology in food produce traceability. WSEAS Transactions on Information Science and Applications, 11, 1551-1560.

Clemens, R. (2003). Meat traceability and consumer assurance in Japan. MATRIC Briefing Paper 03-MBP 5, Midwest Agribusiness Trade Research and Information Center, Iowa State University.

Cole, C. A., \& Balasubramanian, S. K. (1993). Age differences in consumers' search for information: Public policy implications. Journal of Consumer Research, 20, 157-169.

Couper, M. P. (2000). Review: Web surveys: A review of issues and approaches. Public Opinion Quarterly, 64, 464-494.

da Silva, D. L., Correa, P. L. P., \& Najm, L. H. (2010). Requirements analysis for a traceability system for management wood supply chain on Amazon forest. Digital Information Management (ICDIM), 2010 Fifth International Conference, IEEE, 87-94.

Dimara, E., \& Skuras, D. (2003). Consumer evaluations of product certification, geographic association and traceability in Greece. European Journal of Marketing, 37, 690-705.

Essoussi, L. H., \& Linton, J. D. (2010). New or recycled products: How much are consumers willing to pay? Journal of Consumer Marketing, 27, 458-468.

Fenning, T. M., \& Gershenzon, J. (2002). Where will the wood come from? Plantation forests and the role of biotechnology. Trends in Biotechnology, 20, 291-296.

Folinas, D., Manikas, I., \& Manos, B. (2006). Tracebaility data management for food chains. British Food Journal, 108, 622-633.

Fraanje, P. J. (1997). Cascading of pine wood. Resource, Conservation and Recycling, 19, $21-28$.

Gadema, Z., \& Oglethorpe, D. (2011). The use and usefulness of carbon labelling food: A policy perspective from a survey of UK supermarket shoppers. Food Policy, 36, 815-822. 
Gellynck, X., \& Verbeke, W. (2001). Consumer perception of traceability in the meat chain. Agrarwirtschaft, 50, 368-374.

Giraud, R., \& Halawany, R. (2006). Consumers' perception of food traceability in Europe. Paper presented at the 98th EAAE Seminar 'Marketing dynamics within the global trading system: New perspectives', June 29-July 2, Chania, Greece, 1-9.

Gleim, M. R., Smith, J. S., Andrews, D., \& Cronin, J. J. (2013). Against the green: A multimethod examination of the barriers to green consumption. Journal of Retailing, 89, 44-61.

Gold, S., \& Rubik, F. (2009). Consumer attitudes towards timber as a construction material and towards timber frame houses - selected findings of a representative survey among the German population. Journal of Cleaner Production, 17, 303-309.

Gracia, A., \& Zeballos, G. (2005). Attitudes of retailers and consumers toward the EU traceability and labeling system for beef. Journal of Food Distribution Research, 36, 45-56.

GS1 (2009). GS1 MobileCom. Extended Packaging Pilot Handbook (Issue1, 11-Feb-2009). Retrieved June 20, 2014, from http://www.gs1.org/docs/mobile/GS1_Extended_Packagin g_Pilot_-Handbook.pdf.

Hansmann, R., Koellner, T., \& Scholz, R. W. (2006). Influence of consumers' socioecological and economic orientations on preferences for wood products with sustainability labels. Forest Policy and Economics, 8, 239-250.

Hobbs, J. E. (2003). Consumer demand for traceability. Paper presented at the IATRC Annual Meeting, December 15-17, 2002, Monterey, California.

Hobbs, J. E., Bailey, D., Dickinson, D. L., \& Haghiri, M. (2005). Traceability in the Canadian red meat sector: Do consumers care? Canadian Journal of Agricultural Economics, 53, $47-65$.

Husted, B. W., Russo, M. V., Meza, C. E. B., \& Tilleman, S. G. (2014). An exploratory study of environmental attitudes and the willingness to pay for environmental certification in Mexico. Journal of Business Research, 67, 891-899.

Jonsson, O., Lindberg, S., Roos, A., Hugosson, M., \& Lindström, M. (2008). Consumer perceptions and preferences on solid wood, wood-based panels, and composites: A repertory grid study. Wood and Fiber Science, 40, 663-678.

Kalafatis, S. P., Pollard, M., East, R., \& Tsogas, M. H. (1999). Green marketing and Ajzen's theory of planned behavior: a cross-market examination. Journal of Consumer Marketing, $16,441-460$.

Kan, T.-W., Teng, C.-H., \& Chou, W.-S. (2009). Applying QR-Code in Augmented Reality Applications. In S. N. Spencer, M. Nakajima, E. Wu, K. Miyata, D. Thalmann \& Z. Huang (Eds.), Proceedings of the 8th International Conference on VRCAI 2009 (pp. 253-257). Yokohama.

Kanchanapibul, M., Lacka, E., Wang, X., \& Chan, H. K. (2014). An empirical investigation of green purchase behaviour among the young generation. Journal of Cleaner Production, $66,528-536$.

Kehagia, O., Chrysochou, P., Chryssochoidis, G., Krystallis, A., \& Linardakis, M. (2007). European consumers' perceptions, definitions and expectations of traceability and the importance of labels, and the differences in these perceptions by product type. Sociological Ruralis, 47, 400-416. 
Kim, M. H., \& Song, H. B. (2014). Analysis of the global warming potential for wood waste recycling systems. Journal of Cleaner Production, 69, 199-207.

Klein, L. R., \& Ford, G. T. (2003). Consumer search for information in the digital age: An empirical study of prepurchase search for automobiles. Journal of Interactive Marketing, $17,29-49$.

Macias, N., \& Knowles, C. (2011). Examining the effect of environmental certification, wood source, and price on architects' preferences of hardwood flooring. Silva Fennica, 45, $97-109$.

McKeough, T. (2014, March 05). Should I replace fake wood paneling? The New York Times. Retrieved March 10, 2014, from http://www.nytimes.com/2014/03/06/garden/should-ireplace-fake-wood-paneling.html

Miller, K. M., Hofstetter, R., Krohme, H., \& Zhang, Z. J. (2011). How should consumers' willingness to pay be measured? An empirical comparison of state-of-the-art approaches. Journal of Marketing Research, 48, 172-184.

Noble, S. M., Hytko, D. L., \& Phillips, J. (2009). What drives college-age Generation Y consumers? Journal of Business Research, 62, 617-628.

O'Brien, K. A., \& Teisl, M. F. (2004). Eco-information and its effects on consumer values for environmentally certified forest products. Journal of Forest Economics, 10, 75-96.

Ortega, D. L., Wang, H. H., Wu, L., \& Olynk, N. J. (2011). Modeling heterogeneity in consumer preferences for select food safety attributes in China. Food Policy, 36, 318-324.

Park, S.-J., Choi, S., \& Kim, E.-J. (2012). The relationships between socio-demographic variables and concerns about environmental sustainability. Corporate Social Responsibility and Environmental Management, 19, 343-354.

Petty, R. E., \& Cacioppo, J. T. (1986). The Elaboration Likelihood Model of persuasion. In L. Berkowitz (Ed.), Advances in experimental social psychology (Vol. 19, pp. 123-205). New York: Academic Press.

Pieniak, Z., Vanhonacker, F., \& Verbeke, W. (2013). Consumer knowledge and use of information about fish and aquaculture. Food Policy, 40, 25-30.

Rijnsoever, F. J. van, Castaldi, C., \& Dijst, M. J. (2012). In what sequence are information sources consulted by involved consumers? The case of automobile pre-purchase search. Journal of Retailing and Consumer Services, 19, 343-352.

Roos, A., \& Nyrud, A. Q. (2008). Description of green versus environmentally indifferent consumers of wood products in Scandinavia: flooring and decking. Journal of Wood Science, $54,402-407$.

Salaün, Y., \& Flores, K. (2001). Information quality: Meeting the needs of the consumer. International Journal of Information Management, 21, 21-37.

Salazar, J., \& Meil, J. (2009). Prospects for carbon-neutral housing: The influence of greater wood use on the carbon footprint of a single-family residence. Journal of Cleaner Production, 17, 1563-1571.

Scholz, S. W., \& Decker, R. (2007). Measuring the impact of wood species on consumer preferences for wooden furniture by means of the analytic hierarchy process. Forest Products Journal, 57, 23-28. 
Smith, J. B., \& Bristor, J. M. (1994). Uncertainty orientation: Explaining differences in purchase involvement and external search. Psychology \& Marketing, 11, 587-607.

Teisl, M. F. (2003). What we may have is a failure to communicate: Labeling environmentally certified forest products. Forest Science, 49, 668-680.

Thompson, M., Sylvia, G., \& Morrissey, M. T. (2005). Traceability in the United States: Current trends, system design, and potential applications. Reviews in Food Science and Food Safety, 1, 1-7.

Tseng, S.-C., \& Hung, S.-W. (2013). A framework identifying the gaps between customers' expectations and their perceptions in green products. Journal of Cleaner Production, 59, $174-184$.

Tsoumis, G. (2009). Science and Technology of Wood. Structure, Properties, Utilization (reprint of the ed. from 1991). Remagen-Oberwinter: Publishing House Kessel.

Ubilava, D., \& Foster, K. (2009). Quality certification vs. product traceability: Consumer preferences for informational attributes of pork in Georgia. Food Policy, 34, 305-310.

Upham, P., Dendler, L., \& Bleda, M. (2011). Carbon labelling of grocery products: Public perceptions and potential emissions reductions. Journal of Cleaner Production, 19, 348-355.

Vanclay, J. K., Shortiss, J., Aulsebrook, S., Gillespie, A. M., Howell, B. C., Johanni, R., ... Yates, J. (2011). Customer response to carbon labelling of groceries. Journal of Consumer Policy, 34, 153-160.

Veisten, K. (2007). Willingness to pay for eco-labelled wood furniture: Choice-based conjoint analysis versus open-ended contingent valuation. Journal of Forest Economics, 13, 29-48.

Verbeke, W. (2005). Agriculture and the food industry in the information age. European Review of Agricultural Economics, 32, 347-368.

Verbeke, W. (2008). Impact of communication on consumers' food choices. Proceedings of the Nutrition Society, 67, 281-288.

Vidal, J. (2013, May 26). The Sumatran rainforest will mostly disappear within 20 years. The Observer. Retrieved March 10, 2014, from http://www.theguardian.com/world/2013/m ay/26/sumatra-borneo-deforestation-tigers-palm-oil

Walker, N., Patel, N., Davis, F., Milledge, S., \& Hulse, J. (2013). Demand-side interventions to reduce deforestation and forest degradation. London: Oldacres Printers.

Weinfurter, S., \& Eder, A. (2009). Consumer perceptions of innovative wood-polymer composite decking with a focus on environmental aspects. Lenzinger Berichte, 87, 168-178.

Yamamoto, Y., Takeuchi, K., \& Shinkuma, T. (2014). Is there a price premium for certified wood? Empirical evidence from log auction data in Japan. Forest Policy and Economics, 38, 168-172.

Yeaton, K. (2008). Recruiting and managing the 'Why?' generation: Gen Y. The CPA Journal, $78,68-72$. 


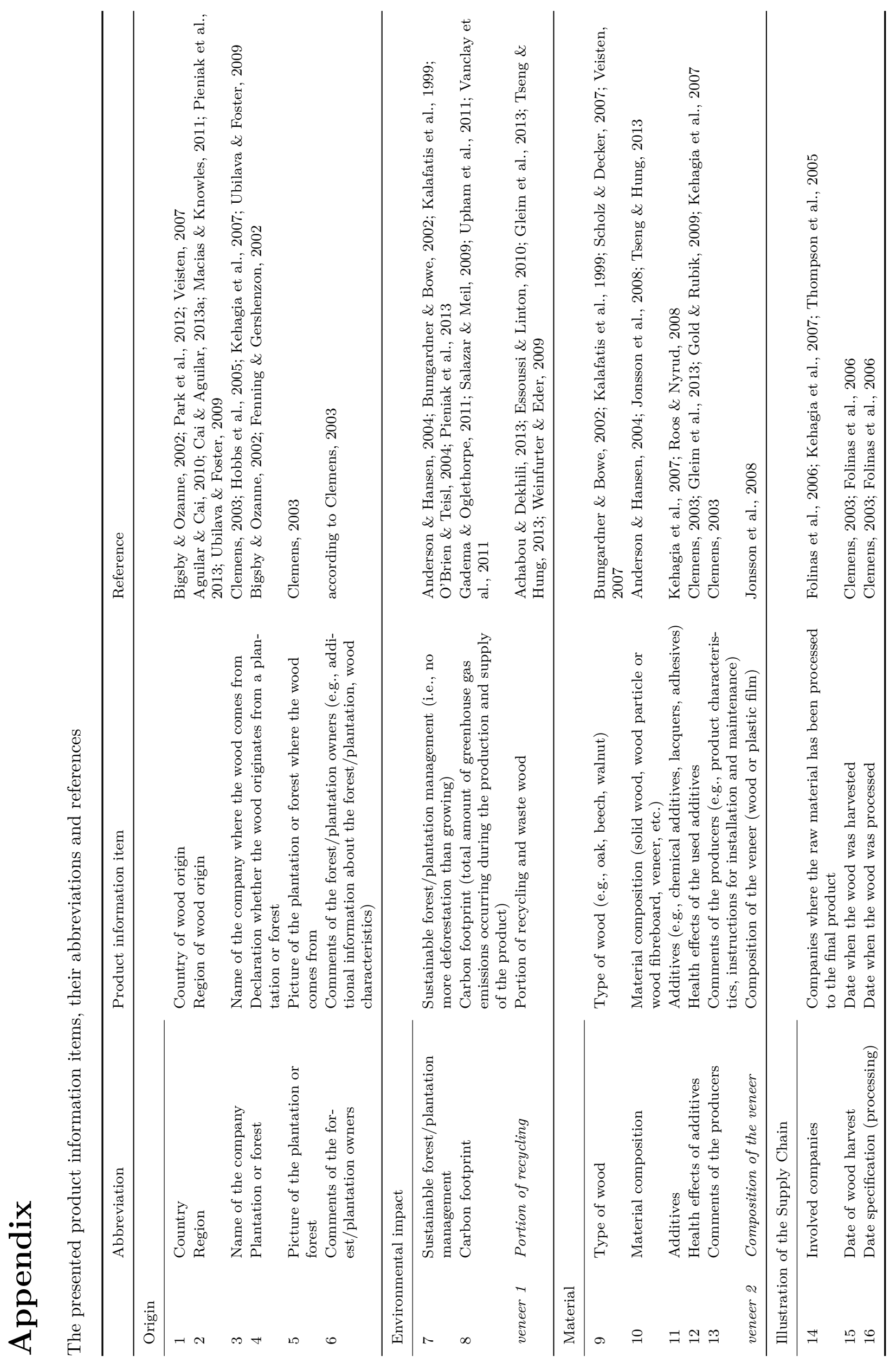




\title{
3 Consumer acceptance of Wood-Polymer Compo- sites: a conjoint analytical approach with a focus on innovative and environmentally concerned con- sumers (Paper 2)
}

This paper is accepted for publication in the Journal of Cleaner Production, Special Volume on Resource Efficiency and Cascading Utilisation of Renewable Materials (Osburg, Strack \& Toporowski), doi: 10.1016/j.jclepro.2015.04.086. Earlier versions of this paper (solely focusing on Study 1) have been presented at the AMA 2014 Marketing 83 Public Policy Conference (Boston), the $4^{\text {th }}{ }^{\text {th }}$ Academy of Marketing Conference (Bournemouth) and the $28^{\text {th }}$ International Congress of Applied Psychology (Paris).

\begin{abstract}
Wood-Polymer Composites (WPCs) can contribute towards resource efficiency as they mainly consist of wood by-products and/or waste materials. The eco-innovative materials represent a hybrid solution on the 'two-evils' continuum' constituted by the competing materials of wood and plastics; the former being too expensive and resource consuming in mass consumption, the latter cheap but environmentally hazardous. However, consumer acceptance of WPCs is questioned due to the merger of components consumers perceive as being contradictory (wood and plastics). Additionally, it is discussed whether consumers' innovativeness enhances WPC acceptance, while eco-friendly consumers may reject WPCs because of environmental concerns related with the synthetic components. To determine the potential market for products made of eco-innovative materials, two German-language online studies $(n=198, n=357)$ were created to examine consumer acceptance of WPCs in relation to the competing materials. Study 1 introduced a 3 (material: wood, WPC, plastics) x 2 (appearance: wooden or synthetic) within-subject design. Consistent with the expectations, study 1 showed a clear preference for wood over plastics based on a convenient sample. WPCs remained in the centre position, even for environmentally concerned consumers. Study 2 was conducted to replicate the findings with a representative sample. It additionally considered consumer innovativeness and included further product categories. WPCs only slightly deviated from the centre position in study 2. Mostly important, study 2 proved that the higher the environmental concern and the innovativeness of consumers, the more WPCs were accepted. When taken together, the results point to a greater WPC market than previous research had indicated. In general, premature concerns about innovative materials can be prevented by consumer acceptance studies examining the new materials' position in a surrounding 'multi evils' continuum'.
\end{abstract}

Keywords

Consumer acceptance, Eco-innovation, WPCs, Conjoint analysis, Green marketing 


\subsection{Introduction}

As raw materials and energy resources become scarce, innovative strategies realising efficient raw material use are required (Crabbé et al., 2013). Within the past few years, suppliers and retailers have significantly invested in the development of green products ${ }^{2}$ (Crabbé et al., 2013; Gleim et al., 2013; Lin et al., 2013). These products are commonly referred to as eco-innovations, meaning innovative products which are more eco-friendly than conventional alternatives (Jansson, 2011). Eco-innovations carry various potentials: Besides a diverse range of environmental benefits and cost-savings because of less resources being used, eco-innovations can function as a differentiation strategy and are linked to competitive advantage (Crabbé et al., 2013; Lin et al., 2013; Medeiros et al., 2014). This implies that the identification of target groups that are interested in eco-innovations and the strategies for how to address these segments become important for the marketing of eco-innovative products.

An important precondition of eco-innovations' market success seems to be consumer awareness of eco-friendly purchase behavior as a means of (ensuring or contributing towards) environmental protection, human health, and the responsible allocation of resources (Chao et al., 2012; Crabbé et al., 2013; Gleim et al., 2013; Grimmer \& Bingham, 2013; Kanchanapibul et al., 2014). However, green products still represent a comparatively lower market share than optimists had suggested (Gleim et al., 2013; Lin \& Huang, 2012; Rex \& Baumann, 2007; Tseng \& Hung, 2013). Given that attitudes do not necessarily translate into behavior, it is essential to empirically examine consumers' purchase intention for eco-innovations (Ozaki, 2011).

Wood-Polymer Composites (WPCs) are such a group of eco-innovative materials, showing the potential to contribute towards more efficient resource utilization (Teuber et al., 2015). WPCs exhibited a worldwide market growth in the last decade, which is predicted to further increase within the next few years (Carus et al., 2008; Eder \& Carus, 2013). When investigating eco-innovations such as WPCs, the pro-environmental attitudes and the innovativeness of consumers can be the most important moderators of acceptance (e.g., Jansson, 2011; Lin \& Huang, 2012). Nonetheless, this group of materials is unknown to many customers and the consumer acceptance is nearly unexplored (Haider \& Eder, 2010; Weinfurter \& Eder, 2009). The present article analyzes consumer acceptance of WPCs in relation to two traditional materials. On the one hand, WPC acceptance is compared with solid wood, which is more expensive than WPCs for several applications and also resource consuming in mass consumption. Many by-products emerge during the production of goods consisting of solid wood which also require a material utilization to improve resource efficiency, however, these by-products are still often directly used for energy (Carus et al., 2008). On the other hand, traditional full plastics are perceived as a cheap material but environmentally hazardous if they are based on fossil fuels.

\subsection{Literature Review}

\subsubsection{Consumers' green purchasing behavior}

A considerable amount of literature has been published on green consumer behavior, primarily investigating consumer acceptance of fast-moving consumer goods (FMCG). Numerous studies in this domain refer to consumers' intention to buy organic food (e.g.,

\footnotetext{
${ }^{2}$ The terms 'green' and 'eco-friendly' are used interchangeably throughout the article.
} 
Marette et al., 2012; Onozaka \& McFadden, 2011; Vermeir \& Verbeke, 2008; Yue et al., 2009). The acceptance of detergents and cosmetics (e.g., Lin \& Huang, 2012; Luchs et al., 2010), green energy (e.g., Diaz-Rainey \& Ashton, 2011; Hartmann \& Apaolaza-Ibáñez, 2012; Ozaki, 2011; Scarpa \& Willis, 2010), and recycled and remanufactured products (e.g., Essoussi \& Linton, 2010; Michaud \& Llerena, 2011) has been explored. Most of the studies suggest an overall consumer acceptance of green FMCG. Thereby, various drivers of eco-friendly consumer behavior are analyzed with (environmental) attitude (e.g., DiazRainey \& Ashton, 2011; Hartmann \& Apaolaza-Ibáñez, 2012; Leonidou et al., 2010; Ozaki, 2011; Vermeir \& Verbeke, 2008), values (e.g., Lin \& Huang, 2012; Urien \& Kilbourne, 2011; Vermeir \& Verbeke, 2008) and socio-demographic characteristics (e.g., do Paço \& Raposo, 2009; Park et al., 2012) as the most often considered determinants. Attitude and values turn out to be better predictors than socio-demographic characteristics, with the latter showing contradictory findings (Diamantopoulos et al., 2003; Diaz-Rainey \& Ashton, 2011; Rex \& Baumann, 2007; Zhao et al., 2014). The value that consumers attribute to eco-friendly products is often assessed by the additional willingness to pay (WTP), i.e., the surcharge consumers would spend for a green product compared to a conventional alternative. While some studies reveal the existence of a marginal or even non-existent WTP (Michaud \& Llerena, 2011; Scarpa \& Willis, 2010), others suggest a substantial surcharge for green products (Krystallis \& Chryssohoidis, 2005; Marette et al., 2012).

Nonetheless, the drivers of green consumer behavior and the WTP can vary between different product categories and even within a category (Essoussi \& Linton, 2010; Krystallis \& Chryssohoidis, 2005; Luchs et al., 2010; Yue et al., 2009). While many studies investigate consumer acceptance of everyday products, only a few consider durable goods characterised by high purchase involvements (Achabou \& Dekhili, 2013; Davies et al., 2012) such as wood-based products. The few existing consumer studies about wood-based products mainly examine the effects of sustainable forest management certification and suggest that consumers prefer buying certified wood products and show an additional WTP for them (e.g., Aguilar \& Vlosky, 2007; Anderson \& Hansen, 2004; Cai \& Aguilar, 2013b; Husted et al., 2014; Thompson et al., 2010; Vlosky et al., 1999). Also for certified wood products, attitudes are identified as important drivers of the purchase decision, whereas socio-demographic characteristics have low predictive power (e.g., Husted et al., 2014; Kalafatis et al., 1999; Thompson et al., 2010). Overall, studies about green consumer behavior suggest that empirical investigations are not superfluous as consumer acceptance of green products is dependent on product category and the investigated materials. Additional studies are therefore required to assess consumer acceptance of new, eco-friendly materials and products. For identifying the predictors of consumer acceptance, the focus should be on attitudes and personality characteristics.

\subsubsection{Consumer acceptance of WPC products}

Research about consumer acceptance of wood-based products primarily concerns solid wood. Innovative composite materials such as WPCs must be examined as well, because they become increasingly important for efficient resource utilization. The concept of WPCs shows the timber industry a new way for a production with almost no waste: WPCs allow for new fields of application for the material utilization of by-products and waste materials from the wood processing and agricultural industry (Carus et al., 2008; Teuber et al., 2015). These fields of applications which, for example, rely on the material's three-dimensional formability, cannot be covered by traditional materials relying on wood 
by-products such as particle boards and pulp and paper. As wood is mostly the main component of WPCs (up to more than 80\%) (Carus et al., 2008; Klyosov, 2007), WPCs have a potential to minimize wood waste and prevent a direct energetic utilization of byproducts. Additionally, the wood components of a WPC could also be part of a later stage of cascading utilization. For example, wood-based products (solid wood products, flake boards, fibre boards etc.) can be recycled and used for WPC production (Krause et al., 2013). The wood component not only influences the physical and mechanical properties of the material, but also the visual properties (Carus et al., 2008): Products consisting of WPCs could exhibit a surface similar to wood or to plastic products.

In addition to the potential of fostering resource efficiency, evaluating the eco-friendliness of WPCs primarily depends on WPC composition and on a comparison with the material(s) replaced by WPCs. WPC composition highly impacts the eco-friendliness so that WPCs may be considered as fully environmentally sound materials if all WPC components show a high eco-friendliness (Teuber et al., 2015). Based on the review of life cycle assessments (LCA), Teuber et al. (2015) conclude that for most applications, WPCs have a higher environmental impact compared with solid wood, but a lower compared with fossil fuel-based neat plastics. Amongst others, material characteristics such as durability are important. For example, it is discussed that WPCs provide an opportunity to extend the durability of solid wood for some applications without requiring additional maintenance on the part of the consumer (Caufield et al., 2005). In this context, WPC recycling is another issue that must be considered in the future and might further enhance WPC eco-friendliness (Teuber et al., 2015).

As stated above, central to these eco-innovative materials is a merger of wood, plastics and additives (Caufield et al., 2005), i.e., components consumers perceive as being contradictory. Therefore, the discussion of consumer acceptance of WPC products can be controversial. Despite numerous studies in the material sciences that aimed to improve the material quality (e.g., Ashrafi et al., 2011; Kuo et al., 2009), only a few consumer studies were conducted. An interview study by Jonsson et al. (2008) with 15 respondents suggested a low WPC acceptance in comparison to solid wood. Weinfurter and Eder (2009) found a minor importance of environmental issues in the consumer segment of 'do-it-yourselfers'. Nevertheless, profound examinations of WPC acceptance and the identification of relevant target segments are still missing.

As WPCs can substitute the two materials they consist of, the first comprehensive investigations of WPC acceptance should rely on a comparison with both pure constituents, i.e., solid wood and full plastics. When consumers must decide between these two established materials, an avoidance-avoidance competition (Miller, 1944) may result. Consumers are confronted with 'two evils' representing the endpoints of a continuum: On the one hand, solid wood, formerly an eco-friendly material, is realized as expensive and too resource consuming in mass consumption. On the other hand, full plastics are perceived as cheap but are noted to be environmentally hazardous. Consumers are expected to prefer wood when having to decide between solid wood and full plastics for themselves. Within the category of wood-based products, consumers typically prefer solid wood to composite materials (Anderson \& Hansen, 2004; Cai \& Aguilar, 2013a; Jonsson et al., 2008). Beyond that, WPCs have natural and synthetic components, so that the eco-innovations serve as a hybrid solution. Therefore, WPCs will be located in the centre of the 'two evils' continuum', lessening the pollution from plastic waste as well as by forestalling exploitation. 
Hypothesis $1\left(H_{1}\right)$. The product choice varies with the product's material. Consumers prefer solid wood over full plastics, while WPCs are positioned in the centre of both (i.e., given an effect coding of the three materials, the a priori contrast of the two established materials (linear material effect code) should be strong whereas the contrast code for the central position will remain insignificant).

Previous research also indicated that consumers place emphasis on the products' appearance. Even for WPC products comprising a synthetic and a natural component, consumers seem to prefer a wood-like surface (Jonsson et al., 2008; Weinfurter \& Eder, 2009). Hence, the natural appearance is expected to be the favoured one.

Hypothesis $2\left(H_{2}\right)$. The product choice varies with the product's appearance. Appearance will have a main effect: A wooden surface will be preferred over a synthetic surface.

On the one hand, some research points to a WTP for green versus environmentally hazardous FMCG (Krystallis \& Chryssohoidis, 2005; Marette et al., 2012). On the other hand, the price premium of eco-friendly products turns out to be a main barrier of green consumer behavior (Gleim et al., 2013; Young et al., 2010). Consumers seem to be especially price sensitive for high-priced and infrequently bought wood products (Cai \& Aguilar, 2013b; Thompson et al., 2010). Similarly, Anderson and Hansen (2004) identify price as the most important factor for the purchase of wood products. Hence, price is expected to be an important additional driver of consumers' choices.

Hypothesis $3\left(H_{3}\right)$. The product choice varies with a product's price. Price will have a negative main effect on consumers' preferences. The higher the price, the less likely the product is chosen.

\subsubsection{Important consumer segments for WPC products}

When determining the acceptance of WPCs, two consumer segments are of special interest. The first refers to those with a high environmental concern (EC). Environmental concern is defined as an individual's general attitude towards the environmental protection (Schultz, 2001). Environmentally concerned consumers typically trust the quality of green products more and purchase those products having a lower environmental impact (Gleim et al., 2013; Grimmer \& Bingham, 2013; Kanchanapibul et al., 2014; Lin \& Huang, 2012; Tseng \& Hung, 2013; Zhao et al., 2014). Additionally, recent evidence suggests that environmentally concerned consumers value eco-friendly products by showing a WTP for a diverse range of green products compared to conventional ones (e.g., Diaz-Rainey \& Ashton, 2011; Tseng \& Hung, 2013; Vlosky et al., 1999; Yue et al., 2009). Therefore, this consumer segment should emphasize the preference for solid wood over full plastics. However, while environmentally concerned consumers accept eco-innovations sometimes, this does not have to apply to WPCs. Environmentally concerned consumers might overvalue the synthetic components they typically reject due to pollution and health concerns, or the perception of it as a cheap and baneful material (Eyerer et al., 2010; Petrescu et al., 2010).

Hypothesis $4\left(\mathrm{H}_{4}\right)$. Environmental concern (EC) interacts with the product's material: The higher the EC of an individual, the stronger her/his preference is for solid wood over full plastics, while WPCs are assimilated to full plastics (i.e., interactions of EC will occur with the linear effect code and the effect code for the central position). 
Besides EC, Lin and Huang (2012) determine novelty seeking as another predictor of green consumption. Similarly, Jansson (2011) identifies consumer innovativeness as an important driver for the acceptance of eco-innovations. This personality trait is conceptualized as an individual's predisposition to purchase a higher amount of new products and to adopt them earlier than the mainstream (Roehrich, 2004). The value that consumers with a high innovativeness ascribe to new products is further proved by their price insensitivity when purchasing innovative products (e.g., Goldsmith et al., 2005; Munnukka, 2008; Ramirez \& Goldsmith, 2009). Based on this, the innovative segment should choose WPCs more often than the average consumer.

Hypothesis $5\left(\mathrm{H}_{5}\right)$. Consumer innovativeness also interacts with the product's material: The higher an individual's innovativeness, the more their WPC choices approach those for solid wood, while the preference for solid wood over full plastics remains unaffected (i.e., an interaction of innovativeness will only occur with the effect code for the central position).

As supposed throughout the last paragraphs, environmentally concerned and innovative consumers represent different market segments. The proposed distinction can be illustrated by the value model comprising ten universal values which are organized in a circumplex structure (Schwartz, 1992, Figure 5) and constitute segments as well as attitudes (e.g., Boer \& Fischer, 2013). The ten values are positioned based on two dimensions. The first refers to an individual's degree of being open to change versus preferring conservative values. The second (self-transcendence vs. self-enhancement) differs between pursuing one's own interests or transcending these by considering welfare and nature. Hence, the high innovativeness segment locates on the left hand side of the circle (openness to change), while the environmentally concerned segment is positioned at the upper quarter (self transcendence, see Figure 5). By assessing environmental concern and innovativeness, four value segments can be effectively distinguished.

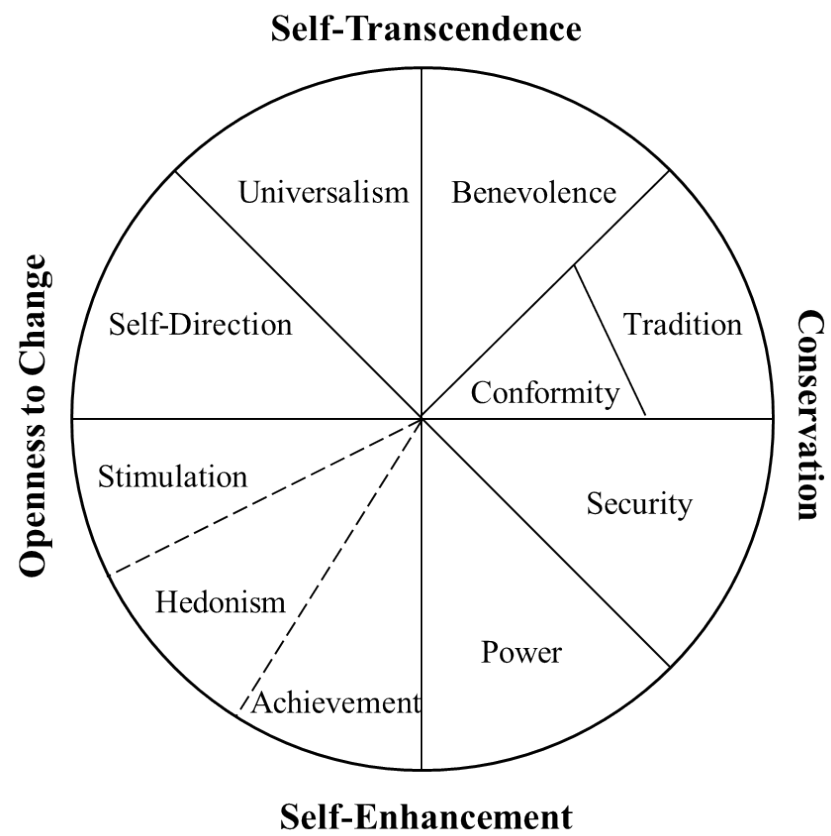

Figure 5: Universal value structure (Schwartz, 1992) 
The assumptions are assessed by online surveys. However, the generalizability of online surveys evaluating consumers' product acceptance could be questioned by claiming that these studies lack some characteristics of real purchase situations, such as the opportunity to receive haptic product information. As an indirect test of generalizability, the Need for Touch (NFT) scale (Peck \& Childers, 2003) is included, which assesses an individual's disposition for haptic product information processing in a purchase situation. If a haptic product examination is important, participants of the online survey who show a high NFT should choose fewer products compared to consumers with a low NFT and they are also expected to differ less between product variants.

Hypothesis $6\left(H_{6}\right)$. If concerns regarding online surveys apply to this context, a negative main effect and a lower discrimination between the different values of the independent variables of material and appearance can be expected for consumers with high NFT.

In the next chapters, two studies are presented, assessing the consumer acceptance position of WPCs on the 'two evils' continuum'. Study 1 considers WPC acceptance with a particular focus on the environmentally concerned consumer segment and includes an investigation of the suitability of online surveys, while study 2 examines the segments of environmentally concerned and of innovative consumers compared to their respective counterparts.

\subsection{Study 1}

The primary objective of study 1 is to investigate WPC acceptance in relation to the competing materials of wood and plastics by using a convenience sample of younger German respondents. In addition to determining the WPC acceptance for the whole sample, we particularly examine the moderation impact of the environmental concern of the consumers and the suitability of online surveys.

\subsubsection{Methods}

\section{Procedure and participants}

Study 1 was an online survey using a 3 (material: solid wood, WPC, plastics) x 2 (appearance: wooden, synthetic surface) within-subjects design. 250 German respondents participated, 198 of whom have fully completed. The mean age was 25.47 years $(S D=3.41$, range from 18-40). $38 \%$ of the respondents were male and $69 \%$ were university students. WPCs were unknown materials for half of the respondents, $42 \%$ knew the term from hearsay, while only $8 \%$ reported good knowledge of WPC. In order to assess the purchase intention, participants were instructed to imagine buying a chair. Furniture was selected as it became an interesting WPC market in recent years since traditional applications (e.g., decking) reached the maturity stage in the European market (Eder \& Carus, 2013). Specifically, the purchase of small furniture was chosen with the purpose of matching the expected younger age of the convenience sample.

In the beginning of the survey, all respondents received the following material information: a) wood: 'solid wood', b) WPC: 'Wood-Plastic-Composite: $70 \%$ wood (mainly wood by-products e.g., sawdust), $30 \%$ plastics, additives', c) polymers: 'synthetically produced material ('plastics'): mineral oil, coal, natural gas'. Additionally, two pictures were shown differing only with respect to the product's appearance (brown synthetic vs. 
brown wooden chair). Participants were recruited through mailed letters and announcements in online platforms. As motivation for participation each respondent was entered in a prize draw for three vouchers, worth 10 to 20 Euros.

\section{Measures}

The online survey consisted of several parts, whereupon the present paper refers to the measurements of EC, NFT, socio-demographic information and the purchase intention, the latter being determined by a choice-based conjoint analysis.

EC. EC was assessed with the 12-item scale from Schultz (2001, German according to Homburg \& Wagner, 2007). Respondents answered on 7-point scales ranging from 1 (not concerned) to 7 (extremely concerned). All items were presented in random order. The EC mean score was $4.74(\mathrm{SD}=1.04)$ and internal consistency was high (Cronbach's $\alpha=$ $0.89)$.

NFT. NFT was measured with a German version (Nuszbaum et al., 2010) of the 12-item scale from Peck and Childers (2003). Respondents answered on 7-point scales ranging from -3 (not at all true) to +3 (exactly true). Cronbach's $\alpha$ was 0.91 for the 12 -item scale.

Choice-based conjoint analysis (CBCA). The purchase intention was measured with a CBCA (Green \& Rao, 1971), allowing to investigate the trade-offs between different product attributes consumers make during purchase decisions. Table 5 presents the three attributes of the CBCA and their levels (for study 1, only the 'chair' cells of Table 5 were realised). The verbal description of the attribute 'appearance' was supplemented with the two pictures introduced in the beginning of the survey. Only specific combinations of material and price were allowed which best reflected current market offers.

Table 5: Attributes and levels of the CBCA (Study 1 and 2)

\begin{tabular}{|c|c|c|c|c|}
\hline Attributes & & & Levels & \\
\hline $\begin{array}{l}\text { Material } \\
\text { Appearance }\end{array}$ & & $\begin{array}{c}\text { solid wood } \\
\text { wooden surface }\end{array}$ & $\begin{array}{c}\text { WPC } \\
\text { synthetic surface }\end{array}$ & plastics \\
\hline Price & $\begin{array}{l}\text { solid wood: } \\
\text { WPC: } \\
\text { plastics: }\end{array}$ & $\begin{array}{c}60 €^{1} / 120 €^{2} / 120 €^{3} \\
50 €^{1} / 100 €^{2} / 150 €^{3} \\
40 €^{1} / 80 €^{2} / 180 €^{3}\end{array}$ & $\begin{array}{l}70 €^{1} / 140 €^{2} / 150 €^{3} \\
60 €^{1} / 120 €^{2} / 180 €^{3} \\
50 €^{1} / 100 €^{2} / 210 €^{3}\end{array}$ & $\begin{array}{l}80 €^{1} / 160 €^{2} / 180 €^{3} \\
70 €^{1} / 140 €^{2} / 210 €^{3} \\
60 €^{1} / 120 €^{2} / 240 €^{3}\end{array}$ \\
\hline
\end{tabular}

Note: Price levels vary as a function of product category

${ }^{1}$ chair (Study 1 and Study 2)

${ }^{2}$ window frame (Study 2)

3 fence (Study 2)

A fractional factorial design reduced the number of choices per participant. Each participant received 14 choice sets, 2 of them fixed and 12 randomly selected by Sawtooth Software, Inc. SSI Web (version 8.2). Every choice set consisted of two alternative chairs, supplemented with a 'none of these' option as the latter represents a possible choice in reality. Respondents were asked to make choices according to actual purchase situations for each choice set. Hence, a CBCA requires hypothetical choices and builds on the assumption that respondents choose those products they would also select in reality. 
A balanced overlap design was employed due to its advantages for estimating main effects and interactions (Chrzan \& Orme, 2000). Examining the multicollinearity of predictors, including their interactions, we found all pairwise effect correlations remaining $|r|<.44$. The largest one was the negative correlation of material (linear) and price, resulting from the two fixed cases causing this correlation. Apart from that, the low intercorrelations allowed for the inclusion of interactions without multicollinearity problems.

\section{Data analysis}

Data management and analysis was performed using SPSS 21. A nominal logistic regression was applied to analyze the CBCA. The categorical dependent variable 'choice' was a dichotomous dummy, taking the values of 1 (selected) and 0 (not selected). Appearance (effect coding: $1=$ wooden, $-1=$ synthetic surface $)$, material linear $(1=$ solid wood, $0=$ WPC, $-1=$ full plastics $)$, material quadratic $(-1=$ solid wood, $2=$ WPC, $-1=$ plastics $)$, price $(1=$ base price $-15 \%, 0=$ base price, $-1=$ base price $+15 \%)$ and their interactions were included as predictors. While the material linear effect code distinguished between solid wood and full plastics, the material quadratic effect code estimated WPC in relation to the competing materials ${ }^{3}$. Price and EC scores were standardized before inclusion.

\subsubsection{Results}

The estimated overall probability to choose WPC (0.33) lay in the centre between solid wood (0.48) and full plastics (0.21). Table 6 shows the estimated coefficients of the logistic regression. Confirming $\mathrm{H}_{1}$, participants preferred solid wood over full plastics (effect size Odds Ratio 2.27, 95\% Confidence Interval (CI) 2.08-2.47), while WPC remained in the centre position (quadratic material Odds Ratio .97, n.s.). Figure 6 illustrates that the higher the EC, the stronger the preference for solid wood over full plastics (Odds Ratio 1.20). As EC and the material quadratic effect code did not interact, WPC remained in the centre position also for environmentally concerned respondents (Odds Ratio 1.01, n.s.). Therefore, $\mathrm{H}_{4}$ is only partially supported; WPC was neither assimilated to the plastics nor to the wooden material.

Appearance and price were additional significant predictors of an individual's choice, with a wooden over a synthetic surface (Odds Ratio 1.60, as predicted by $\mathrm{H}_{2}$ ) and a lower over a higher price being preferred (Odds Ratio 1.57, in support of $\mathrm{H}_{3}$ ). Furthermore, appearance interacted with the linear material effect code (Odds Ratio 1.68), while the interaction did not appear with the material quadratic effect code (Odds Ratio 1.01, n.s.): Respondents especially favoured a wooden surface when the product consisted of solid wood. As indicated by Figure 6, this preference was accentuated for environmentally concerned respondents (material linear x appearance x EC: Odds Ratio 1.11).

Finally, the results show that respondents with a high NFT did not choose fewer products compared with other participants (OR .98, n.s.). No interaction including NFT was significant. Hence, $\mathrm{H}_{6}$ is not supported.

\footnotetext{
${ }^{3} \mathrm{~A}$ significant linear material effect code indicates that consumers show a preference for one of the established materials, while a significant quadratic material effect code suggests that WPC deviates from the centre position of the 'two-evils' continuum'.
} 
Table 6: Results of the logistic regression (Study 1)

\begin{tabular}{lcc}
\hline & \multicolumn{2}{c}{ Parameter Estimates } \\
\hline & $\mathrm{B}(\mathrm{SE})$ & $\begin{array}{c}\text { Odds Ratio } \\
(95 \% \mathrm{CI})\end{array}$ \\
\hline Intercept & $-.71(.03)^{* * *}$ & \\
Material linear & $.82(.04)^{* * *}$ & $2.27(2.08-2.47)$ \\
Material quadratic & $-.03(.02)$ & $.97(.93-1.01)$ \\
Appearance & $.47(.03)^{* * *}$ & $1.60(1.50-1.70)$ \\
Price & $.45(.04)^{* * *}$ & $1.57(1.44-1.70)$ \\
NFT & $-.02(.03)$ & $.98(.93-1.05)$ \\
Material linear x Appearance & $.52(.04)^{* * *}$ & $1.68(1.55-1.81)$ \\
Material linear x EC & $.18(.04)^{* * *}$ & $1.20(1.11-1.30)$ \\
Material linear x Appearance x EC & $.10(.04)^{* *}$ & $1.11(1.02-1.20)$ \\
Material linear x NFT & $-.01(.04)$ & $.99(.91-1.07)$ \\
Material linear x Appearance x NFT & $.06(.04)$ & $1.06(.98-1.15)$ \\
Material quadratic x Appearance & $.00(.02)$ & $1.00(.96-1.05)$ \\
Material quadratic x EC & $.01(.02)$ & $1.01(.97-1.06)$ \\
Material quadratic x Appearance x EC & $.01(.02)$ & $1.01(.97-1.06)$ \\
Material quadratic x NFT & $.01(.02)$ & $1.01(.97-1.06)$ \\
Material quadratic x Appearance x NFT & $-.02(.02)$ & $.98(.94-1.02)$ \\
Appearance x EC & $.02(.03)$ & $1.02(.95-1.08)$ \\
Appearance x NFT & $.03(.03)$ & $1.03(.97-1.10)$ \\
\hline & $\chi^{2}(15)=938.17^{* * *}$ \\
\hline
\end{tabular}

Note: ${ }^{*} \mathrm{p}<.05,{ }^{* *} \mathrm{p}<.01,{ }^{* * *} \mathrm{p}<.001$

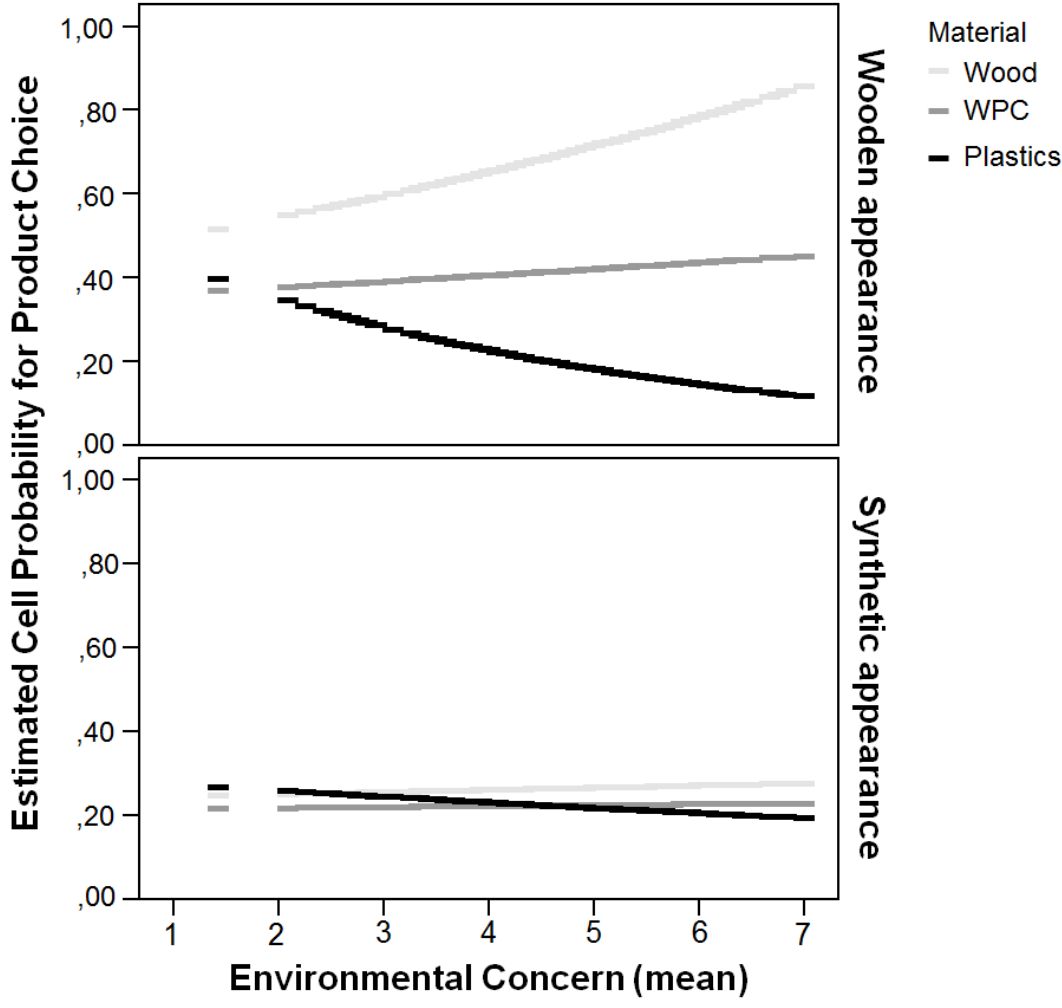

Figure 6: Predicted probability for product choice depending on Environmental Concern in the 3 (material) x 2 (appearance) design (Study 1) 


\subsubsection{Discussion}

This is the first consumer study demonstrating that the choices for WPCs are located in the perfect centre of the 'two evils' continuum'. While most of the hypothesised effects were proven, one result referring to the environmentally concerned consumer segment was unexpected. Although the preference for solid wood over full plastics was accentuated for environmentally concerned consumers, as predicted by the first part of $\mathrm{H}_{4}$, they did not devalue WPCs simultaneously due to the synthetic components they typically reject (Eyerer et al., 2010; Petrescu et al., 2010). Hence, there seems to be a greater market for WPC products than it has been previously assumed. Nevertheless, this finding should be interpreted cautiously because of the sample's low mean age. Younger consumers take environmental issues into special consideration when making a purchase decision, resulting in greener consumer behavior than shown on average (Kanchanapibul et al., 2014; Tseng \& Hung, 2013). Therefore, several reasons are discussed. Amongst others, this generation grew up in an era where environmental issues were emphasised more and education was more important than ever before (Tseng \& Hung, 2013). Kanchanapibul et al. (2014) argue that younger consumers particularly consider the future effects of their own behavior. Because of this, Study 1 shows that WPC products seem to be interesting for young consumers, so WPCs may be promising materials for products which are typically bought by the younger generation such as ready-to-assemble furniture. Nevertheless, the mentioned considerations require a follow-up study to analyze whether the obtained results are also confirmed when accessing a representative sample. A follow-up study can also rely on an online survey. Study 1 encounters concerns regarding the necessity for a haptic product evaluation as the results were independent of an individual's disposition to touch a product prior to a purchase.

\section{$3.4 \quad$ Study 2}

The main objectives of study 2 are to replicate the findings of the first study with a sample being representative for the German population and to investigate the innovativeness of consumers moderating their WPC acceptance. Study 2 also explores the possibility that the findings are generalizable to products other than furniture, as research indicates that the acceptance of green products may vary highly between different product categories (Essoussi \& Linton, 2010). Thus, pricier WPC products belonging to other application areas are considered as well.

\subsubsection{Methods}

\section{Procedure and participants}

Study 2 used a 3 (material: solid wood, WPC, plastics) x 2 (appearance: wooden, synthetic surface) x 3 (product category: chair, window frame, fence) mixed-factorial design with product category as a between-subject factor. 513 German members of a commercial online panel (Global Market Insite, Inc.) participated in an online survey using Sawtooth Software, whereof 156 had to be excluded from the analysis due to doubtful data. Data of 357 participants were analyzed. The mean age was 48.45 years $(S D=15.91$, range from 18-87) and gender was distributed nearly equally (46\% male respondents). The mean duration of education was 14.29 years $(S D=3.33)$ and the mean household size was 2.38 $(S D=1.19)$. For the majority of the respondents $(60 \%)$, WPCs were unknown prior to their participation, while $37 \%$ knew these materials from hearsay and only $3 \%$ indicated good knowledge. 
All respondents received the same text as in study 1, except that corresponding pictures varied with product category. Photographs, which were provided according to the assigned condition, illustrated the two appearances (brown synthetic vs. brown wooden chair; white synthetic vs. brown wooden window frame; white synthetic vs. brown wooden fence).

\section{Measures}

This study consisted of several parts. In the following, we will focus solely on the measurement of EC, innovativeness, value importance, socio-demographic information and the purchase intention (CBCA).

EC and innovativeness. EC was measured with the 12-item scale from Schultz (2001), and innovativeness with Roehrich's 6-item Innovativeness Scale (RIS; 1995, as cited in Roehrich, 2004, translated by the first author). Respondents answered on 7-point scales ranging from 1 (not concerned / does not apply at all) to 7 (extremely concerned / fully applies). The mean scores were $4.97(S D=1.18)$ for EC and $3.54(S D=1.34)$ for RIS. Internal consistency was high (EC: Cronbach's $\alpha=0.93$, RIC: Cronbach's $\alpha=0.93$ ).

Value Circumplex. The 10-item scale of the World Values Survey (2006) assessed the value circumplex. Respondents evaluated their similarity to fictitious personal descriptions on 6 -point scales ranging from 1 (not at all similar) to 6 (perfectly similar). The ratings were combined to form the two axes of the value circle of Figure 5 (Dobewall \& Strack, 2014).

$C B C A$. Again, the dependent variable was measured with a CBCA (for attributes and levels see Table 5). The only difference compared to study 1 was the variation of the product category (chair, window frame, fence) according to the experimental condition. All pairwise effect correlations were $|r|<.18$.

\section{Data analysis}

Data analysis was similar to study 1. Additionally, the standardised RIS scores and the corresponding interactions were included as further predictors. To ensure generalizability, the variable 'product' only defines three subsamples in the design of the model. This should support generalizing its main effect over more products because possible interactions add to the error variance. However, interactions of material and product are not within the scope of this research.

\subsubsection{Results}

Before the CBCA was analyzed, we checked the expected orthogonality of the environmental concern and the innovativeness in the representative sample. The value circumplex positioning showed that EC was mainly related to the self-transcendence vs. selfenhancement value dimension $(r=.19$ and $r=-.06$ for the second dimension), while RIS primarily corresponded with the openness to change vs. conservation dimension $(r=-.24$ and $r=-.08$ for the first dimension). Figure 7 illustrates that EC and RIS were nearly orthogonally arranged and therefore can affect purchase intentions independently.

Figure 8 illustrates the positioning of WPC in relation to solid wood and full plastics depending on the product's surface. Similar to study 1, the overall predicted choice prob- 


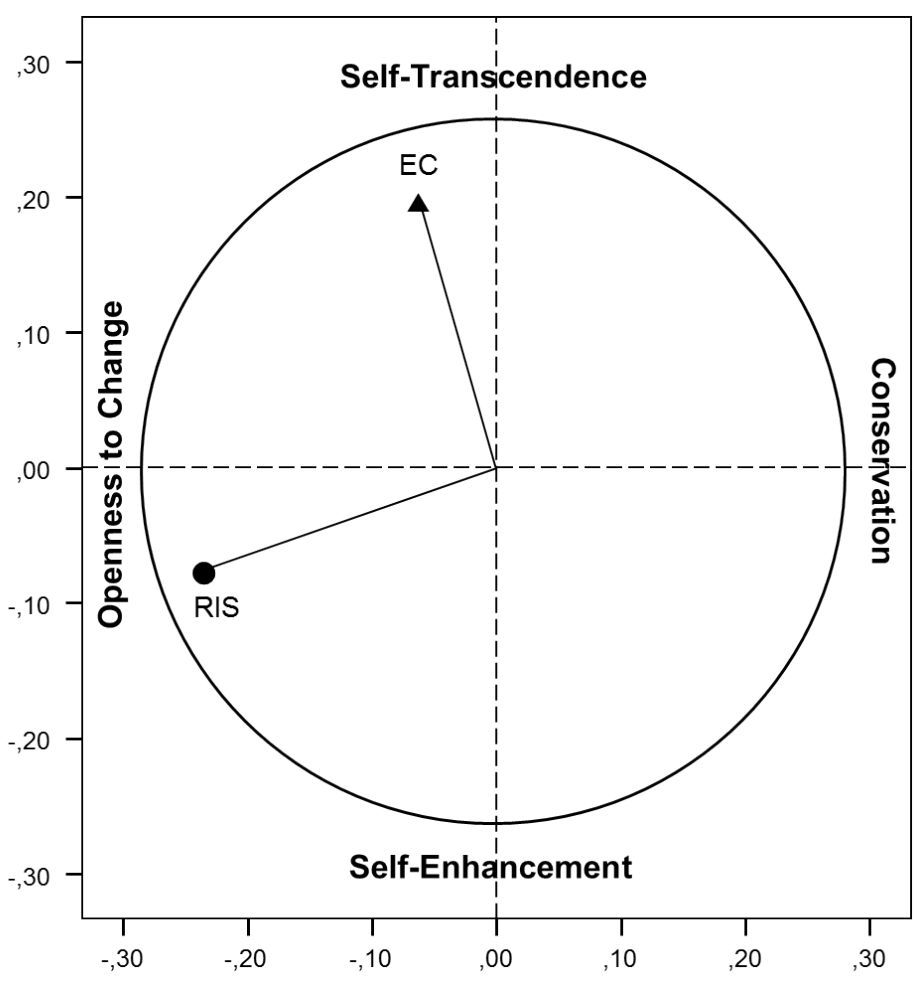

Figure 7: Positioning of EC and RIS in the Value Circumplex (Study 2)

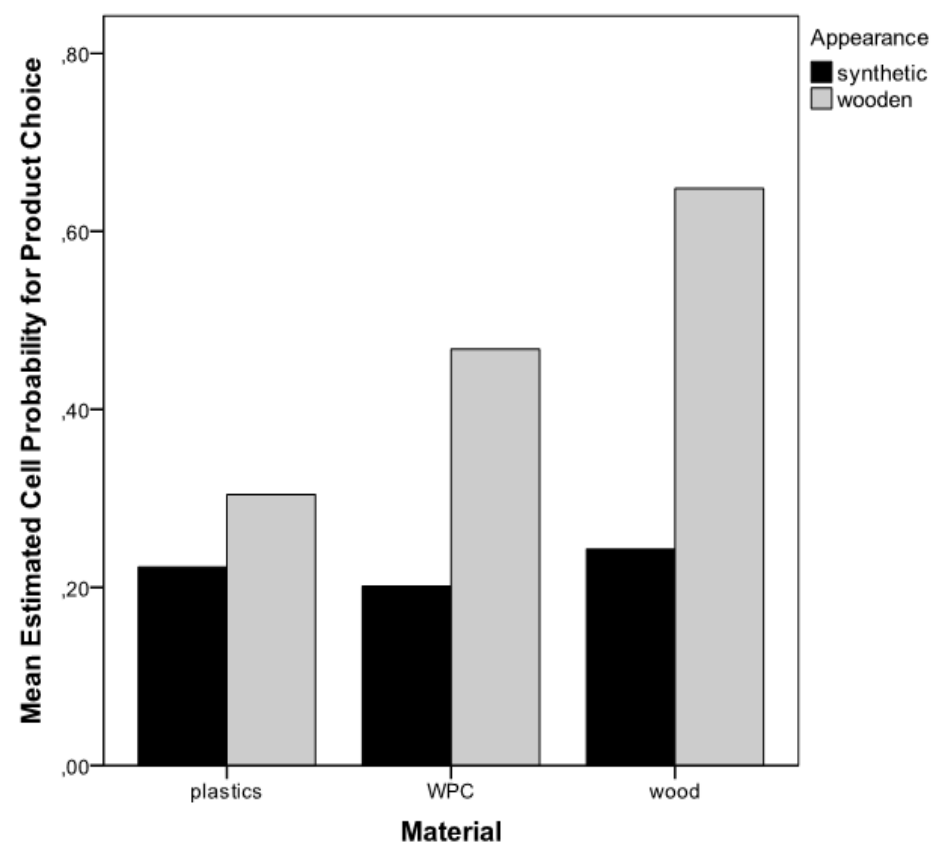

Figure 8: Predicted probability for product choice in the 3 (material) x 2 (appearance) design (Study 2) 
Table 7: Results of the logistic regression (Study 2)

\begin{tabular}{lcc}
\hline & \multicolumn{2}{c}{ Parameter Estimates } \\
\hline & $\mathrm{B}(\mathrm{SE})$ & $\begin{array}{l}\text { Odds Ratio } \\
(95 \% \mathrm{CI})\end{array}$ \\
\hline Intercept & $-.70(.02)^{* * *}$ & \\
Material linear & $.44(.03)^{* * *}$ & $1.55(1.46-1.64)$ \\
Material quadratic & $-.03(.02)^{*}$ & $.97(.94-1.00)$ \\
Appearance & $.58(.02)^{* * *}$ & $1.79(1.71-1.87)$ \\
Price & $.31(.03)^{* * *}$ & $1.37(1.30-1.44)$ \\
Material linear x Appearance & $.33(.03)^{* * *}$ & $1.39(1.32-1.47)$ \\
Material linear x EC & $.10(.03)^{* *}$ & $1.11(1.04-1.17)$ \\
Material linear x Appearance x EC & $-.02(.03)$ & $.99(.93-1.05)$ \\
Material linear x RIS & $.00(.03)$ & $1.00(.94-1.06)$ \\
Material linear x Appearance x RIS & $-.04(.03)$ & $.96(.91-1.02)$ \\
Material quadratic x Appearance & $.02(.02)$ & $1.02(.99-1.06)$ \\
Material quadratic x EC & $.04(.02)^{*}$ & $1.04(1.00-1.07)$ \\
Material quadratic x Appearance x EC & $.00(.02)$ & $1.00(.97-1.03)$ \\
Material quadratic x RIS & $.03(.02)^{*}$ & $1.03(1.00-1.07)$ \\
Material quadratic x Appearance x RIS & $-.00(.02)$ & $1.00(.96-1.03)$ \\
Appearance x EC & $.07(.03)^{* *}$ & $1.07(1.02-1.12)$ \\
Appearance x RIS & $.00(.02)$ & $1.00(.95-1.05)$ \\
\hline & $\chi^{2}(16)=1364.08^{* * *}$ \\
\hline Note: $*$ p $<.05 * * p<.01, * * * p<.001$ & &
\end{tabular}

ability was higher for solid wood (0.45) than for full plastics (0.26). Table 7 provides the results of the logistic regression, thereby confirming the significant main effect of the linear material effect code (Odds Ratio 1.55, CI 1.46-1.64). In contrast to study 1, the predicted overall probability to choose WPC (0.33) deviated slightly from the centre. The low effect size reveals that WPC was chosen marginally less than the mean (Odds Ratio $.97)$. Hence, $\mathrm{H}_{1}$ is only partially supported.

Appearance emerged as another predictor of the choice: As shown in Figure 8, respondents clearly preferred a wooden over a synthetic surface (Odds Ratio 1.79, in support of $\mathrm{H}_{2}$ ). The interaction of appearance and material was again only significant for the linear (Odds Ratio 1.39), but not for the material quadratic effect code (Odds Ratio 1.02, n.s.). In line with $\mathrm{H}_{3}$, price was another important driver of the choice (Odds Ratio 1.37).

An individual's EC interacted with the linear material effect code, therefore proving an accentuated preference for solid wood over full plastics (Odds Ratio 1.11). The interaction was also significant for the material quadratic effect code but, contrary to the expectations, the WPC position deviated upwards from the centre (Odds Ratio 1.04) for environmentally concerned consumers. The left panels of Figure 9 underline: the higher the EC, the higher the probability to choose WPC. Hence, $\mathrm{H}_{4}$ is only partially confirmed, as EC consumers tended to assimilate WPC to wood. Comparing Table 6 and Table 7, appearance interacted with EC only in study 2 (Odds Ratio 1.07), while the three-way interaction of appearance, EC and the linear material effect code was no longer significant (Odds Ratio .99, n.s.). 


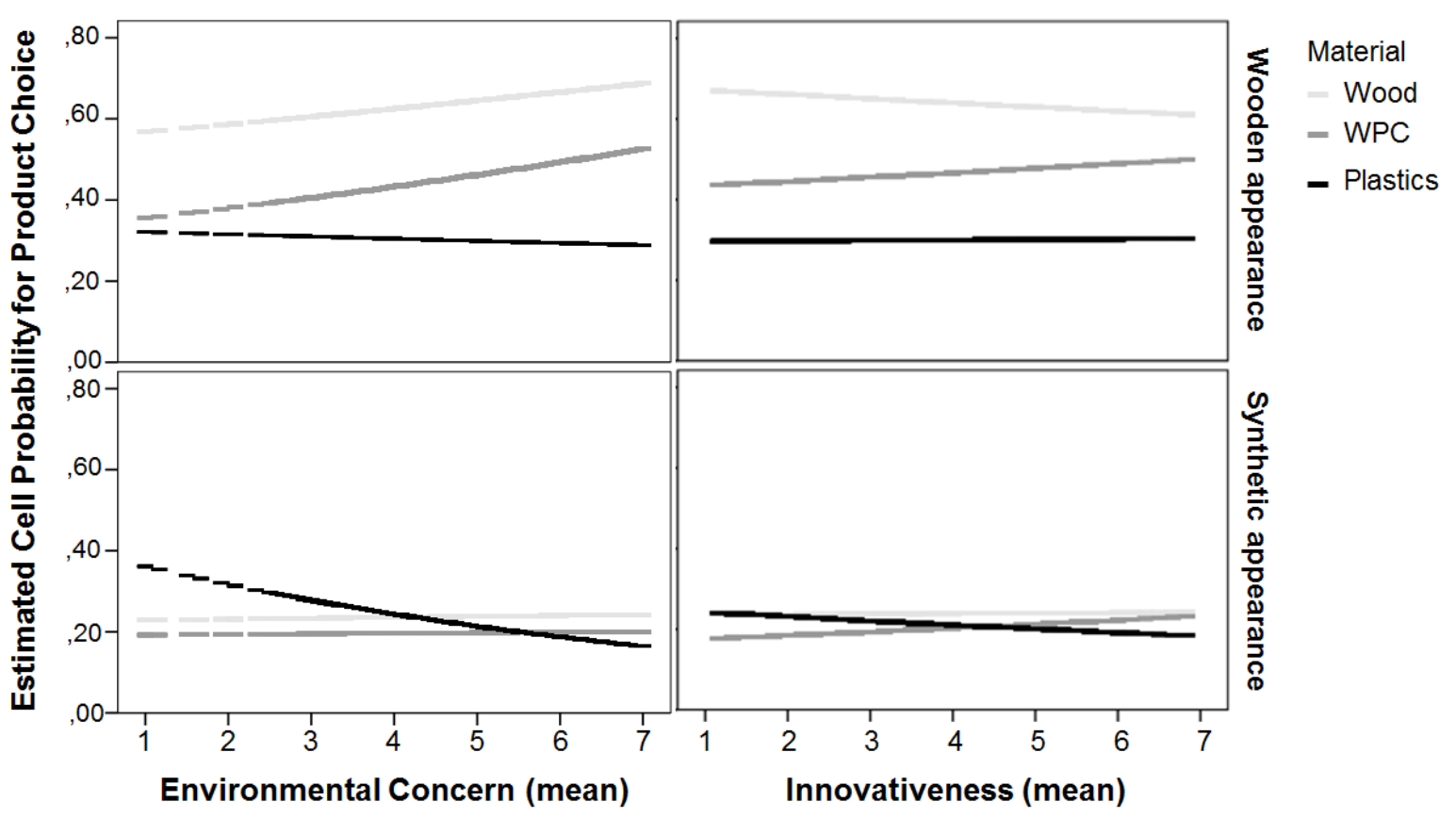

Figure 9: Predicted probability for product choice depending on Environmental Concern and Innovativeness in the 3 (material) x 2 (appearance) design (Study 2)

Additionally and in line with $\mathrm{H}_{5}$, RIS interacted with the quadratic (Odds Ratio 1.03), but not with the linear material effect code (Odds Ratio 1.00, n.s.). Hence, high consumer innovativeness also led to increased WPC choices, as visualized in the right panels of Figure 9.

\subsubsection{Discussion}

Study 2 investigates consumer acceptance of WPCs across different product categories with a sample representative for the German population. Two important and distinctive target groups for WPCs were identified, as the choice probabilities of both segments deviated upwards from the centre of the 'two evils' continuum': According to the predictions, consumers expressing high innovativeness favoured the eco-innovations. Contrary to the assumptions, environmentally concerned consumers did not downgrade, but even upgraded WPC. The synthetic components of WPCs did not lead to a rejection as expected based on previous research (Eyerer et al., 2010; Petrescu et al., 2010). Although WPCs were positioned slightly below the centre for the overall sample, these results suggest positive sales prospects in environmental and in innovative consumer segments.

\subsection{General Discussion}

By-products of the wood-processing industry are still primarily used for energy purposes. However, a material usage of these by-products has the potential to foster resource efficiency and cascading utilization. WPCs are new materials consisting of wood by-products, therefore being promising eco-innovations. Nevertheless, consumer acceptance was controversial for a long time, as WPCs consist of materials that consumers perceive as being conflictive (wood and plastics).

We conducted two consumer studies to determine WPC acceptance in relation to the two competing materials making up the eco-innovations. The assessment was based on 
a 'two evils' continuum', as consumers usually must decide between materials either being perceived as eco-friendly but expensive and resource consuming in mass consumption (i.e., solid wood) or cheap but environmentally hazardous (i.e., full plastics). The present studies found that consumers perceived WPC as a hybrid solution so that the eco-innovative materials were positioned around the centre of the 'two evils' continuum'. While WPC took the exact centre position in study 1, which analyzed a younger sample, the eco-innovations only slightly deviated in study 2 which provided a more representative sample of consumers. Kanchanapibul et al. (2014) already argued that green products do no longer represent a niche market, but become rather attractive for the mainstream market; based on the present studies the same conclusion can be drawn for eco-innovative materials. Furthermore, study 2 presents evidence that WPCs are attractive materials for various product categories. This is an important finding as it is crucial to replace a wide range of environmentally hazardous products by eco-friendly alternatives in the mainstream market in order to realize green consumption behaviors comprehensively (Rex \& Baumann, 2007).

Beyond that, the studies considered WPC acceptance for two consumer segments which should be analyzed in conjunction with eco-innovative materials: innovative and environmentally concerned consumers. The different value circumplex positioning of consumers with high EC and high innovativeness proved that the segments are distinctive. While the innovative consumer segment was expected to choose WPC more frequently than the average consumer, previous research had suggested that the environmentally concerned segment maybe would reject WPC (Eyerer et al., 2010; Petrescu et al., 2010; Weinfurter \& Eder, 2009). Nevertheless, in our data, WPC deviated upwards on the 'two evils' continuum' for both segments indicating that even environmentally concerned consumers are open to eco-innovative composite materials containing synthetic components.

There is another reason why the WPC positioning around the centre is already a promising result. Although most investigations about green consumption refer to FMCG, only a few consider pricier products. Recent studies about the introduction of sustainability in the luxury sector demonstrated that consumers reject these efforts and especially devalue luxury products consisting of recycled materials (Achabou \& Dekhili, 2013; Davies et al., 2012). Achabou and Dekhili (2013) stress that recycling and luxury products are psychologically incompatible. Based on these observations, a clear WPC rejection could have also been possible in our study, as all participants were informed that WPC mainly consist of by-products which could be perceived as being inferior. Furthermore, Luchs et al. (2010) show that sustainability claims can even have a negative effect on consumer acceptance of products where strength is an important factor. As strength is essential for the products considered in the present studies, the empirical positioning of WPC is quite encouraging.

In addition to the material, both studies reveal two further determinants of consumers' choices. On the one hand, appearance is an important factor in study 1 and the most important predictor of consumers' choice behavior in study 2. Consumers favour natural over synthetic appearances. For example, this might be due to the fact that they ascribe higher quality to the product and show more product trust given a wooden surface. A wooden surface is particularly important for solid wood products as they are even more preferred over synthetic materials when the natural material is visible. On the other hand, product price affected consumers' choices. The influence of price was somewhat higher in 
study 1, possibly due to respondents' younger mean age which might be associated with higher price sensitivity. Hence, it becomes important to offer the products at competitive prices.

\subsubsection{Practical implications}

The present studies provide further evidence that WPCs are still unknown by many consumers. Hence, potential customers should receive material information so that they consider these eco-innovations when reaching a purchase decision. Additional strategies should be pursued rather than just informing consumers about the mere WPC existence, because previous research had indicated that pricier goods are typically associated with more functional risks. Therefore, measures such as relying on established brand names, issuing warranties and providing consumers with more and detailed product information should be taken to reduce the perceived risks and further increase the purchase intention (Essoussi \& Linton, 2010; Gleim et al., 2013).

Additional marketing implications reveal when considering the two consumer segments having a higher purchase intention than the average consumer. The consumer segment characterized by high innovativeness could be reached by foregrounding the newness of the materials and the innovative combination of two established materials. Material properties differing from conventional alternatives should also be highlighted (e.g., nearly free, three-dimensional formability). Referring to the environmentally concerned segment, it is recommended to direct the attention to the environmental compatibility of WPC. This could not only increase the purchase probability of environmentally concerned consumers, but also of the mainstream consumers, as green consumer behavior is becoming increasingly conventional (Kanchanapibul et al., 2014).

From the results of the two studies, implications for WPC production arise as well. Firstly, it is suggested to further reduce the environmental impact of WPC. European WPC producers typically resort to new and fossil-fuel based plastics (Weinfurter \& Eder, 2009). Replacing these by recycled plastics or bioplastics would lead to even more eco-friendly materials probably facilitating another market growth. Further studies conducted by the materials sciences are needed to thoroughly assess WPC eco-friendliness and its dependence on material composition. Reliable comparisons of the WPC eco-friendliness with competing materials are also required. Consumers must be provided with the results to allow for informed purchase decisions and to enable eco-friendly consumers to choose those WPCs with a low environmental impact. Secondly, consumers' preferences for a wooden surface must be considered. Products were highly favoured when the utilization of natural resources was obvious. Hence, it is recommended to adapt the product's appearance to consumers' preferences.

\subsubsection{Limitations and suggestions for future research}

The major finding of the present studies is that the market for WPC products did not reveal a pessimistic point of view as much as previous research had indicated. Generally, such premature concerns about innovative materials can be prevented by consumer acceptance measurements examining the new material's position in a surrounding 'multi evils' continuum'. Therefore, this approach is recommended as a basis for future research. 
Despite the promising results concerning consumer acceptance of WPCs, some limitations of the present studies must be considered. Due to the intention-to-behavior gap reported in the literature (e.g., Sheeran, 2002; Webb \& Sheeran, 2006), studies measuring consumers' purchase intention should be interpreted with caution. The purchase intention was assessed with a CBCA in both of the presented online surveys. This indirect measurement is more similar to actual purchase situations than a direct retrieval of the purchase intention mostly resulting in the mentioned gap. As participants could not touch materials and products during the survey, the NFT scale was included and encountered some concerns by showing that an individual's disposition for haptic product information processing did not influence the choices. Nonetheless, biases of a CBCA which result from the fact that participants only make hypothetical decisions must be acknowledged so that this research may be subject to some biases described by Mitchell and Carson (1989), such as incentives to misrepresent responses (participants do not state their actual WTP), amenity misspecification bias (wrong perception of the provided good) or sample nonresponse bias. Observing real purchase behavior would therefore be more advantageous, though being difficult to realize (e.g., accessing real sales figures). Additionally, the CBCA only included a limited amount of attributes (material, appearance and price). Other product characteristics could influence the product choice as well (e.g., material composition (wood percentage, type of wood, wood origin), product availability, environmental certification) and should be investigated in future research. A methodological issue refers to the independency of attributes of the CBCA, which is not given as we selected price as an attribute. Price depended on material as we used mean market prices. Furthermore, the present studies compare consumer acceptance of WPCs with WPC's pure constituents, i.e., solid wood and full plastics. These are the most obvious and important materials WPCs could replace, however, future studies must also assess WPC in relation to other competing materials such as stone as a construction material or other biopolymers that are used for consumer goods. Further work also needs to be done to prove whether the results we obtained in this research could be generalized to the WPC market of other countries, as the participants of both studies were solely German consumers.

\subsection{Conclusions}

An efficient use of resources includes a material utilization of by-products. While new materials based upon these by-products are in development, they will fail without achieving consumer acceptance. Two consumer studies examine the acceptance of WPCs which are eco-innovative materials containing a high amount of wood by-products and/or wood waste, but consumer acceptance is controversially discussed. However, both consumer studies suggest that the purchase intention for WPC is located around the middle of solid wood and full plastics. Consumer segments with high EC and innovativeness are important target groups as they evaluate WPCs better than the average consumer. Hence, the market for eco-innovative materials such as WPC may be greater than it has been previously expected. This knowledge should help to encourage research about detailed drivers of consumer acceptance of WPCs and further eco-innovative materials. Marketing gains insights into how to better target consumers being interested in WPCs and how to assess consumer acceptance of innovative materials in relation to established ones. Additionally, it appears important that material sciences aim at improving WPC characteristics and eco-friendliness. 


\section{Acknowledgements}

This research was supported by the German Research Foundation (DFG), grant GRK 1703/1 for the Research Training Group 'Resource Efficiency in Interorganizational Networks - Planning Methods to Utilize Renewable Resources'.

\section{References}

Achabou, M. A., \& Dekhili, S. (2013). Luxury and sustainable development: Is there a match? Journal of Business Research, 66, 1896-1903.

Aguilar, F. X., \& Vlosky, R. P. (2007). Consumer willingness to pay price premiums for environmentally certified wood products in the U.S. Forest Policy and Economics, 9, 1100-1112.

Anderson, R. C., \& Hansen, E. N. (2004). The impact of environmental certification on preferences for wood furniture: A conjoint analysis approach. Forest Products Journal, 54, $42-50$.

Ashrafi, M., Vaziri, A., \& Nayeb-Hashemi, H. (2011). Effect of processing variables and fiber reinforcement on the mechanical properties of wood plastic composites. Journal of Reinforced Plastics and Composites, 30, 1939-1945.

Boer, D., \& Fischer, R. (2013). How and when do personal values guide our attitudes and sociality? Explaining cross-cultural variability in attitude-value linkages. Psychological Bulletin, 139, 1113-1147.

Cai, Z., \& Aguilar, F. X. (2013a). Consumer stated purchasing preferences and corporate social responsibility in the wood products industry: A conjoint analysis in the U.S. and China. Ecological Economics, 95, 118-127.

Cai, Z., \& Aguilar, F. X. (2013b). Meta-analysis of consumer's willingness-to-pay premiums for certified wood products. Journal of Forest Economics, 1, 15-31.

Carus, M., Gahle, C., \& Korte, H. (2008). Market and future trends for wood-polymer composites in Europe: The example of Germany. In K. Oksman Niska \& M. Sain (Eds.), Wood-polymer composites (pp. 300-330). Cambridge: Woodhead Publishing Limited.

Caufield, D. F., Clemons, C., Jacobson, R. E., \& Rowell, R. M. (2005). Wood thermoplastic composites. In R. M. Rowell (Ed.), Handbook of wood chemistry, wood composites (pp. 365-378). Boca Raton, FL: Taylor and Francis.

Chao, C.-W., Reid, M., \& Mavondo, F. T. (2012). Consumer innovativeness influence on really new product adoption. Australasian Marketing Journal, 20, 211-217.

Chrzan, K., \& Orme, B. (2000). An overview and comparison of design strategies for choicebased conjoint analysis. Sawtooth Software: Research paper series.

Crabbé, A., Jacobs, R., van Hoof, V., Bergmans, A., \& van Acker, K. (2013). Transition towards sustainable material innovation: Evidence and evaluation of the Flemish case. Journal of Cleaner Production, 56, 63-72.

Davies, I. A., Lee, Z., \& Ahonkhai, I. (2012). Do consumers care about ethical-luxury? Journal of Business Ethics, 106, 37-51.

Diamantopoulos, A., Schlegelmilch, B. B., Sinkovics, R. R., \& Bohlen, G. M. (2003). Can sociodemographics still play a role in profiling green consumers? A review of the evidence and an empirical investigation. Journal of Business Research, 56, 465-480. 
Diaz-Rainey, I., \& Ashton, J. K. (2011). Profiling potential green electricity tariff adopters: Green consumerism as an environmental policy tool? Business Strategy and the Environment, 20, 456-470.

Dobewall, H., \& Strack, M. (2014). Relationship of Inglehart's and Schwartz's value dimensions revisited. International Journal of Psychology, 49, 240-248.

do Paço, A. M. F., \& Raposo, M. L. B. (2009). "Green" segmentation: An application to the Portuguese consumer market. Marketing Intelligence \& Planning, 27, 364-379.

Eder, A., \& Carus, M. (2013). Global trends in Wood-Plastic Composites (WPC). bioplastics, 4, 16-17.

Essoussi, L. H., \& Linton, J. D. (2010). New or recycled products: How much are consumers willing to pay? Journal of Consumer Marketing, 27, 458-468.

Eyerer, P., Beilharz, F., Hübner, C., Kupfer, T., \& Ulrich, C. (2010). Opportunities and (in particular) risks of use (utilization phase) of plastic structural components. In P. Eyerer (Ed.), Polymers - Opportunities and risks I: General environmental aspects (pp. 363-389). Berlin: Springer.

Gleim, M. R., Smith, J. S., Andrews, D., \& Cronin, J. J. (2013). Against the green: A multimethod examination of the barriers to green consumption. Journal of Retailing, 89, 44-61.

Goldsmith, R. E., Kim, D., Flynn, L. R., \& Kim, W.-M. (2005). Price sensitivity and innovativeness for fashion among Korean consumers. Journal of Social Psychology, 145, $501-508$

Green, P. E., \& Rao, V. R. (1971). Conjoint measurement for quantifying judgemental data. Journal of Marketing Research, 8, 355-363.

Grimmer, M., \& Bingham, T. (2013). Company environmental performance and consumer purchase intentions. Journal of Business Research, 66, 1945-1953.

Haider, A., \& Eder, A. (2010). Markets, applications, and processes for Wood Polymer Composites (WPC) in Europe. In A. Teischinger et al. (Eds.), Processing technologies for the forest and biobased products industries, PTF BPI 2010 (pp. 146-151). Kuchl: Salzburg University of Applied Sciences.

Hartmann, P., \& Apaolaza-Ibáñez, V. (2012). Consumer attitude and purchase intention toward green energy brands: The roles of psychological benefits and environmental concern. Journal of Business Research, 65, 1254-1263.

Homburg, A., \& Wagner, U. (2007). Faktoren individueller Bedrohungs-, Wirksamkeits- und Kostenbewertung bei Umweltstressoren [Factors of Individual Threat, Efficacy and Cost Appraisal in the Context of Environmental Stressors]. Social Psychology, 38, 53-65.

Husted, B. W., Russo, M. V., Meza, C. E. B., \& Tilleman, S. G. (2014). An exploratory study of environmental attitudes and the willingness to pay for environmental certification in Mexico. Journal of Business Research, 67, 891-899.

Jansson, J. (2011). Consumer eco-innovation adoption: Assessing attitudinal factors and perceived product characteristics. Business Strategy and the Environment, 20, 192-210.

Jonsson, O., Lindberg, S., Roos, A., Hugosson, M., \& Lindström, M. (2008). Consumer perceptions and preferences on solid wood, wood-based panels, and composites: A repertory grid study. Wood and Fiber Science, 40, 663-678. 
Kalafatis, S. P., Pollard, M., East, R., \& Tsogas, M. H. (1999). Green marketing and Ajzen's theory of planned behaviour a cross-market examination. Journal of Consumer Marketing, 16, 441-460.

Kanchanapibul, M., Lacka, E., Wang, X., \& Chan, H. K. (2014). An empirical investigation of green purchase behaviour among the young generation. Journal of Cleaner Production, $66,528-536$.

Klyosov, A. A. (2007). Wood-Plastic Composites. Hoboken, NJ: John Wiley \& Sons, Inc.

Krause, K., Müller, M., Militz, H., \& Krause, A. (2013). Efficient utilization of wood sources for wood-polymer composites. In J. Geldermann \& M. Schumann (Eds.), First International Conference on Resource Efficiency in Interorganizational Networks - ResEff 2013 (pp. 94-105). Göttingen: Universitätsverlag Göttingen.

Krystallis, A., \& Chryssohoidis, G. (2005). Consumers' willingness to pay for organic food: Factors that affect it and variation per organic product type. British Food Journal, 10\%, $320-343$.

Kuo, P.-Y., Wang, S.-Y., Chen, J.-H., Hsueh, H.-C., \& Tsai, M.-J. (2009). Effects of material compositions on the mechanical properties of wood-plastic composites manufactured by injection molding. Materials \& Design, 30, 3489-3496.

Leonidou, L. C., Leonidou, C. N., \& Kvasova, O. (2010). Antecedents and outcomes of consumer environmentally friendly attitudes and behaviour. Journal of Marketing Management, 26, $1319-1344$.

Lin, P.-C., \& Huang, Y.-H. (2012). The influence factors on choice behavior regarding green products based on the theory of consumption values. Journal of Cleaner Production, 22, $11-18$.

Lin, R.-J., Tan, K.-H., \& Geng, Y. (2013). Market demand, green product innovation, and firm performance: Evidence from Vietnam motorcycle industry. Journal of Cleaner Production, 40, 101-107.

Luchs, M. G., Naylor, R. W., Irwin, J. R., \& Raghunathan, R. (2010). The sustainability liability: Potential negative effects of ethicality on product preference. Journal of Marketing, 74, 18-31.

Marette, S., Messean, A., \& Millet, G. (2012). Consumers' willingness to pay for eco-friendly apples under different labels: Evidences from a lab experiment. Food Policy, 37, 151-161.

Medeiros, J. F. de, Ribeiro, J. L. D., \& Cortimiglia, M. N. (2014). Success factors for environmentally sustainable product innovation: A systematic literature review. Journal of Cleaner Production, 65, 76-86.

Michaud, C., \& Llerena, D. (2011). Green consumer behaviour: An experimental analysis of willingness to pay for remanufactured products. Business Strategy and the Environment, 20, 408-420.

Miller, N. E. (1944). Experimental studies of conflict. In J. M. Hunt (Ed.), Personality and the behavior disorders (pp. 431-465). New York, NY: Roland.

Mitchell, R. C., \& Carson, R. T. (1989). Using surveys to value public goods: The contingent valuation method. Washington, DC: Resources for the Future.

Munnukka, J. (2008). Customers' purchase intentions as a reflection of price perception. Journal of Product Brand Management, 17, 188-196. 
Nuszbaum, M., Voss, A., Klauer, K. C., \& Betsch, T. (2010). Assessing individual differences in the use of haptic information using a German translation of the Need for Touch Scale. Social Psychology, 41, 263-274.

Onozaka, Y., \& McFadden, D. (2011). Does local labeling complement or compete with other sustainable labels? A conjoint analysis of direct and joint values for fresh produce claims. American Journal of Agricultural Economics, 93, 693-706.

Ozaki, R. (2011). Adopting sustainable innovation: What makes consumers sign up to green electricity? Business Strategy and the Environment, 20, 1-17.

Park, S.-J., Choi, S., \& Kim, E.-J. (2012). The relationships between socio-demographic variables and concerns about environmental sustainability. Corporate Social Responsibility and Environmental Management, 19, 343-354.

Peck, J., \& Childers, T. L. (2003). Individual differences in haptic information processing. The "Need for Touch" scale. Journal of Consumer Research, 30, 430-442.

Petrescu, I., Ispas, C., \& Mohora, C. (2010). Risk assessment in the implementation of composite materials (Proceedings in Manufacturing Systems No. 5). Retrieved August 10, 2013, from http://icmas.eu/recenzare2010/248-Petrescu.doc

Ramirez, E., \& Goldsmith, R. E. (2009). Some antecedents of price sensitivity. Journal of Marketing Theory and Practice, 17, 199-213.

Rex, E., \& Baumann, H. (2007). Beyond ecolabels: What green marketing can learn from conventional marketing. Journal of Cleaner Production, 15, 567-576.

Roehrich, G. (2004). Consumer innovativeness. Concepts and measurements. Journal of Business Research, 5\%, 671-677.

Scarpa, R., \& Willis, K. (2010). Willingness-to-pay for renewable energy: Primary and discretionary choice of British households' for micro-generation technologies. Energy Economics, 32, 129-136.

Schultz, P. (2001). The structure of environmental concern: Concern for self, other people, and the biosphere. Journal of Environmental Psychology, 21, 327-339.

Schwartz, S. H. (1992). Universals in the content and structure of values: Theoretical advances and empirical tests in 20 countries. Advances in Experimental Social Psychology, 25, 1-65.

Sheeran, P. (2002). Intention-behavior relations: A conceptual and empirical review. European Review of Social Psychology, 12, 1-36.

Teuber, L., Osburg, V.-S., Toporowski, W., Militz, H., \& Krause, A. (2015). Wood Polymer Composites and their contribution to cascading utilisation. Journal of Cleaner Production. doi: $10.1016 /$ j.jclepro.2015.04.009

Thompson, D. W., Anderson, R. C., Hansen, E. N., \& Kahle, L. R. (2010). Green segmentation and environmental certification: Insights from forest products. Business Strategy and the Environment, 19, 319-334.

Tseng, S.-C., \& Hung, S.-W. (2013). A framework identifying the gaps between customers' expectations and their perceptions in green products. Journal of Cleaner Production, 59, $174-184$.

Urien, B., \& Kilbourne, W. (2011). Generativity and self-enhancement values in eco-friendly behavioral intentions and environmentally responsible consumption behavior. Psychology \& Marketing, 28, 69-90. 
Vermeir, I., \& Verbeke, W. (2008). Sustainable food consumption among young adults in Belgium: Theory of planned behaviour and the role of confidence and values. Ecological Economics, 64, 542-553.

Vlosky, R. P., Ozanne, L. K., \& Fontenot, R. J. (1999). A conceptual model of US consumer willingness-to-pay for environmentally certified wood products. Journal of Consumer Marketing, 16, 116-136.

Webb, T. L., \& Sheeran, P. (2006). Does changing behavioral intentions engender behavior change? A meta-analysis of the experimental evidence. Psychological Bulletin, 132, $249-268$.

Weinfurter, S., \& Eder, A. (2009). Consumer perceptions of innovative wood-polymer composite decking with a focus on environmental aspects. Lenzinger Berichte, 87, 168-178.

World Values Survey (2006). Weltwertestudie 2006. Retrieved October 11, 2013, from http: //www.worldvaluessurvey.org

Young, W., Hwang, K., McDonald, S., \& Oates, C. J. (2010). Sustainable consumption: Green consumer behaviour when purchasing products. Sustainable Development, 18, 20-31.

Yue, C., Alfnes, F., \& Jensen, H. H. (2009). Discounting spotted apples: Investigating consumers' willingness to accept cosmetic damage in an organic product. Journal of Agricultural and Applied Economics, 41, 29-46.

Zhao, H.-H., Gao, Q., Wu, Y.-P., Wang, Y., \& Zhu, X.-D. (2014). What affects green consumer behavior in China? A case study from Qingdao. Journal of Cleaner Production, 63, 143-151. 


\title{
4 An empirical investigation of the determinants in- fluencing consumers' planned choices of eco-inno- vative materials (Paper 3)
}

This paper is invited for second round review in the International Journal of Innovation and Sustainable Development (Osburg).

\begin{abstract}
Wood-Polymer Composites (WPCs) are eco-innovative materials combining wood and plastics. Due to the novelty, little is known about consumer acceptance of WPCs. Investigating the drivers of consumers' WPC choices reveals consumers' perception of the materials' advantages over competing ones. The predictors of WPC acceptance were examined within a Theory of Planned Behavior (Ajzen, 1991) framework. An online survey $(N=357)$, varying material $\mathrm{x}$ appearance within and product category between subjects, was conducted in Germany. Structural equation modelling revealed that the attitudes toward environmental and innovative product aspects and the subjective norm explain the intention to buy WPC products $\left(R^{2}=.56\right)$. Consumers' choice behavior was assessed with a choice-based conjoint analysis and predicted by the behavioral intention and perceived behavioral control $\left(R^{2}=.39\right)$. Hence, the present study identifies important drivers of WPC acceptance that could be useful for deriving certain marketing implications, potentially fostering more eco-friendly consumption.
\end{abstract}

\section{Keywords}

Green marketing, Composites, Eco-innovation, Theory of Planned Behavior, Conjoint analysis 


\subsection{Eco-innovative materials facilitating efficient resource uti- lization}

Efficient resource utilization has gained increasing importance due to a competition for limited resources. At the same time, the various environmental problems facing humanity necessitate eco-friendly solutions. Therefore, materials have been developed to fulfil both the needs for competition and sustainability. These eco-innovative materials have several advantages, e.g., a diverse range of environmental benefits, cost-savings because of less resources being used, and competitive advantage (Crabbé et al., 2013; Lin et al., 2013; Medeiros et al., 2014). Even though they are promising, these materials will fail without achieving consumer acceptance. Wood-Polymer Composites (WPCs) are such a group of eco-innovative materials which consist of wood (up to more than 80\%), plastics and additives (Klyosov, 2007). These materials are claimed to represent an innovative approach, facilitating sustainable and efficient resource utilization (Suttie, 2007).

Although extensive research has been carried out in the material sciences on a continuous material improvement (e.g., Ashrafi et al., 2011; Bledzki \& Faruk, 2003; Kuo et al., 2009), only a few studies have attempted to examine consumer acceptance of WPC products (e.g., Jonsson et al., 2008; Osburg et al., 2014, 2015; Weinfurter \& Eder, 2009). As the consumer studies focused on the mere acceptance of WPCs, sometimes also on its dependence on the materials' appearance (Osburg et al., 2014, 2015), and identified innovative and environmentally concerned consumers as important target groups for WPC products (Osburg et al., 2015), it is necessary to comprehensively analyze the determinants of consumer acceptance. Identifying the determinants allows for the definition of certain factors that could increase consumer acceptance of WPC products. The investigation has to be carried out in relation to solid wood and full plastics, since the eco-innovations can substitute both traditional materials. Hence, this article aims to examine the predictors, taking recourse to a theoretical framework using the Theory of Planned Behavior (TPB; Ajzen, 1991).

\subsection{Literature review}

\subsubsection{WPCs and their acceptance by consumers}

WPCs are eco-innovative materials which try to combine the advantages of two of the most important materials that have been made available (Schwendemann, 2008) ${ }^{4}$. While it is partially possible to utilize WPCs similar to wood, an extrusion comparable to plastics leads to uniform materials and appearances (Suttie, 2007). Contrary to solid wood, WPCs require low maintenance and have been discussed as having a superior durability for outdoor applications resulting in lower life cycle costs (Caufield et al., 2005; Pritchard, 2004; Suttie, 2007). Additionally, in comparison to wood, WPCs are characterized by lower water absorption and no splintering (Caufield et al., 2005; Pritchard, 2004). Compared to plastics, WPCs are thermally more stable and are especially promising when taking into account the increasing prices of fossil fuels which are used to manufacture plastics (Carus et al., 2008, 2014; Eder \& Carus, 2013; Suttie, 2007).

\footnotetext{
${ }^{4}$ The below discussed properties and performances of WPCs are a selection of parameters which should be examined when comparing WPCs with the established materials. However, the listing has to be considered carefully as the specification of the advantages depends on the definite WPC composition (Caufield et al., 2005). For a detailed overview of WPCs contribution to efficient resource utilization and its dependency on WPC composition see Teuber et al. (2015).
} 
In the face of eco-friendliness and resource efficiency, both established materials show (some) disadvantages. Ecological advantages of WPCs not only emerge in comparison with fossil fuel based plastics, which are typically acknowledged as being environmentally hazardous, but also when compared to solid wood. Products consisting of solid wood are typically perceived as being eco-friendly. However, WPCs also possess environmental advantages compared to solid wood as these materials mainly substitute tropical timber which is often used for outdoor decking (Carus et al., 2008; Eder \& Carus, 2013). In light of resource efficiency, it has to be acknowledged that solid wood in general consumes a large amount of resources in mass production. As a huge variety of wood waste and wood by-products can be used for the production of WPCs, these materials provide a new opportunity for the timber industry to experience a production with almost no waste, thereby realizing additional material utilizations of resources prior to a conversion into energy (Carus et al., 2008; Teuber et al., 2015). To achieve a further improvement of WPC eco-friendliness, several studies currently try to address factors influencing a better recyclability of WPCs (e.g., Beg \& Pickering, 2008a, b; Petchwattana et al., 2012; Shahi et al., 2012).

Despite all these advantages, consumer acceptance of WPCs is disputable, due to the conjunction of contradictory perceived constituents, wood and plastics, the latter typically associated with health and environmental concerns as well as inferior quality (Eyerer et al., 2010; Petrescu et al., 2010). The potential challenge that consumers might be concerned about WPCs is also suggested by the prediction of consumers' intention to buy plastic lumber which is a material consisting of virgin and/or recycled plastics. Singh (2010) mentions that although plastic lumber is superior to solid wood in several aspects (e.g., maintenance, splintering), consumers perceive plastics as inferior to wood which requires a considerable marketing effort to convince potential consumers of the benefits of plastic lumber. Hence, the material aspects valued by consumers have to be investigated and used for the marketing of materials such as plastic lumber or WPCs. It seems to be important that consumers recognize how these materials differentiate from competing materials as consumers' perception of product advantages has been identified as an important driver of new product success (Henard \& Szymanski, 2001).

\subsubsection{Predicting eco-friendly consumption based on the Theory of Planned Behavior}

The Theory of Planned Behavior (TPB) and its predecessor, the Theory of Reasoned Action (TRA; Ajzen \& Fishbein, 1980; Fishbein \& Ajzen, 1975), are important theories for analysing behavioral choices (Chatzidakis et al., 2007; Groot \& Steg, 2007; Vermeir \& Verbeke, 2008). Amongst others, successful applications are related to the prediction of various forms of eco-friendly (consumer) behavior, including sustainable and organic food consumption (Nocella et al. 2012; Vermeir \& Verbeke, 2008), choices of eco-friendly hotels and restaurants (Han et al., 2010; Kim et al., 2013), acceptance of green energy (Litvine \& Wüstenhagen, 2011; Read et al., 2013), use of public transportation (Donald et al., 2014; Groot \& Steg, 2007), implementation of recycling (Chan \& Bishop, 2013; Park \& Ha, 2012; Rhodes et al., 2014; Wan et al., 2014), reduction of resource consumption (Richetin et al., 2012; Webb et al., 2014) and the purchase of solid wood products (Kalafatis et al., 1999). The superiority of the TPB over competing theories, e.g., ValueBelief-Norm Theory (Stern, 2000; Stern et al., 1999), has been proven for the explanation of eco-friendly behavior (e.g., Kaiser et al., 2005; López-Mosquera \& Sánchez, 2012). Due to the empirical evidence showing that the TPB is suitable for identifying the drivers of 


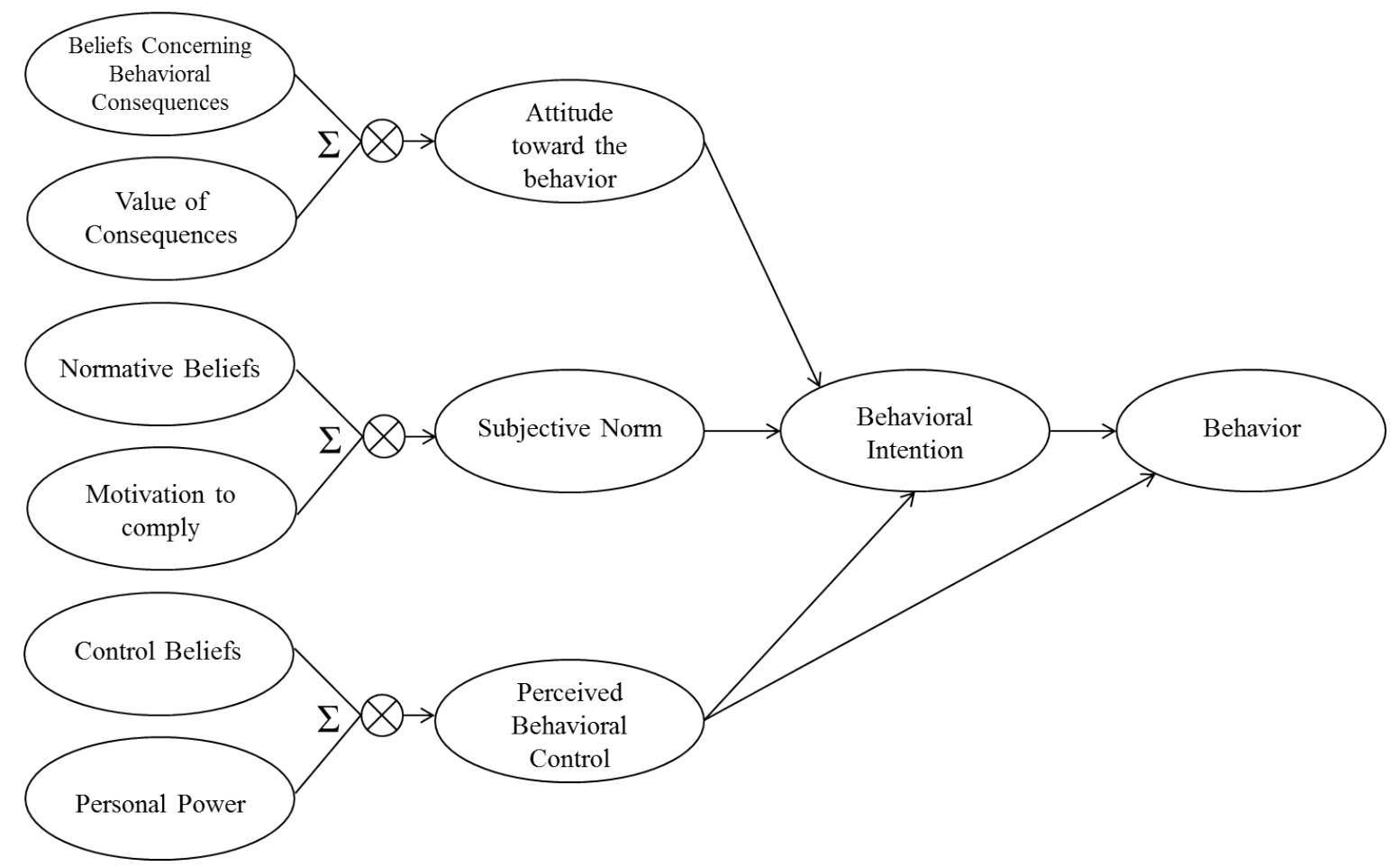

Figure 10: The Theory of Planned Behavior (Ajzen, 1991)

eco-friendly (consumer) behavior and as the choice of an eco-friendly product represents a deliberative decision (Follows \& Jobber, 2000), this model is chosen to investigate the determinants of consumer acceptance of eco-innovative materials.

An important assumption of the TPB (Figure 10) is that the intention to perform a behavior is the immediate antecedent of behavior execution. The intention is generally understood to subsume all motivational factors driving an individual to be consistent with the investigated behavior, therefore representing a measure of an individual's effort or willingness to try to engage in a specific behavior (Ajzen, 1991). Thereby, the intention serves as a mediator between three conceptually independent behavioral determinants and the behavior, whereby the importance of the predictors varies according to the investigated behavior (Ajzen \& Fishbein, 2005): a positive or negative evaluation of the considered behavior (attitude toward the behavior), the perceived social pressure to perform or suppress the behavior (subjective norm) as well as an individual's perceived ease or difficulty to carry out the behavior (perceived behavioral control; PBC). Besides, $\mathrm{PBC}$ is the only driver of the intention with an additional direct influence on the behavior, given $\mathrm{PBC}$ corresponds with an individual's actual control. In general, the stronger that the attitude and the subjective norm are, and the greater the $\mathrm{PBC}$ is, the higher an individual's behavioral intention will be. Also, the higher that the behavioral intention is, the more likely an individual will transform the intention toward behavior execution (Ajzen, 1991; Hrubes et al., 2001). However, as difficulties might arise when conducting a specific behavior, the PBC representing a proxy for the actual control should be considered as a second direct determinant of the behavior execution (Hrubes et al., 2001). The addition of PBC as a driver of the behavioral intention distinguishes the TPB from its predecessor, the TRA. Considering the PBC became fundamental, as the TRA did not satisfactorily predict behaviors over which individuals have only limited volitional control (Ajzen, 1991). Hence, the TPB is superior over the TRA for investigations where the behavior under consideration is restricted by certain factors, e.g., time, effort and money. 
Another main assumption of the TPB is that an individual's behavior follows reasonably from his or her salient beliefs (Ajzen, 1991), while recent research has supported the importance of beliefs for predicting green consumer behavior (Pagiaslis \& Krystallis, 2014). More precisely, Figure 10 illustrates that all three determinants of the intention are formed based on an expectancy (belief strength) times value (evaluation) approach: The belief strength refers to the subjective probability that a behavior will result in a specific outcome (Fishbein \& Ajzen, 1975) and is weighted by an individual's evaluation of the associated outcome (Ajzen, 1991; Ajzen \& Fishbein, 2005). Subsequently, the products are aggregated (Ajzen, 1991), resulting in the three antecedents of the intention. Calling the attitude toward the behavior $A$, it is determined by the following equation (Ajzen, 1991; Fishbein \& Ajzen, 1975)

$$
A \propto \sum_{i=1}^{n} b_{i} e_{i}
$$

with the strength of each belief $(b)$ being multiplied with an individual's evaluation $(e)$. This approach assures that not only the strengths of the beliefs are considered, but also the values an individual ascribes to the expected outcomes.

The purpose of the present study is to develop an understanding of WPC acceptance in relation to the established materials of solid wood and full plastics by testing all the TPB components as comparative scores. Hence, the expectancy of an outcome of a WPC purchase is compared with the expectancy of the same outcome due to a solid wood or full plastics purchase: b_comp.WPC $=$ b_WPC-mean(b_wood, b_WPC, b_plastics). Appearance has to be considered since it is discussed as an important driver of consumers' intention to purchase WPC products (Osburg et al., 2014, 2015). WPCs could either look like plastics or solid wood with the appearance being dependent on the materials' composition and the wood species being used (Clemons, 2008; Pritchard, 2004). As two main characteristics of WPCs are their eco-friendliness, as well as their innovativeness (Osburg et al., 2015), it is further assumed that the distinct attitudes toward environmental product aspects and innovative product aspects have to be separated in the TPB framework. Based on this assumption, it is hypothesized that the attitude toward environmental product aspects $\left(\mathrm{H}_{1}\right)$ as well as the attitude toward innovative product aspects $\left(\mathrm{H}_{2}\right)$ influence consumers' purchase intention in addition to the subjective norm and the PBC.

\subsection{Methods}

\subsubsection{Participants and procedure}

Data were collected from December $13^{\text {th }}$ to December $19^{\text {th }}, 2013.513$ respondents representative for the German population, drawn from a commercial panel (Global Market Insite, Inc.), participated in an online survey to assess consumers' purchase intention. 156 participants had to be excluded from data analysis due to incomplete answers resulting in a sample of 357. Appendix A presents the sample characteristics. The mean age was 48.45 years $(S D=15.91)$ and gender was distributed nearly equally ( $46 \%$ male respondents). WPCs were unknown for $60 \%$ of the respondents prior to their participation, while $37 \%$ knew the term from hearsay and only $3 \%$ reported good material knowledge. As a low WPC awareness had been indicated by previous studies (Osburg et al., 2014, 2015), the term WPC was explained in the beginning of the survey ('Wood-Plastic-Composite: $70 \%$ wood (mainly wood by-products e.g., sawdust), 30\% plastics, additives'). Photographs 
were shown according to the assigned product category to illustrate the two appearances (brown synthetic vs. brown wooden chair; white synthetic vs. brown wooden window frame; white synthetic vs. brown wooden fence). The photographs of the three materials within a given appearance level and product category were identical.

The study design was set as follows: Material (solid wood, WPC, full plastics) x appearance (wooden, synthetic surface) were varied within and product category (chair, window frame, fence) between subjects. Thereby, participants were randomly assigned to one of the three product categories. These product categories were chosen as construction (e.g., decking, siding, fencing) is currently the most important sector for WPC applications (Carus et al., 2014). Nevertheless, a growing importance of WPC furniture and other WPC construction applications such as window frames and doors has been predicted for the next decade as the traditional WPC application of decking reached the maturity stage in the European market (Carus et al., 2014; Eder \& Carus, 2013).

\subsubsection{Measures}

The online survey consisted of several parts, whereupon the present paper refers to the assessment of the TPB constructs including a choice-based conjoint analysis and sociodemographic information.

The TPB items were developed based on literature research comprising of I) an identification of the relevant material characteristics, II) studies showing the effects of specific material properties on consumer decisions, and III) TPB studies about eco-friendly consumer behavior. This resulted in the contents of the attitude (environmental aspects and innovative aspects), subjective norm, and PBC items. Based on these sources, expectancy and value component items were formulated. Appendix B documents the revealed items and the corresponding references.

Participants estimated the likelihood of the expectancy components (i.e., behavioral beliefs, normative beliefs, control beliefs) on 5-point-scales ranging from ' $0 \%$ / never applies' to ' $100 \%$ / always applies'. Respondents were requested to assess the value components (i.e., value of consequences, motivation to comply, personal power) on 7-point scales, ranging from -3 (bad) to +3 (good). While it was sufficient to assess each value component only once per participant, the expectancy components were measured for each combination of material and appearance, resulting in six targets per item.

Attitudes toward environmental product aspects and innovative product aspects. Three items assessed the respective behavioral beliefs concerning environmental aspects of the product (e.g., 'This chair ${ }^{5}$ is eco-friendly.') and the related value of the consequence (e.g., 'I evaluate the eco-friendliness of a chair as...'). Again, three items were presented for the behavioral beliefs related to innovative aspects of the product (e.g., 'This chair is creative and fancy.') and the corresponding value of the consequence (e.g., 'I evaluate creativity and fanciness of a chair as...').

\footnotetext{
${ }^{5}$ Depending on the assigned condition, 'chair' was replaced by either 'window frame' or 'fence'. This applies to all following item examples.
} 
Subjective Norm. The normative beliefs were measured with three items (e.g., 'My household members would like this chair'), just as the motivation to comply (e.g., 'Being consistent with my household members' preference is...').

Perceived Behavioral Control. Four items assessed the control beliefs (e.g., 'Reading product information is essential for evaluating the quality of this chair.') and another four items measured the corresponding personal power (e.g., 'I evaluate having to read product information about a chair in order to estimate its quality is...').

Behavioral intention. Two items measured the intention to purchase the considered product: 'If I wanted to buy chairs, I would take a closer look at this chair' (BI1) and 'If I had to buy a chair today, I would buy this chair' (BI2). Both items were assessed for each combination of material and appearance. Respondents answered on a 5-point scale, ranging from 1 (disagree) to 5 (agree).

Choice behavior. A choice-based conjoint analysis (CBCA; Green \& Rao, 1971) was conducted to receive a proxy variable for respondents' purchase behavior. The number of choices per participant was reduced by a fractional factorial design. Each participant received 14 choice sets with two alternative products and a no-choice option. Two sets were fixed and 12 randomly assigned by Sawtooth Software, Inc. SSI Web (version 8.2). A balanced overlap design was employed due to its advantages for estimating main effects and interactions (Chrzan \& Orme, 2000). Table 8 documents the attributes of the CBCA and their levels. While all levels were shown verbally, the description of the 'appearance' levels was supplemented with the photographs introduced in the beginning of the survey. According to Table 8, material correlated with price to reflect current market offers.

\subsubsection{Data analyses}

In the first step of data preparation, the comparative belief items were calculated describing the relative expectancy for WPCs. Thereby, the average expectancy over all material and appearance combinations was substracted from the mean expectancy for both WPC products (i.e., wooden and synthetic surface).

Similarly, the purchase intention was ipsatized to estimate the preference for WPC products in relation to solid wood and full plastics, and to eliminate any acquiescence. The attitude toward environmental product aspects, attitude toward innovative product aspects, subjective norm, and PBC products were computed by multiplying each comparative belief item with the corresponding value item, the latter rescaled to $-1 /+1$.

Table 8: Attributes and levels of the CBCA

\begin{tabular}{|c|c|c|c|c|}
\hline \multirow{2}{*}{$\begin{array}{l}\text { Attributes } \\
\text { Material }\end{array}$} & & \multicolumn{3}{|c|}{ Levels } \\
\hline & & solid wood & WPC & plastics \\
\hline Appearance & & wooden surface & synthetic surface & \\
\hline \multirow[t]{3}{*}{ Price } & solid wood: & $60 €^{1} / 120 €^{2} / 120 €^{3}$ & $70 €^{1} / 140 €^{2} / 150 €^{3}$ & $80 €^{1} / 160 €^{2} / 180 €^{3}$ \\
\hline & $W P C:$ & $50 €^{1} / 100 €^{2} / 150 €^{3}$ & $60 €^{1} / 120 €^{2} / 180 €^{3}$ & $70 €^{1} / 140 €^{2} / 210 €^{3}$ \\
\hline & plastics: & $40 €^{1} / 80 €^{2} / 180 €^{3}$ & $50 €^{1} / 100 €^{2} / 210 €^{3}$ & $60 €^{1} / 120 €^{2} / 240 €^{3}$ \\
\hline
\end{tabular}

Note: Price levels vary as a function of product category

${ }^{1}$ chair, ${ }^{2}$ window frame, ${ }^{3}$ fence 
Table 9: Means and standard deviations of the TPB items

\begin{tabular}{lcccc}
\hline & \multicolumn{2}{c}{$\begin{array}{c}\text { Comparative } \\
\text { expectancy component }\end{array}$} & \multicolumn{2}{c}{$\begin{array}{c}\text { Value } \\
\text { component }\end{array}$} \\
\cline { 2 - 5 } Item Label & Mean & SD & Mean & SD \\
\hline Attitude (environmental aspects; AE) & & & & \\
AE1 & -0.17 & 0.60 & 0.64 & 0.40 \\
AE2 & -0.34 & 0.65 & 0.60 & 0.41 \\
AE3 & -0.01 & 0.70 & 0.63 & 0.39 \\
Attitude (innovative aspects; AI) & & & & \\
AI1 & 0.00 & 0.54 & 0.42 & 0.45 \\
AI2 & 0.12 & 0.64 & 0.32 & 0.45 \\
AI3 & 0.33 & 0.79 & 0.44 & 0.43 \\
Subjective Norm (SN) & & & & \\
SN1 & -0.14 & 0.56 & 0.48 & 0.46 \\
SN2 & -0.12 & 0.51 & 0.02 & 0.49 \\
SN3 & -0.16 & 0.57 & 0.53 & 0.44 \\
Perceived Behavioral Control (PBC) & & & & \\
PBC1 & -0.11 & 0.55 & -0.43 & 0.47 \\
PBC2 & 0.14 & 0.49 & 0.23 & 0.57 \\
PBC3 & -0.24 & 0.56 & -0.54 & 0.48 \\
PBC4 & -0.40 & 0.58 & -0.31 & 0.63 \\
\hline
\end{tabular}

From the CBCA, the resulting individual utility values (part-worth utilities; Green \& Rao, 1971) were computed for all attributes. Specifically, the part-worth utility for WPC served as the operationalization of WPC choice behavior. Rescaled zero-centred differences were used instead of raw values, as the former eliminate individual scale factor differences.

Data were prepared for subsequent analysis with SPSS 21. The TPB variables were computed and the input correlation matrix for structural equation modelling was generated. Subsequently, the proposed TPB model was tested with LISREL 9.1.

\subsection{Results}

\subsubsection{Descriptive statistics}

Table 9 reports means and standard deviations for the comparative expectancy and value items. WPCs were perceived to be slightly less ecologically beneficial overall, but somewhat more innovative than the mean over all three materials, given a higher ecological image of the solid wood alternative. The perceived WPC preference of relevant others also deviates from the centre position between wood and plastics. Overall, WPCs seem to have fewer factors which might impede the participant's acceptance compared to the established materials. Both behavioral intention ratings reveal that WPCs were marginally less preferred than the average of all three materials (BI1: $M=-.08, S D=.77, t=-2.09$, $p=.038$; BI2: $M=-.05, S D=.67, t=-1.30, p=.194)$.

\subsubsection{Test of the proposed TPB model}

The test of the proposed TPB model suggests PBC was not a significant determinant for behavioral intention, so this path was eliminated. The resulting model (Table 10) with 95 degrees of freedom reached a good global fit: The Root Mean Square Error of Approximation $(\mathrm{RMSEA})=.048$ was below the .06 cut-off (Hooper et al., 2008), the Goodness 
Table 10: Standardized path coefficients and significance levels of the measurement model

\begin{tabular}{lccc}
\hline Parameter Estimate & Standardized & SE & p-value \\
\hline Attitude (environmental aspects) $\rightarrow$ AE1 & 0.74 & 0.05 & 0.001 \\
Attitude (environmental aspects) $\rightarrow$ AE2 & 0.45 & 0.06 & 0.001 \\
Attitude (environmental aspects) $\rightarrow$ AE3 & 0.75 & 0.05 & 0.001 \\
Attitude (innovative aspects) $\rightarrow$ AI1 & 0.67 & 0.06 & 0.001 \\
Attitude (innovative aspects) $\rightarrow$ AI2 & 0.50 & 0.06 & 0.001 \\
Attitude (innovative aspects) $\rightarrow$ AI3 & 0.67 & 0.06 & 0.001 \\
Subjective norm $\rightarrow$ SN1 & 0.87 & 0.05 & 0.001 \\
Subjective norm $\rightarrow$ SN2 & 0.23 & 0.06 & 0.001 \\
Subjective norm $\rightarrow$ SN3 & 0.80 & 0.05 & 0.001 \\
PBC $\rightarrow$ PBC1 & 0.24 & 0.07 & 0.001 \\
PBC $\rightarrow$ PBC2 & 0.20 & 0.07 & 0.005 \\
PBC $\rightarrow$ PBC3 & 0.63 & 0.09 & 0.001 \\
PBC $\rightarrow$ PBC4 & 0.55 & 0.08 & 0.001 \\
Behavioral Intention $\rightarrow$ BI1 & 0.85 & 0.02 & 0.001 \\
Behavioral Intention $\rightarrow$ BI2 & 0.84 & 0.04 & 0.001 \\
\hline
\end{tabular}

Table 11: Correlation matrix of the latent variables

\begin{tabular}{|c|c|c|c|c|c|c|c|}
\hline \multicolumn{2}{|c|}{ Latent Construct } & \multirow{2}{*}{$\frac{1}{1.00}$} & \multirow[t]{2}{*}{2} & \multirow[t]{2}{*}{3} & \multirow[t]{2}{*}{4} & \multirow[t]{2}{*}{5} & \multirow[t]{2}{*}{6} \\
\hline 1 & Attitude (environmental aspects) & & & & & & \\
\hline 2 & Attitude (innovative aspects) & 0.62 & 1.00 & & & & \\
\hline 3 & Subjective Norm & 0.47 & 0.59 & 1.00 & & & \\
\hline 4 & Perceived Behavioral Control & 0.33 & 0.34 & 0.18 & 1.00 & & \\
\hline 5 & Behavioral Intention & 0.58 & 0.60 & 0.70 & 0.22 & 1.00 & \\
\hline 6 & Choice Behavior & 0.35 & 0.39 & 0.43 & 0.26 & 0.61 & 1.00 \\
\hline
\end{tabular}

of Fit Index $(\mathrm{GFI})=.944$, the Normed Fit Index $(\mathrm{NFI})=.942$ and the Comparative Fit Index $(\mathrm{CFI})=.973$ were all above the .90 and .95 cut-off criteria (Hooper et al., 2008).

Table 11 shows the correlation matrix between the latent variables. The correlations suggest that increases in attitude (environmental aspects as well as innovative aspects) and subjective norm are accompanied by a higher behavioral intention. Subjective norm shows the highest correlation with behavioral intention, while PBC only reached a small correlation. The drivers of behavioral intention correlate similarly with choice behavior. The high correlation between behavioral intention and choice behavior is in line with TPB assumptions.

Table 12 presents the parameter estimates of the structural model. Attitude toward environmental product aspects $(\beta=.19)$, attitude toward innovative product aspects $(\beta=.20)$, and subjective norm $(\beta=.48)$ explained $56 \%$ of the variance in behavioral intention. Both behavioral intention $(\beta=.58)$ and $\mathrm{PBC}(\beta=.13)$ predicted an individual's choice behavior $\left(R^{2}=.39\right)$.

To sum up, the proposed TPB model was supported with the exception of a direct influence of $\mathrm{PBC}$ on behavioral intention (Figure 11). Hence, $\mathrm{H}_{1}$ and $\mathrm{H}_{2}$ are confirmed. 
Table 12: Standardized path coefficients and significance levels of the structural model

\begin{tabular}{lccc}
\hline Parameter Estimate & Standardized & SE & p-value \\
\hline Attitude (environmental aspects) $\rightarrow$ Behavioral Intention & 0.19 & 0.08 & 0.022 \\
Attitude (innovative aspects) $\rightarrow$ Behavioral Intention & 0.20 & 0.09 & 0.022 \\
Subjective norm $\rightarrow$ Behavioral Intention & 0.48 & 0.07 & 0.001 \\
Behavioral Intention $\rightarrow$ Choice Behavior & 0.58 & 0.05 & 0.001 \\
PBC $\rightarrow$ Choice Behavior & 0.13 & 0.06 & 0.033 \\
\hline
\end{tabular}

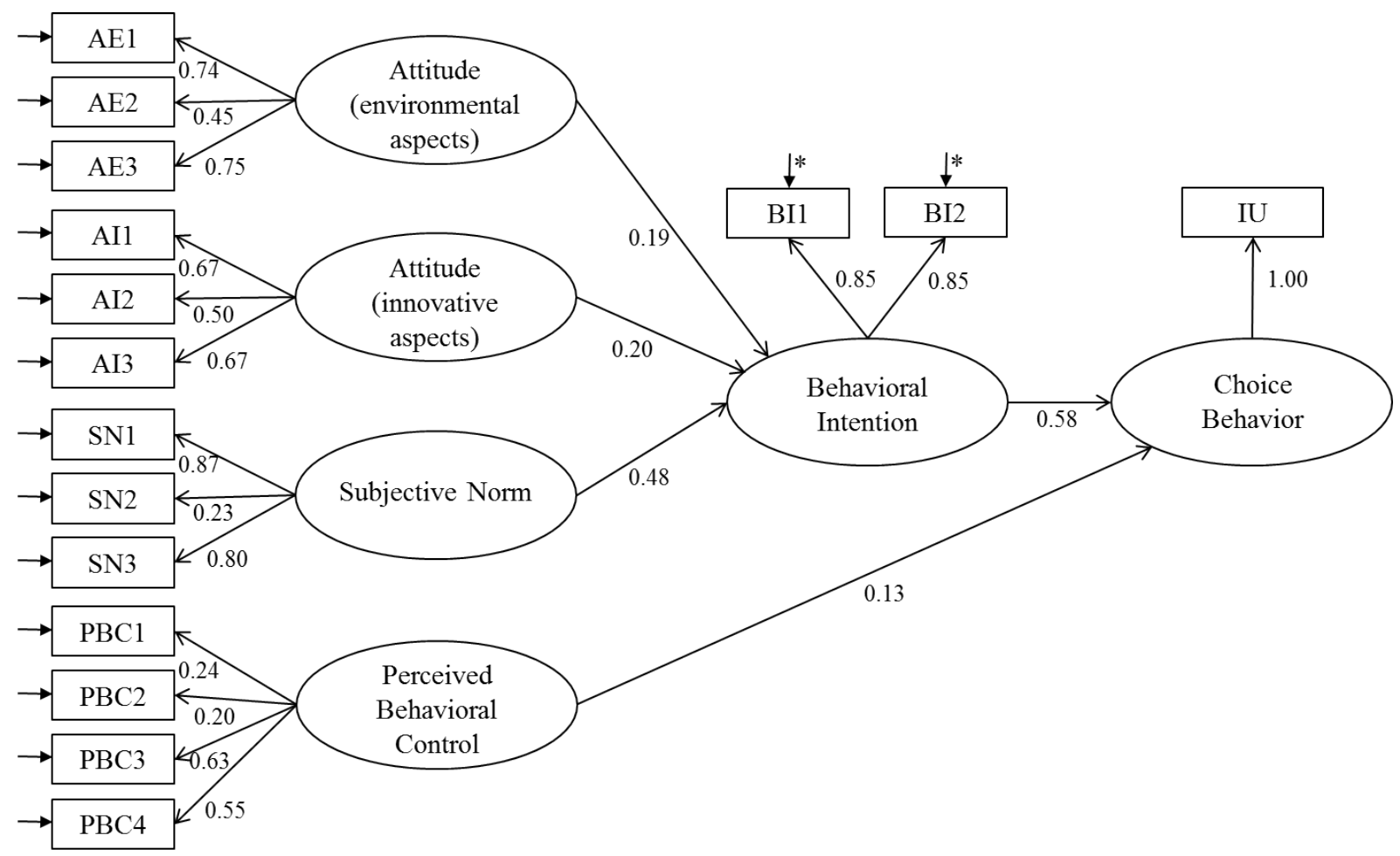

Notes:

$\mathrm{AE}=$ Attitude (environmental aspects), $\mathrm{AI}=$ Attitude (innovative aspects), $\mathrm{SN}=$ Subjective Norm, $\mathrm{PBC}=$ Perceived Behavioral Control, BI = Behavioral Intention, IU = Individual Utility Values from the CBCA. AE, AI, SN and PBC items represent the product of the comparative expectancies with the value component. ${ }^{*}$ The Error Variances of BI1 and BI2 were set equal and of IU were set equal zero to allow identification

Figure 11: The final TPB model

\subsection{Discussion}

WPCs are innovative and eco-friendly materials as they are a novel approach to optimize resource efficiency of the production in the timber industry. However, due to the novelty of these materials, there is a lack of research concerning consumer acceptance of WPC products and especially its antecedents. The present work builds on the TPB (Ajzen, 1991) which has successfully predicted various instances of eco-friendly consumer behavior (e.g., Donald et al., 2014; Read et al., 2013; Vermeir \& Verbeke, 2008; Wan et al., 2014). Therefore, a theoretical framework based on the TPB is used to identify important drivers of consumer acceptance of WPC products. To generalize WPC acceptance across diverse fields of application, different product categories are included in the online survey. 
Overall, the results of the present study demonstrate the utility of the TPB as a framework for identifying the drivers of consumers' intention to buy WPC products and their choice behavior. According to Henard and Szymanski (2001), the differentiation from conventional alternatives is an important aspect. The results of the present study imply that respondents, who perceived the advantages of WPCs and valued the benefits, intended to buy WPC products and chose them more frequently. Specifically, attitude toward environmental product aspects, attitude toward innovative product aspects and the subjective norm emerged as significant predictors of the behavioral intention. The path coefficients revealed that the subjective norm has the strongest influence, maybe because all three product categories are used at home and are the target of family decisions, therefore leading to strong social pressure. Attitude toward environmental product aspects and attitude toward innovative product aspects are of equal importance. These findings support the previously stated importance of innovativeness in relation to green consumption (Englis \& Phillips, 2013). Contrary to TPB assumptions, PBC did not significantly affect the behavioral intention. The centrality of the subjective norm and the insignificance of other paths are also shown in studies predicting the acceptance of green energy (Read et al., 2013) and wood products (Kalafatis et al., 1999) as well as the choice of an eco-friendly restaurant (Kim et al., 2013) where the subjective norm was the most important determinant of the behavioral intention. The behavioral intention ratings assessing WPC acceptance in relation to solid wood and full plastics showed that consumers' intention to buy WPC products is, if at all, only slightly below the intention averaged across all three materials. Therefore, these results are in line with current research suggesting that consumers' choices for WPC products are just in between products consisting of solid wood and full plastics (Osburg et al., 2014, 2015). Finally, the present study shows while PBC was not a significant predictor of the behavioral intention, this component had an influence on consumers' choice behavior in addition to the behavioral intention. According to the assumptions of Ajzen (1991), PBC seemed to be a good proxy of the actual control with high PBC facilitating behavior execution.

The present study reveals several implications for the marketing of WPC products. Firstly, the strong influence of the subjective norm strengthens the necessity to promote WPCs as a social trend. This finding is in line with previous research showing that the social circle can lead to more environmentally friendly consumption patterns (Harries et al., 2013). Therefore, marketing should not only address individual consumers, but also their social circle. It should be highlighted that WPC products are beneficial for an individual's significant others. The need to present WPCs as socially acceptable materials is supported by the descriptive statistics. These show respondents expected that their significant others' preferences for WPCs deviate slightly downwards from an intermediate position. Secondly, both attitude components' significance imply marketing should additionally promote an eco-friendly and innovative image of WPCs. An innovative image could be fostered by accentuating the novel combination of wood and plastic components leading to materials with additional value compared to established materials (e.g., nearly free, three-dimensional formability). The importance of an eco-friendly WPC image is suggested by the value consumers ascribed to all items referring to environmental product aspects. Its creation is dependent on the field of application and the question of whether WPCs should substitute plastics or solid wood in the specific case. In general, an eco-friendly image could be enforced if consumers are informed that WPCs are less resource-consuming materials by taking the cascade utilization seriously. As fossil fuel based plastics are typically perceived as environmentally hazardous, an eco-friendly WPC 
image should be easy to communicate. In comparison to solid wood, the environmental benefits resulting from a material utilization of wood-by products should be highlighted as well as the usefulness of WPCs for applications where tropical timber is commonly used. However, marketing has to simultaneously encounter the anticipating risk that consumers associate the utilization of by-products with a minor quality, as it has been shown for higher-priced products consisting of recycled materials (Achabou \& Dekhili, 2013; Davies et al., 2012). Therefore, a proof of the material quality is recommendable, e.g., taking recourse to certification systems. The descriptive statistics indicate another topic for the marketing of these materials by showing that consumers especially question the recyclability of WPCs. As current studies suppose that a WPC is recyclable at the end of the product's life cycle (Beg \& Pickering, 2008a, b; Petchwattana et al., 2012; Shahi et al., 2012), this information should be conveyed to potential customers. Thirdly, the results indicate that consumers notice fewer factors impeding a purchase for WPC products in comparison to the mean of the established alternatives. The only potential barrier consumers perceive to be more present is the necessity to deal with product information which might be attributable to the novelty of WPCs. Hence, marketing should provide consumers with more information about WPCs, while potential customers should be reinforced that WPCs have a good price-performance ratio by drawing attention to the benefits of WPCs consumers already acknowledge (i.e., low consequential costs and maintenance of the product). The recommendation to inform consumers is supported by the fact that most of the respondents were not familiar with WPCs.

Nevertheless, the present study has some limitations which provide suggestions for future research. Obviously, TPB studies typically rely on self-reported measures which might show biases such as overestimation. Similarly, the individual utility values of the CBCA as a proxy variable of the consumer behavior may be limited. As choice behavior only approaches actual purchase decisions, future research should try to measure real consumer behavior (e.g., by relying on market data). However, the present approach tries to cope with one aspect of the validity problem by the mandatory comparison of beliefs and intentions between all three competing materials. Hence, the acquiescence often responsible for overestimation bias was eliminated.

Subsequent studies should also broaden the spectrum of the compared materials. WPCs indeed mostly compete against solid wood and full plastics. However, for some fields of application, WPCs should be compared with additional materials (such as stone as a popular decking material besides solid wood). In this context, it has to be regarded as well that the current study considers full plastics as an environmentally hazardous material. This definitely applies to the majority of plastics used, which are based on fossil fuels. As the plastics industry increasingly realizes the necessity to use an alternative raw material base, plastic manufacturers start to replace conventional plastics with bioplastics. Hence, consumer acceptance of WPCs should also be examined in comparison with more eco-friendly plastic variants. Additionally, subsequent studies should address the generalizability of the present findings for other markets where WPCs are more or less common than in Germany. Overall, the present study could present an interesting framework for future research investigating consumer acceptance of new materials and/or products which are based on a combination of established ones. 


\subsection{Conclusions}

In summary, the continuously growing global resource demand and various environmental problems require a development of resource efficient materials. WPCs are promising ecoinnovative materials as they mainly consist of wood by-products which are used for energy otherwise. However, the market success of WPC products depends on consumers. The present study, which is built on a TPB framework, helps to understand the determinants of consumer acceptance. Thereby, the subjective norm emerges as an important driver of the purchase intention, just as do attitudes toward environmental and innovative product aspects. Therefore, marketing should use these findings as a starting point for developing strategies to further increase WPC acceptance and to contribute to the realization of a more sustainable consumption.

\section{References}

Achabou, M. A., \& Dekhili, S. (2013). Luxury and sustainable development: Is there a match? Journal of Business Research, 66, 1896-1903.

Ajzen, I. (1991). The theory of planned behavior. Organizational Behavior and Human Decision Processes, 50, 179-211.

Ajzen, I., \& Fishbein, M. (1980). Understanding attitudes and predicting social behavior. Englewood Cliffs, NJ: Prentice-Hall.

Ajzen, I., \& Fishbein, M. (2005). The influence of attitudes on behavior. In D. Albarracin, B. T. Johnson \& M. P. Zanna (Eds.), The handbook of attitudes (pp. 173-221). Mahwah, NJ: Lawrence Erlbaum Associates.

Ashrafi, M., Vaziri, A., \& Nayeb-Hashemi, H. (2011). Effect of processing variables and fiber reinforcement on the mechanical properties of wood plastic composites. Journal of Reinforced Plastics and Composites, 30, 1939-1945.

Beg, M. D. H., \& Pickering, K. L. (2008a). Reprocessing of wood fibre reinforced polypropylene composites. Part I: Effects on physical and mechanical properties. Composites Part A: Applied Science and Manufacturing, 39, 1091-1100.

Beg, M. D. H., \& Pickering, K. L. (2008b). Reprocessing of wood fibre reinforced polypropylene composites. Part II: Hygrothermal ageing and its effects. Composites Part A: Applied Science and Manufacturing, 39, 1565-1571.

Bledzki, A. K., \& Faruk, O. (2003). Wood fibre reinforced polypropylene composites: effect of fibre geometry and coupling agent on physico-mechanical properties. Applied Composite Materials, 10, 365-379.

Bumgardner, M. S., \& Bowe, S. A. (2002). Species selection in secondary wood products: Implications for product design and promotion. Wood and Fiber Science, 34, 408-418.

Carus, M., Eder, A., Dammer, L., Korte, H., Scholz, L., Essel, R., \& Breitmayer, E. (2014). Wood-plastic composites (WPC) and natural fibre composites (NFC): European and global markets and future trends (Version 2014-03). Hürth: nova-Institut GmbH.

Carus, M., Gahle, C., \& Korte, H. (2008). Market and future trends for wood-polymer composites in Europe: The example of Germany. In K. Oksman Niska \& M. Sain (Eds.), Wood-polymer composites (pp. 300-330). Cambridge: Woodhead Publishing Limited. 
Caufield, D. F., Clemons, C., Jacobson, R. E., \& Rowell, R. M. (2005). Wood thermoplastic composites. In R. M. Rowell (Ed.), Handbook of wood chemistry, wood composites (pp. 365-378). Boca Raton, FL: Taylor and Francis.

Chan, L., \& Bishop, B. (2013). A moral basis for recycling: Extending the theory of planned behaviour. Journal of Environmental Psychology, 36, 96-102.

Chatzidakis, A., Hibbert, S., \& Smith, A. P. (2007). Why people don't take their concerns about fair trade to the supermarket: The role of neutralization. Journal of Business Ethics, 74, $89-100$.

Chrzan, K., \& Orme, B. (2000). An overview and comparison of design strategies for choicebased conjoint analysis. Sawtooth Software: Research paper series.

Clemons, C. (2008). Raw materials for wood-polymer composites. In K. Oksman Niska \& M. Sain (Eds.), Wood-polymer composites (pp. 1-22). Cambridge: Woodhead Publishing Limited.

Crabbé, A., Jacobs, R., van Hoof, V., Bergmans, A., \& van Acker, K. (2013). Transition towards sustainable material innovation: Evidence and evaluation of the Flemish case. Journal of Cleaner Production, 56, 63-72.

Davies, I. A., Lee, Z., \& Ahonkhai, I. (2012). Do consumers care about ethical-luxury? Journal of Business Ethics, 106, 37-51.

Donald, I., Cooper, S., \& Conchie, S. (2014). An extended theory of planned behavior model of the psychological factors affecting commuters' transport mode use. Journal of Environmental Psychology, 40, 39-48.

Eder, A., \& Carus, M. (2013). Global trends in Wood-Plastic Composites (WPC). Bioplastics, 4, 16-17.

Eder, A., \& Haider, A. (2011). Marktchancen für Wood Polymer Composites im deutschsprachigen Raum [Market opportunities for Wood Polymer Composites in German speaking countries]. Holztechnologie, 52, 44-49.

Englis, B. G., \& Phillips, D. M. (2013). Does innovativeness drive environmentally conscious consumer behavior. Psychology \& Marketing, 30, 160-172.

Ewing, G. (2001). Altruistic, egoistic, and normative effects on curbside recycling. Environment and Behavior, 33, 733-764.

Eyerer, P., Beilharz, F., Hübner, C., Kupfer, T., \& Ulrich, C. (2010). Opportunities and (in particular) risks of use (utilization phase) of plastic structural components. In P. Eyerer (Ed.), Polymers - Opportunities and risks I: General environmental aspects (pp. 363-389). Berlin: Springer.

Fishbein, M., \& Ajzen, I. (1975). Belief, attitude, intention and behavior: An introduction to theory and research. Addison-Wesley series in social psychology. Reading, MA: AddisonWesley.

Follows, S. B. \& Jobber, D. (2000). Environmentally responsible purchase behaviour: a test of a consumer model. European Journal of Marketing, 34, 723-746.

Green, P. E., \& Rao, V. R. (1971). Conjoint measurement for quantifying judgemental data. Journal of Marketing Research, 8, 355-363. 
Groot, J. I. M. de, \& Steg, L. (2007). General beliefs and the theory of planned behavior: The role of environmental concerns in the TPB. Journal of Applied Social Psychology, 37, $1817-1836$.

Haider, A., \& Eder, A. (2010). Markets, applications, and processes for Wood Polymer Composites (WPC) in Europe. In A. Teischinger et al. (Eds.), Processing technologies for the forest and biobased products industries, PTF BPI 2010 (pp. 146-151). Kuchl: Salzburg University of Applied Sciences.

Han, H., Hsu, L.-T., \& Sheu, C. (2010). Application of the theory of planned behavior to green hotel choice: Testing the effect of environmental friendly activities. Tourism Management, 31, 325-334.

Harries, T., Rettie, R., Studley, M., Burchell, K., \& Chambers, S. (2013). Is social norms marketing effective? A case study in domestic electricity consumption. European Journal of Marketing, 47, 1458-1475.

Henard, D. H., \& Szymanski, D. M. (2001). Why some new products are more successful than others. Journal of Marketing Research, 38, 362-375.

Hooper, D., Coughlan, J., \& Mullen, M. R. (2008). Structural Equation Modelling: Guidelines for Determining Model Fit. Electronic Journal of Business Research Methods, 6, 53-60.

Horn, D., \& Salvendy, G. (2006). Consumer-based assessment of product creativity: A review and reappraisal. Human Factors and Ergonomics in Manufacturing $\mathcal{G}$ Service Industries, $16,155-175$.

Hrubes, D., Ajzen, I., \& Daigle, J. (2001). Predicting hunting intentions and behavior: An application of the theory of planned behaviour. Leisure Sciences, 23, 165-178.

Jonsson, O., Lindberg, S., Roos, A., Hugosson, M., \& Lindström, M. (2008). Consumer perceptions and preferences on solid wood, wood-based panels, and composites: A repertory grid study. Wood and Fiber Science, 40, 663-678.

Kaiser, F. G., Hübner, G., \& Bogner, F. X. (2005). Contrasting the theory of planned behavior with the value-belief-norm model in explaining conservation behavior. Journal of Applied Social Psychology, 35, 2150-2170.

Kalafatis, S. P., Pollard, M., East, R., \& Tsogas, M. H. (1999). Green marketing and Ajzen's theory of planned behaviour a cross-market examination. Journal of Consumer Marketing, $16,441-460$.

Kim, Y. J., Njite, D., \& Hancer, M. (2013). Anticipated emotion in consumers' intentions to select eco-friendly restaurants: Augmenting the theory of planned behavior. International Journal of Hospitality Management, 34, 255-262.

Klyosov, A. A. (2007). Wood-Plastic Composites. Hoboken, NJ: John Wiley \& Sons, Inc.

Kuo, P.-Y., Wang, S.-Y., Chen, J.-H., Hsueh, H.-C., \& Tsai, M.-J. (2009). Effects of material compositions on the mechanical properties of wood-plastic composites manufactured by injection molding. Materials \& Design, 30, 3489-3496.

Lin, R.-J., Tan, K.-H., \& Geng, Y. (2013). Market demand, green product innovation, and firm performance: Evidence from Vietnam motorcycle industry. Journal of Cleaner Production, 40, 101-107.

Litvine, D., \& Wüstenhagen, R. (2011). Helping "light green" consumers walk the talk: Results of a behavioural intervention survey in the Swiss electricity market. Ecological Economics, $70,462-474$. 
López-Mosquera, N., \& Sánchez, M. (2012). Theory of planned behavior and the value-beliefnorm theory explaining willingness to pay for a suburban park. Journal of Environmental Management, 113, 251-262.

Medeiros, J. F. de, Ribeiro, J. L. D., \& Cortimiglia, M. N. (2014). Success factors for environmentally sustainable product innovation: A systematic literature review. Journal of Cleaner Production, 65, 76-86.

Nocella, G., Boecker, A., Hubbard, L., \& Scarpa, R. (2012). Eliciting consumer preferences for certified animal-friendly foods: Can elements of the theory of planned behavior improve choice experiment analysis? Psychology \& Marketing, 29, 850-868.

Osburg, V.-S., Strack, M. \& Toporowski, W. (2014). Choices between wood, plastics, and innovative wood plastic composites: Do consumers accept eco-innovations? In E. Miller, G. Milne \& E. Iyer (Eds.), AMA 2014 Marketing and Public Policy Conference Proceedings, Vol. 24 (pp. 83-84). Chicago, IL: American Marketing Association.

Osburg, V.-S., Strack, M. \& Toporowski, W. (2015). Consumer acceptance of Wood-Polymer Composites: A conjoint analytical approach with a focus on innovative and environmentally concerned consumers. Journal of Cleaner Production. doi: 10.1016/j.jclepro.2015.0 4.086

Pagiaslis, A., \& Krystallis, A. (2014), Green consumption behavior antecedents: Environmental concern, knowledge, and beliefs. Psychology 83 Marketing, 31, 335-348.

Pakarinen, T. J., \& Asikainen, A. T. (2001). Consumer segments for wooden household furniture. European Journal of Wood and Wood Products, 59, 217-227.

Park, J., \& Ha, S. (2012). Understanding pro-environmental behavior: A comparison of sustainable consumers and apathetic consumers. International Journal of Retail \& Distribution Management, 40, 388-403.

Petchwattana, N., Covavisaruch, S., \& Sanetuntikul, J. (2012). Recycling of wood-plastic composites prepared from poly (vinyl chloride) and wood flour. Construction and Building Materials, 28, 557-560.

Petrescu, I., Ispas, C., \& Mohora, C. (2010). Risk assessment in the implementation of composite materials (Proceedings in Manufacturing Systems No. 5). Retrieved August 10, 2013, from http://icmas.eu/recenzare2010/248-Petrescu.doc

Pritchard, G. (2004). Two technologies merge: Wood plastic composites. Plastics, Additives and Compounding, 6, 18-21.

Read, D. L., Brown, R. F., Thorsteinsson, E. B., Morgan, M., \& Price, I. (2013). The theory of planned behaviour as a model for predicting public opposition to wind farm developments. Journal of Environmental Psychology, 36, 70-76.

Reid, L., Sutton, P., \& Hunter, C. (2010). Theorizing the meso level: the household as a crucible of pro-environmental behaviour. Progress in Human Geography, 34, 309-327.

Rhodes, R. E., Beauchamp, M. R., Conner, M., Bruijn, G.-J. de, Kaushal, N., \& LatimerCheung, A. (2014). Prediction of depot-based specialty recycling behavior using an extended Theory of Planned Behavior. Environment and Behavior, 1-23.

Richetin, J., Perugini, M., Conner, M., Adjali, I., Hurling, R., Sengupta, A., \& Greetham, D. (2012). To reduce and not to reduce resource consumption? That is two questions. Journal of Environmental Psychology, 32, 112-122. 
Schwendemann, D. (2008). Manufacturing technologies for Wood-Polymer Composites. In K. Oksman Niska, \& M. Sain (Eds.), Wood-polymer composites (pp. 72-100). Cambridge: Woodhead Publishing Limited.

Shahi, P., Behravesh, A. H., Daryabari, S. Y., \& Lotfi, M. (2012). Experimental investigation on reprocessing of extruded wood flour/HDPE composites. Polymer Composites, 33, 753-763.

Singh, S. C. (2010). Strategies to make the manufacturing processes more environment friendly. Management Insight, VI, 49-58.

Sparks, P., \& Shepherd, R. (1992). Self-identity and the theory of planned behavior: Assessing the role of identification with 'Green consumerism'. Social Psychology Quarterly, 55, $388-399$.

Stern, P. C. (2000). New environmental theories: Toward a coherent theory of environmentally significant behaviour. Journal of Social Issues, 56, 407-424.

Stern, P. C., Dietz, T., Abel, T., Guagnano, G. A., \& Kalof, L. (1999). A value-belief-norm theory of support for social movements: The case of environmentalism. Human Ecology Review, 6, 81-97.

Suttie, E. (2007). Briefing note for Forestry Commission - an update on Wood Plastic Composites (WPC). Retrieved September 2, 2014, from http://www.forestry.gov.uk/pdf/WoodPl asticComposites_update_june07.pdf/\protect $\backslash \mathrm{T} 1 \backslash$ textdollarFILE/WoodPlasticComposit es_update_june07.pdf

Taylor, S., \& Todd, P. (1995). An integrated model of waste management behaviour: A test of household recycling and composting intentions. Environment and Behavior, 27, 603-630.

Teuber, L., Osburg, V.-S., Toporowski, W., Militz, H., \& Krause, A. (2015). Wood Polymer Composites and their contribution to cascading utilisation. Journal of Cleaner Production. doi: $10.1016 /$ j.jclepro.2015.04.009

Thompson, D. W., Hansen, E. N., Knowles, C., \& Muszynski, L. (2010). Opportunities for wood plastic composite products in the US highway construction sector. BioResources, 5, $1336-1552$.

Vermeir, I., \& Verbeke, W. (2008). Sustainable food consumption among young adults in Belgium: Theory of planned behaviour and the role of confidence and values. Ecological Economics, 64, 542-553.

Vogt, D., Karus, M., Ortmann, S., Schmidt, C., \& Gahle, C. (2006). Wood-Plastic-Composites (WPC) - Märkte in Nordamerika, Japan und Europa mit Schwerpunkt auf Deutschland: Technische Eigenschaften - Anwendungsgebiete - Preise - Märkte - Akteure [Wood-PlasticComposites (WPC) - Markets in North America, Japan and Europe with emphasis on Germany: Engineering properties - Fields of application - Prices - Markets - Actors]. Retrieved on June 18, 2013, from http://www.nova-institut.de/pdf/06-01_WPC-Studie .pdf(accessed18June2013)

Wan, C., Shen, G. Q., \& Yu, A. (2014). The moderating effect of perceived policy effectiveness on recycling intention. Journal of Environmental Psychology, 37, 55-60.

Webb, T. L., Benn, Y., \& Chang, B. P. (2014). Antecedents and consequences of monitoring domestic electricity consumption. Journal of Environmental Psychology, 40, 228-238.

Weinfurter, S., \& Eder, A. (2009). Consumer perceptions of innovative wood-polymer composite decking with a focus on environmental aspects. Lenzinger Berichte, 87, 168-178. 


\section{Appendix A}

Characteristics of respondents

\begin{tabular}{|c|c|c|}
\hline Variable & & Number of Respondents \\
\hline \multirow{2}{*}{ Gender } & Male & 164 \\
\hline & Female & 193 \\
\hline \multirow[t]{9}{*}{ Profession } & Student & 34 \\
\hline & Employee & 111 \\
\hline & Executive employee & 29 \\
\hline & Freelancer & 34 \\
\hline & Executive & 22 \\
\hline & Housewife/-husband & 20 \\
\hline & Retiree & 91 \\
\hline & Unemployed & 14 \\
\hline & Others & 2 \\
\hline \multirow{6}{*}{ Household size } & 1 & 79 \\
\hline & 2 & 151 \\
\hline & 3 & 65 \\
\hline & 4 & 45 \\
\hline & 5 & 12 \\
\hline & $>5$ & 5 \\
\hline \multirow[t]{8}{*}{ Monthly household income } & $<500 €$ & 5 \\
\hline & $500-999 €$ & 29 \\
\hline & $1000-1999 €$ & 101 \\
\hline & $2000-2999 €$ & 114 \\
\hline & $3000-3999 €$ & 67 \\
\hline & $4000-4999 €$ & 24 \\
\hline & $5000-5999 €$ & 10 \\
\hline & $>6000 €$ & 7 \\
\hline \multirow[t]{3}{*}{ WPC knowledge } & unknown & 212 \\
\hline & known from hearsay & 133 \\
\hline & well known & 12 \\
\hline Total number of respondents & & 357 \\
\hline
\end{tabular}




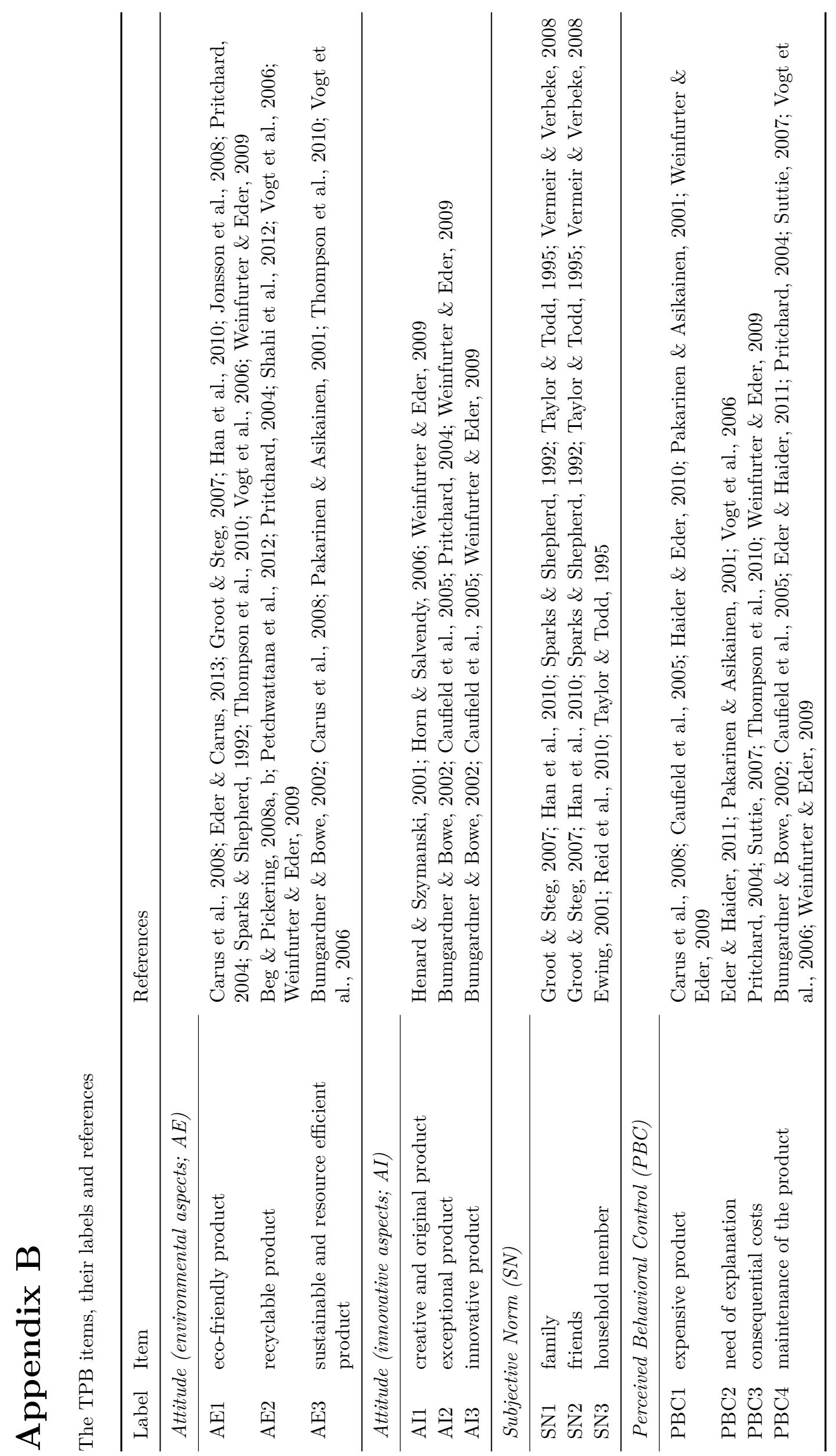




\section{General discussion and conclusion}

Following the investigation of the research questions based on three independent papers, this chapter aims to consolidate the major results, thereby highlighting the overall contribution of the project (section 5.1). Limitations of the presented studies and corresponding recommendations for future research are provided (section 5.2), prior to a concluding remark (section 5.3).

\subsection{Main results and implications}

The findings advance the understanding of consumer acceptance of products consisting of materials that are based on renewable resources. The project has shown that different research questions emerge depending on the material's novelty. While consumers' choices are assessed for innovative wood-based materials, drivers of the acceptance and target groups are investigated for both traditional and innovative wood-based materials. To summarize the main results of the project, Table 13 addresses the research questions presented in section 1.2.3.

In summary, Paper 1 indicates that the access to product information is an approach to increase product trust and purchase intentions of environmentally-friendly products and resource efficient materials. This finding supports and extends consumer studies carried out about the provision of FMCG product information (e.g., Clemens, 2003; Hobbs et al., 2005; Ortega et al., 2011; Pieniak et al., 2013; Ubilava \& Foster, 2009). Nevertheless, the provided product information has to match with the consumer segment that is intended for. How this can be achieved is discussed below. Focusing on consumer acceptance of innovative wood-based materials in comparison with competing materials, Paper 2 points to a greater market for WPC products as it has been predicted by previous concerns anticipating that environmentally oriented consumers may reject WPCs (Eyerer et al., 2010; Petrescu et al., 2010; Weinfurter \& Eder, 2009). While consumer acceptance of WPC products is in between solid wood and full plastic products, innovative and environmentally oriented consumers showed a stronger preference for WPCs compared to the average consumer. Hence, marketing has to rely on two different communication strategies which are also explained below. An important finding of Paper 3 is that consumers' relevant others have the strongest effect on purchase intention for the investigated product categories of construction and furniture. Therefore, this study underlines the relevance of the social circle with respect to eco-friendly (consumer) behavior, as it has been suggested by previous research (e.g., Kalafatis et al., 1999; Kim et al., 2013; Read et al., 2013). While innovative and environmental product aspects also influence the intention to buy WPC products, perceived behavioral barriers such as product price, consequential costs, explanation requirements and maintenance, determine consumers' actual choices.

Taken together, the papers provide insight into determinants of consumers' intention to buy wood-based materials. Paper 3 examines various drivers of consumers' choices for innovative materials on a TPB approach, whereas Paper 1 reveals that consumers value the provision of wood product information which can in turn be regarded as another predictor for consumer acceptance of wood-based materials. Additionally, Paper 1 and 2 aim to identify target groups for wood-based materials and for specific strategies that tend to enhance consumer acceptance. An environmentally oriented consumer segment emerged as a target group for both eco-innovative materials and the provision of wood product 


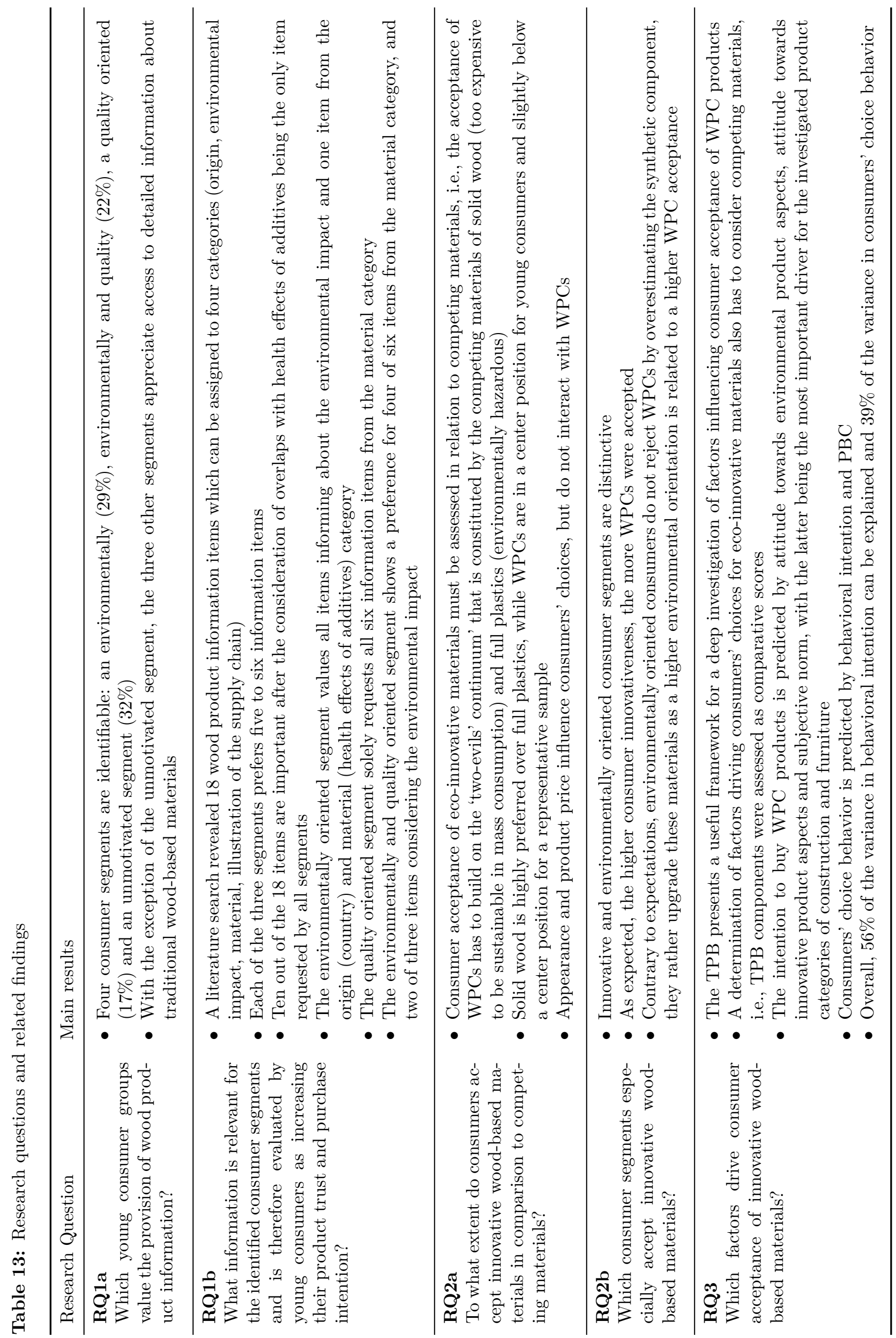


information. Innovative consumers are another consumer segment of interest for WPCs, while quality oriented customers are sensitized for product information about traditional wood-based materials. This supports previous studies showing the necessity of quality assurance for green products (Lin \& Huang, 2012), and identifying similar target groups for other eco-innovations such as alternative fuel vehicles (Jansson, 2011).

From a methodological point of view, Paper 2 and 3 highlight the relevance to assess innovations in relation to established products they are competing with. An approach is introduced that helps to assess consumer acceptance of new materials based on the 'two-old evils' continuum'. It is proposed that other studies use a similar procedure when estimating the market for new products. Furthermore, it is demonstrated how to examine competing products within a TPB framework by testing all TPB components as comparative scores. Both papers also present that a CBCA is useful to simulate consumers' purchase behavior when a direct measurement is difficult to obtain. Additionally, it is shown that the CBCA can also retrieve a proxy for actual behavior in a TPB framework.

Practical implications primarily arise for the marketing of products that consist of materials based on renewable resources, but also for producers of these products and business informatics. Marketing should address the suggested importance of communicating environmental product aspects and related consumer concerns such as the recyclability of WPCs, which has been questioned by consumers in Paper 3. Several approaches might be suitable, though Paper 1 stresses the usefulness of a traceability system providing consumers with detailed product information. As discussed, consumers perceive an access to product information at the POS as superior over the widespread certification labels. To enable consumers to have the ability to retrieve detailed information of products that are based on renewable resources, all supply chain members must provide the required information so that marketing can address consumers. Thereby, environmental benefits of the products and materials should be stressed, though the delivery of further information is of equal importance. Additionally, marketing should target the identified consumer segments. This can be achieved by preparing different information packages so that consumers can assign themselves as suggested in Paper 1. A retailer's typical consumer groups should also be identified so that marketing activities can better respond to consumers' needs, e.g., by emphasizing the material's eco friendliness, newness and/or quality. Beyond that, Paper 3 indicates that marketing should not only target an individual consumer, but incorporate the social background as it seems to be important for consumers that their choices of eco-friendly durable goods are supported by those around them. Marketing should also address the revealed purchase barriers of WPC products, e.g., by providing information that introduces the new materials to consumers.

Implications for manufacturers arise from Paper 2 and 3. It is suggested to adapt the appearance of the material to consumer preferences, as consumers highly prefer not only traditional, but also innovative wood-based materials, when the utilization of renewable resources is obvious. Additionally, the materials' eco-friendliness should be further improved. This implies a development of new materials which contribute to a more ecofriendly and resource efficient consumption as well as an improvement of existing ones. Concerning WPCs, European producers should consider replacing fossil fuel-based plastics by recycled plastics or bio-plastics and also using recycled wood fibers as is common in North America (Carus et al., 2008). This might help to broaden the market by complying with the desires of environmentally oriented consumers. Furthermore, business 
informatics should build on the findings of Paper 1 as they suggest an implementation of a traceability system that allows consumers to access detailed product information at the POS. Consumers should be able to retrieve product information at the POS by scanning QR-codes which requires that business informatics provides the needed solution.

Overall, all papers show that market research is important for understanding consumers' choices of materials that are based on renewable resources, and to assess and foster their acceptance of eco-friendly and resource efficient materials. Market research can therefore significantly contribute to environmental movement.

\subsection{Limitations and future research}

As with all research, there are certain limitations that must be acknowledged. Firstly, solid wood and particleboards were chosen to represent traditional wood-based materials, and WPCs were selected as innovative materials - obviously this is not an exhaustive range, but rather a pragmatic decision. Similarly, WPC acceptance and its drivers were only assessed in relation to the two most obvious competing materials, i.e., solid wood and full plastics. As the plastic industry starts to replace conventional plastics with bioplastics, consumers' evaluation of WPCs in comparison with a more eco-friendly plastic would also be of interest. For some product categories which were not at the fore of the presented studies, further competing materials could also be considered, e.g., stone as a popular decking material. Secondly, not only materials, but also product categories had to be selected. Though a product range was investigated, including furniture (bookshelf, chair) and construction (window frame, fence), other fields of application such as the automotive industry and technical applications are in need of further investigation, particularly for WPCs. Thirdly, exclusively German consumers participated in the studies so that the generalizability to other WPC markets has yet to be proven. Furthermore, Paper 1 used a convenience sample mostly including students within an age range of 1830 years. More research is recommended that uses an older and more diverse sample. Fourthly, the studies relied on online surveys. Paper 2 and 3 drew on individual utility values of a CBCA as a proxy for purchase decisions. Though this indirect approach simulates actual consumer behavior better than the commonly used direct questions about an individual's probable behavior, the observation of real purchase behavior may have extended knowledge further. This could also encounter the limitations of self-report measures. Finally, a selection of factors influencing consumer acceptance of materials based on renewable resources was examined. Referring to material characteristics, the CBCA only included a limited amount of possible predictors, though wood origin and percentage as well as portion of recycling could influence consumers' choices amongst others. Concerning individual predictors, factors other than consumer's environmental orientation and innovativeness might also determine the purchase decision, e.g., purchase involvement, health consciousness and socioeconomic status. Additionally, material availability seems to be important for products consisting of natural materials, since quality and availability of renewable resources may change periodically.

The project has highlighted additional questions in need of further investigation. Paper 1 suggests providing consumers with detailed product information so future work is needed about the information presentation format (e.g., text, table, image, graphic), and the selection and presentation of reference values which help consumers to better evaluate the information (e.g., according to the traffic light system used for nutrition labeling). 
Since the capturing, processing and provision of consumers' valued product information is a significant costs, it is necessary to examine consumers' WTP for having access to detailed product information. The economic feasibility of the information provision must be evaluated by taking recourse to the WTP and increases in sales rate. Thereby, benefits resulting from the information provision in the $\mathrm{B} 2 \mathrm{~B}$ area must also be taken into consideration such as the reduction of information asymmetry and uncertainty. Though Appelhanz et al. (2015) address these issues to some extent, a cost-benefit analysis is still required based on real data from a prototype implementation. Paper 3 indicates that consumers partially question the eco-friendliness and primarily the recyclability of WPCs. Further research is needed to identify information that might increase the perception of WPCs as environmentally compatible and especially resource efficient materials. An information provision as presented in Paper 1 might eventually be of high value. However, as the capturing and provision of product information is expensive, corresponding products must first be accepted by consumers and established to a certain degree as it applies to traditional wood-based materials, before a traceability system based information provision for WPC products can be achieved. In the meantime, other presentation formats should be examined and provided to inform consumers about environmental aspects of WPCs. In a similar way, future studies might help to clarify how the target groups that are identified in Paper 2 might best be addressed. Further investigations could also focus on the generalizability of the obtained findings to other materials that are based on renewable resources. Though wood was selected because of its importance as a renewable recourse, it would be interesting to identify determinants of consumer acceptance of renewable resources with an agricultural origin as well as corresponding target groups and consumers' information needs. Finally, even though the utilization of resource efficient materials supports more sustainable consumption, an overall reduced consumption behavior remains an important area of future research.

\subsection{Conclusions}

Products consisting of materials that are based on renewable resources support ecofriendly and resource efficient consumption if material utilizations of primary (e.g., solid wood) and secondary processed materials (e.g., sawmill by-products, waste wood) are realized. However, consumer acceptance of these materials is a prerequisite for their market success. The presented studies identified factors driving consumers' choices and important target groups by considering traditional (solid wood, particleboards) and innovative wood-based materials (WPCs). It is shown that the provision of ten out of 18 investigated wood product information items increases product trust and purchase intention, whereas the preferred information items vary among the four revealed consumer segments. Furthermore, although solid wood is highly preferred over full plastics, the choices for WPCs are located in the center of both, promising a fair market share. Innovative and environmentally oriented consumers are identified as two important target groups for WPC products. Appearance, environmental and innovative aspects of WPC products emerge as determinants of consumers' choices, though an individual's social environment has the strongest influence for the investigated product categories of furniture and construction. Hence, communication treatments must build on environmental benefits of WPCs especially in relation to their resource efficiency, new material characteristics and the identified choice barriers by not only addressing the individual, but also the social circle. Overall, this knowledge helps to better match marketing activities with consumers' demands. 


\section{References}

Appelhanz, S., Schumann, M., Osburg, V.-S., \& Toporowski, W. (2015). Traceability system for capturing, processing and providing consumer relevant information about wood prodcuts: System solution and its economic feasibility. Journal of Cleaner Production. doi:10.1016/j.jclepro.2015.02.034

Carus, M., Gahle, C., \& Korte, H. (2008). Market and future trends for wood-polymer composites in Europe: The example of Germany. In K. Oksman Niska \& M. Sain (Eds.), Wood-polymer composites (pp. 300-330). Cambridge: Woodhead Publishing Limited.

Clemens, R. (2003). Meat traceability and consumer assurance in Japan. MATRIC Briefing Paper 03-MBP 5, Midwest Agribusiness Trade Research and Information Center, Iowa State University.

Eyerer, P., Beilharz, F., Hübner, C., Kupfer, T., \& Ulrich, C. (2010). Opportunities and (in particular) risks of use (utilization phase) of plastic structural components. In P. Eyerer (Ed.), Polymers - Opportunities and risks I: General environmental aspects (pp. 363-389). Berlin: Springer.

Hobbs, J. E., Bailey, D., Dickinson, D. L., \& Haghiri, M. (2005). Traceability in the Canadian red meat sector: Do consumers care? Canadian Journal of Agricultural Economics, 53, $47-65$

Jansson, J. (2011). Consumer eco-innovation adoption: Assessing attitudinal factors and perceived product characteristics. Business Strategy and the Environment, 20, 192-210.

Kalafatis, S. P., Pollard, M., East, R., \& Tsogas, M. H. (1999). Green marketing and Ajzen's theory of planned behaviour a cross-market examination. Journal of Consumer Marketing, $16,441-460$.

Kim, Y. J., Njite, D., \& Hancer, M. (2013). Anticipated emotion in consumers' intentions to select eco-friendly restaurants: Augmenting the theory of planned behavior. International Journal of Hospitality Management, 34, 255-262.

Lin, P.-C., \& Huang, Y.-H. (2012). The influence factors on choice behavior regarding green products based on the theory of consumption values. Journal of Cleaner Production, 22, $11-18$.

Ortega, D. L., Wang, H. H., Wu, L., \& Olynk, N. J. (2011). Modeling heterogeneity in consumer preferences for select food safety attributes in China. Food Policy, 36, 318-324.

Petrescu, I., Ispas, C., \& Mohora, C. (2010). Risk assessment in the implementation of composite materials (Proceedings in Manufacturing Systems No. 5). Retrieved August 10, 2013, from http://icmas.eu/recenzare2010/248-Petrescu.doc

Pieniak, Z., Vanhonacker, F., \& Verbeke, W. (2013). Consumer knowledge and use of information about fish and aquaculture. Food Policy, 40, 25-30.

Read, D. L., Brown, R. F., Thorsteinsson, E. B., Morgan, M., \& Price, I. (2013). The theory of planned behaviour as a model for predicting public opposition to wind farm developments. Journal of Environmental Psychology, 36, 70-76.

Ubilava, D., \& Foster, K. (2009). Quality certification vs. product traceability: Consumer preferences for informational attributes of pork in Georgia. Food Policy, 34, 305-310.

Weinfurter, S., \& Eder, A. (2009). Consumer perceptions of innovative wood-polymer composite decking with a focus on environmental aspects. Lenzinger Berichte, 87, 168-178. 


\section{References (complete thesis)}

Achabou, M. A., \& Dekhili, S. (2013). Luxury and sustainable development: Is there a match? Journal of Business Research, 66, 1896-1903.

Aguilar, F. X., \& Cai, Z. (2010). Conjoint effect of environmental labeling, disclosure of forest of origin and price on consumer preferences for wood products in the US and UK. Ecological Economics, 70, 308-316.

Aguilar, F. X., \& Vlosky, R. P. (2007). Consumer willingness to pay price premiums for environmentally certified wood products in the U.S. Forest Policy and Economics, 9, 1100-1112.

Ajzen, I. (1991). The theory of planned behavior. Organizational Behavior and Human Decision Processes, 50, 179-211.

Ajzen, I., \& Fishbein, M. (1980). Understanding attitudes and predicting social behavior. Englewood Cliffs, NJ: Prentice-Hall.

Ajzen, I., \& Fishbein, M. (2005). The influence of attitudes on behavior. In D. Albarracin, B. T. Johnson \& M. P. Zanna (Eds.), The handbook of attitudes (pp. 173-221). Mahwah, NJ: Lawrence Erlbaum Associates.

Anderson, R. C., \& Hansen, E. N. (2004). The impact of environmental certification on preferences for wood furniture: A conjoint analysis approach. Forest Products Journal, 54, $42-50$.

Appelhanz, S., Schumann, M., Osburg, V.-S., \& Toporowski, W. (2015). Traceability system for capturing, processing and providing consumer relevant information about wood prodcuts: System solution and its economic feasibility. Journal of Cleaner Production. doi:10.1016/j.jclepro.2015.02.034

Ashori, A. (2008). Wood-plastic composites as promising green-composites for automotive industries!. Bioresource Technology, 99, 4661-4667.

Ashrafi, M., Vaziri, A., \& Nayeb-Hashemi, H. (2011). Effect of processing variables and fiber reinforcement on the mechanical properties of wood plastic composites. Journal of Reinforced Plastics and Composites, 30, 1939-1945.

Barnes, S. (2012, November 10). Saving the orang-utan. The Times Magazine. Retrieved March 10, 2014, from http://www.thetimes.co.uk/tto/magazine/article3590919.ece

Beg, M. D. H., \& Pickering, K. L. (2008a). Reprocessing of wood fibre reinforced polypropylene composites. Part I: Effects on physical and mechanical properties. Composites Part A: Applied Science and Manufacturing, 39, 1091-1100.

Beg, M. D. H., \& Pickering, K. L. (2008b). Reprocessing of wood fibre reinforced polypropylene composites. Part II: Hygrothermal ageing and its effects. Composites Part A: Applied Science and Manufacturing, 39, 1565-1571.

Bernard, J. C., \& Bernard, D. J. (2009). What is it about organic milk? An experimental analysis. American Journal of Agricultural Economics, 91, 826-836.

Bigsby, H., \& Ozanne, L. K. (2002). The purchase decision: Consumers and environmentally certified wood products. Forest Products Journal, 52, 100-105.

Bledzki, A. K., \& Faruk, O. (2003). Wood fibre reinforced polypropylene composites: effect of fibre geometry and coupling agent on physico-mechanical properties. Applied Composite Materials, 10, 365-379. 
Boer, D., \& Fischer, R. (2013). How and when do personal values guide our attitudes and sociality? Explaining cross-cultural variability in attitude-value linkages. Psychological Bulletin, 139, 1113-1147.

Borin, N., Cerf, D. C., \& Krishnan, R. (2011). Consumer effects of environmental impact in product labeling. Journal of Consumer Marketing, 28, 76-86.

Brown, J. H., Burnside, W. R., Davidson, J. P. D., Dunn, W., Hamilton, M. J., Nekola, J. C., . . Zuo, W. (2011). Energetic limits to economic growth. BioScience, 61, 19-26.

Bumgardner, M. S., \& Bowe, S. A. (2002). Species selection in secondary wood products: Implications for product design and promotion. Wood and Fiber Science, 34, 408-418.

Cai, Z., \& Aguilar, F. X. (2013a). Consumer stated purchasing preferences and corporate social responsibility in the wood products industry: A conjoint analysis in the U.S. and China. Ecological Economics, 95, 118-127.

Cai, Z., \& Aguilar, F. X. (2013b). Meta-analysis of consumer's willingness-to-pay premiums for certified wood products. Journal of Forest Economics, 1, 15-31.

Carus, M., Eder, A., Dammer, L., Korte, H., Scholz, L., Essel, R., \& Breitmayer, E. (2014). Wood-plastic composites (WPC) and natural fibre composites (NFC): European and global markets and future trends (Version 2014-03). Hürth: nova-Institut GmbH.

Carus, M., Gahle, C., \& Korte, H. (2008). Market and future trends for wood-polymer composites in Europe: The example of Germany. In K. Oksman Niska \& M. Sain (Eds.), Wood-polymer composites (pp. 300-330). Cambridge: Woodhead Publishing Limited.

Caufield, D. F., Clemons, C., Jacobson, R. E., \& Rowell, R. M. (2005). Wood thermoplastic composites. In R. M. Rowell (Ed.), Handbook of wood chemistry, wood composites (pp. 365-378). Boca Raton, FL: Taylor and Francis.

Central Intelligence Agency (2014). The World Factbook. Retrieved November 24, 2014, from http://cs.fit.edu/ ryan/factbook/factbook/index.html

Chan, L., \& Bishop, B. (2013). A moral basis for recycling: Extending the theory of planned behaviour. Journal of Environmental Psychology, 36, 96-102.

Chao, C.-W., Reid, M., \& Mavondo, F. T. (2012). Consumer innovativeness influence on really new product adoption. Australasian Marketing Journal, 20, 211-217.

Chapman, I. (2014). The end of peak oil? Why this topic is still relevant despite recent denials. Energy Policy, 64, 93-101.

Chatzidakis, A., Hibbert, S., \& Smith, A. P. (2007). Why people don't take their concerns about fair trade to the supermarket: The role of neutralization. Journal of Business Ethics, 74, $89-100$.

Chen, R.-S., Chen, C.-C., Yeh, K. C., Chen, Y.-C., \& Kuo, C.-W. (2008). Using RFID technology in food produce traceability. WSEAS Transactions on Information Science and Applications, 11, 1551-1560.

Chrzan, K., \& Orme, B. (2000). An overview and comparison of design strategies for choicebased conjoint analysis. Sawtooth Software: Research paper series.

Clemens, R. (2003). Meat traceability and consumer assurance in Japan. MATRIC Briefing Paper 03-MBP 5, Midwest Agribusiness Trade Research and Information Center, Iowa State University. 
Clemons, C. (2008). Raw materials for wood-polymer composites. In K. Oksman Niska \& M. Sain (Eds.), Wood-polymer composites (pp. 1-22). Cambridge: Woodhead Publishing Limited.

Cole, C. A., \& Balasubramanian, S. K. (1993). Age differences in consumers' search for information: Public policy implications. Journal of Consumer Research, 20, 157-169.

Connelly, L., \& Koshland, C. P. (1997). Two aspects of consumption: Using an energy-based measure of degradation to advance the theory and implementation of industrial ecology. Resources, Conservation and Recycling, 19, 199-217.

Couper, M. P. (2000). Review: Web surveys: A review of issues and approaches. Public Opinion Quarterly, 64, 464-494.

Crabbé, A., Jacobs, R., van Hoof, V., Bergmans, A., \& van Acker, K. (2013). Transition towards sustainable material innovation: Evidence and evaluation of the Flemish case. Journal of Cleaner Production, 56, 63-72.

da Silva, D. L., Correa, P. L. P., \& Najm, L. H. (2010). Requirements analysis for a traceability system for management wood supply chain on Amazon forest. Digital Information Management (ICDIM), 2010 Fifth International Conference, IEEE, 87-94.

Davies, I. A., Lee, Z., \& Ahonkhai, I. (2012). Do consumers care about ethical-luxury? Journal of Business Ethics, 106, 37-51.

Diamantopoulos, A., Schlegelmilch, B. B., Sinkovics, R. R., \& Bohlen, G. M. (2003). Can sociodemographics still play a role in profiling green consumers? A review of the evidence and an empirical investigation. Journal of Business Research, 56, 465-480.

Diaz-Rainey, I., \& Ashton, J. K. (2011). Profiling potential green electricity tariff adopters: Green consumerism as an environmental policy tool? Business Strategy and the Environment, 20, 456-470.

Dimara, E., \& Skuras, D. (2003). Consumer evaluations of product certification, geographic association and traceability in Greece. European Journal of Marketing, 37, 690-705.

Dobewall, H., \& Strack, M. (2014). Relationship of Inglehart's and Schwartz's value dimensions revisited. International Journal of Psychology, 49, 240-248.

Donald, I., Cooper, S., \& Conchie, S. (2014). An extended theory of planned behavior model of the psychological factors affecting commuters' transport mode use. Journal of Environmental Psychology, 40, 39-48.

do Paço, A. M. F., \& Raposo, M. L. B. (2009). "Green" segmentation: An application to the Portuguese consumer market. Marketing Intelligence 83 Planning, 27, 364-379.

Eder, A., \& Carus, M. (2013). Global trends in Wood-Plastic Composites (WPC). Bioplastics, 4, 16-17.

Eder, A., \& Haider, A. (2011). Marktchancen für Wood Polymer Composites im deutschsprachigen Raum [Market opportunities for Wood Polymer Composites in German speaking countries]. Holztechnologie, 52, 44-49.

Englis, B. G., \& Phillips, D. M. (2013). Does innovativeness drive environmentally conscious consumer behavior. Psychology \&3 Marketing, 30, 160-172.

Eshun, J. F., Potting, J., \& Leemans, R. (2012). Wood waste minimization in the timber sector of Ghana: A systems approach to reduce environmental impact. Journal of Cleaner Production, 26, 67-78. 
Essoussi, L. H., \& Linton, J. D. (2010). New or recycled products: How much are consumers willing to pay? Journal of Consumer Marketing, 27, 458-468.

Ewing, G. (2001). Altruistic, egoistic, and normative effects on curbside recycling. Environment and Behavior, 33, 733-764.

Eyerer, P., Beilharz, F., Hübner, C., Kupfer, T., \& Ulrich, C. (2010). Opportunities and (in particular) risks of use (utilization phase) of plastic structural components. In P. Eyerer (Ed.), Polymers - Opportunities and risks I: General environmental aspects (pp. 363-389). Berlin: Springer.

Fenning, T. M., \& Gershenzon, J. (2002). Where will the wood come from? Plantation forests and the role of biotechnology. Trends in Biotechnology, 20, 291-296.

Fishbein, M., \& Ajzen, I. (1975). Belief, attitude, intention and behavior: An introduction to theory and research. Addison-Wesley series in social psychology. Reading, MA: AddisonWesley.

Folinas, D., Manikas, I., \& Manos, B. (2006). Tracebaility data management for food chains. British Food Journal, 108, 622-633.

Follows, S. B. \& Jobber, D. (2000). Environmentally responsible purchase behaviour: a test of a consumer model. European Journal of Marketing, 34, 723-746.

Fraanje, P. J. (1997). Cascading of pine wood. Resource, Conservation and Recycling, 19, $21-28$.

Gadema, Z., \& Oglethorpe, D. (2011). The use and usefulness of carbon labelling food: A policy perspective from a survey of UK supermarket shoppers. Food Policy, 36, 815-822.

Gellynck, X., \& Verbeke, W. (2001). Consumer perception of traceability in the meat chain. Agrarwirtschaft, 50, 368-374.

Ghanbari, A., Madhoushi, M., \& Ashori, A. (2014). Wood Plastic Composite Panels: Influence of the species, formulation variables and blending process on the density and withdrawal strength of fasteners. Journal of Polymers and the Environment, 22, 260-266.

Giraud, R., \& Halawany, R. (2006). Consumers' perception of food traceability in Europe. Paper presented at the 98th EAAE Seminar 'Marketing dynamics within the global trading system: New perspectives', June 29-July 2, Chania, Greece, 1-9.

Gleim, M. R., Smith, J. S., Andrews, D., \& Cronin, J. J. (2013). Against the green: A multimethod examination of the barriers to green consumption. Journal of Retailing, 89, 44-61.

Godfray, H. C. J., Beddington, J. R., Crute, I. R., Haddad, L., Lawrence, D., Muir, J. F., . . . Toulmin, C. (2010). Food security. The challenge of feeding 9 billion people. Science, 327, 812-818.

Gold, S., \& Rubik, F. (2009). Consumer attitudes towards timber as a construction material and towards timber frame houses - selected findings of a representative survey among the German population. Journal of Cleaner Production, 17, 303-309.

Goldsmith, R. E., Kim, D., Flynn, L. R., \& Kim, W.-M. (2005). Price sensitivity and innovativeness for fashion among Korean consumers. Journal of Social Psychology, 145, $501-508$.

Gracia, A., \& Zeballos, G. (2005). Attitudes of retailers and consumers toward the EU traceability and labeling system for beef. Journal of Food Distribution Research, 36, 45-56. 
Green, P. E., \& Rao, V. R. (1971). Conjoint measurement for quantifying judgemental data. Journal of Marketing Research, 8, 355-363.

Grimmer, M., \& Bingham, T. (2013). Company environmental performance and consumer purchase intentions. Journal of Business Research, 66, 1945-1953.

Groot, J. I. M. de, \& Steg, L. (2007). General beliefs and the theory of planned behavior: The role of environmental concerns in the TPB. Journal of Applied Social Psychology, 37, $1817-1836$.

GS1 (2009). GS1 MobileCom. Extended Packaging Pilot Handbook (Issue1, 11-Feb-2009). Retrieved June 20, 2014, from http://www.gs1.org/docs/mobile/GS1_Extended_Packagin g_Pilot_-Handbook.pdf.

Haider, A., \& Eder, A. (2010). Markets, applications, and processes for Wood Polymer Composites (WPC) in Europe. In A. Teischinger et al. (Eds.), Processing technologies for the forest and biobased products industries, PTF BPI 2010 (pp. 146-151). Kuchl: Salzburg University of Applied Sciences.

Han, H., Hsu, L.-T., \& Sheu, C. (2010). Application of the theory of planned behavior to green hotel choice: Testing the effect of environmental friendly activities. Tourism Management, $31,325-334$.

Hansmann, R., Koellner, T., \& Scholz, R. W. (2006). Influence of consumers' socioecological and economic orientations on preferences for wood products with sustainability labels. Forest Policy and Economics, 8, 239-250.

Harries, T., Rettie, R., Studley, M., Burchell, K., \& Chambers, S. (2013). Is social norms marketing effective? A case study in domestic electricity consumption. European Journal of Marketing, 47, 1458-1475.

Hartmann, P., \& Apaolaza-Ibáñez, V. (2012). Consumer attitude and purchase intention toward green energy brands: The roles of psychological benefits and environmental concern. Journal of Business Research, 65, 1254-1263.

Henard, D. H., \& Szymanski, D. M. (2001). Why some new products are more successful than others. Journal of Marketing Research, 38, 362-375.

Hobbs, J. E. (2003). Consumer demand for traceability. Paper presented at the IATRC Annual Meeting, December 15-17, 2002, Monterey, California.

Hobbs, J. E., Bailey, D., Dickinson, D. L., \& Haghiri, M. (2005). Traceability in the Canadian red meat sector: Do consumers care? Canadian Journal of Agricultural Economics, 53, $47-65$.

Homburg, A., \& Wagner, U. (2007). Faktoren individueller Bedrohungs-, Wirksamkeits- und Kostenbewertung bei Umweltstressoren [Factors of Individual Threat, Efficacy and Cost Appraisal in the Context of Environmental Stressors]. Social Psychology, 38, 53-65.

Hooper, D., Coughlan, J., \& Mullen, M. R. (2008). Structural Equation Modelling: Guidelines for Determining Model Fit. Electronic Journal of Business Research Methods, 6, 53-60.

Horn, D., \& Salvendy, G. (2006). Consumer-based assessment of product creativity: A review and reappraisal. Human Factors and Ergonomics in Manufacturing 85 Service Industries, $16,155-175$.

Hrubes, D., Ajzen, I., \& Daigle, J. (2001). Predicting hunting intentions and behavior: An application of the theory of planned behaviour. Leisure Sciences, 23, 165-178. 
Husted, B. W., Russo, M. V., Meza, C. E. B., \& Tilleman, S. G. (2014). An exploratory study of environmental attitudes and the willingness to pay for environmental certification in Mexico. Journal of Business Research, 67, 891-899.

Jansson, J. (2011). Consumer eco-innovation adoption: Assessing attitudinal factors and perceived product characteristics. Business Strategy and the Environment, 20, 192-210.

Jansson, J., Marell, A., \& Nordlund, A. (2011). Exploring consumer adoption of a high involvement eco-innovation using value-belief-norm theory. Journal of Consumer Behaviour, 10, $51-60$.

Jonsson, O., Lindberg, S., Roos, A., Hugosson, M., \& Lindström, M. (2008). Consumer perceptions and preferences on solid wood, wood-based panels, and composites: A repertory grid study. Wood and Fiber Science, 40, 663-678.

Kaiser, F. G., Hübner, G., \& Bogner, F. X. (2005). Contrasting the theory of planned behavior with the value-belief-norm model in explaining conservation behavior. Journal of Applied Social Psychology, 35, 2150-2170.

Kalafatis, S. P., Pollard, M., East, R., \& Tsogas, M. H. (1999). Green marketing and Ajzen's theory of planned behaviour a cross-market examination. Journal of Consumer Marketing, $16,441-460$.

Kan, T.-W., Teng, C.-H., \& Chou, W.-S. (2009). Applying QR-Code in Augmented Reality Applications. In S. N. Spencer, M. Nakajima, E. Wu, K. Miyata, D. Thalmann \& Z. Huang (Eds.), Proceedings of the 8th International Conference on VRCAI 2009 (pp. 253-257). Yokohama.

Kanchanapibul, M., Lacka, E., Wang, X., \& Chan, H. K. (2014). An empirical investigation of green purchase behaviour among the young generation. Journal of Cleaner Production, $66,528-536$.

Keenan, T. M., Tanenbaum, S. W., Stipanovic, A. J., \& Nakas, J. P. (2004). Production and characterization of Poly- $\beta$-hydroxyalkanoate Copolymers from Burkholderia cepacia utilizing Xylose and Levulinic acid. Biotechnology Progress, 20, 1697-1704.

Kehagia, O., Chrysochou, P., Chryssochoidis, G., Krystallis, A., \& Linardakis, M. (2007). European consumers' perceptions, definitions and expectations of traceability and the importance of labels, and the differences in these perceptions by product type. Sociological Ruralis, 47, 400-416.

Kim, M. H., \& Song, H. B. (2014). Analysis of the global warming potential for wood waste recycling systems. Journal of Cleaner Production, 69, 199-207.

Kim, Y. J., Njite, D., \& Hancer, M. (2013). Anticipated emotion in consumers' intentions to select eco-friendly restaurants: Augmenting the theory of planned behavior. International Journal of Hospitality Management, 34, 255-262.

Klein, L. R., \& Ford, G. T. (2003). Consumer search for information in the digital age: An empirical study of prepurchase search for automobiles. Journal of Interactive Marketing, $17,29-49$.

Klyosov, A. A. (2007). Wood-Plastic Composites. Hoboken, NJ: John Wiley \& Sons, Inc.

Krause, K., Müller, M., Militz, H., \& Krause, A. (2013). Efficient utilization of wood sources for wood-polymer composites. In J. Geldermann \& M. Schumann (Eds.), First International Conference on Resource Efficiency in Interorganizational Networks - ResEff 2013 (pp. 94-105). Göttingen: Universitätsverlag Göttingen. 
Krystallis, A., \& Chryssohoidis, G. (2005). Consumers' willingness to pay for organic food: Factors that affect it and variation per organic product type. British Food Journal, 10\%, $320-343$.

Kuo, P.-Y., Wang, S.-Y., Chen, J.-H., Hsueh, H.-C., \& Tsai, M.-J. (2009). Effects of material compositions on the mechanical properties of wood-plastic composites manufactured by injection molding. Materials \& Design, 30, 3489-3496.

Leible, L., Kälber, S., \& Nieke, E. (2001). Nachwachsende Rohstoffe - eine Zwischenbilanz [Renewable resources - an interim result]. In A. Grundwald (Ed.), Jahrbuch des Instituts für Technikfolgenabschätzung und Systemanalyse (ITAS) 1999/2000 [Annual book of the Institute for Technology Assessment and Systems Analysis (ITAS) 1999/2000] (pp. 25-41). Eggenstein: Wilhelm Stober GmbH.

Leonidou, L. C., Leonidou, C. N., \& Kvasova, O. (2010). Antecedents and outcomes of consumer environmentally friendly attitudes and behaviour. Journal of Marketing Management, 26, $1319-1344$.

Lin, P.-C., \& Huang, Y.-H. (2012). The influence factors on choice behavior regarding green products based on the theory of consumption values. Journal of Cleaner Production, 22, $11-18$.

Lin, R.-J., Tan, K.-H., \& Geng, Y. (2013). Market demand, green product innovation, and firm performance: Evidence from Vietnam motorcycle industry. Journal of Cleaner Production, 40, 101-107.

Litvine, D., \& Wüstenhagen, R. (2011). Helping "light green" consumers walk the talk: Results of a behavioural intervention survey in the Swiss electricity market. Ecological Economics, $70,462-474$.

Lloyd, B., \& Subbarao, S. (2009). Development challenges under the Clean Development Mechanism (CDM) - Can renewable energy initiatives be put in place before peak oil? Energy Policy, 3, 237-245.

López-Mosquera, N., \& Sánchez, M. (2012). Theory of planned behavior and the value-beliefnorm theory explaining willingness to pay for a suburban park. Journal of Environmental Management, 113, 251-262.

Luchs, M. G., Naylor, R. W., Irwin, J. R., \& Raghunathan, R. (2010). The sustainability liability: Potential negative effects of ethicality on product preference. Journal of Marketing, $74,18-31$.

Macias, N., \& Knowles, C. (2011). Examining the effect of environmental certification, wood source, and price on architects' preferences of hardwood flooring. Silva Fennica, 45, 97-109.

Marette, S., Messean, A., \& Millet, G. (2012). Consumers' willingness to pay for eco-friendly apples under different labels: Evidences from a lab experiment. Food Policy, 37, 151-161.

McKeough, T. (2014, March 05). Should I replace fake wood paneling? The New York Times. Retrieved March 10, 2014, from http://www.nytimes.com/2014/03/06/garden/should-ireplace-fake-wood-paneling.html

Medeiros, J. F. de, Ribeiro, J. L. D., \& Cortimiglia, M. N. (2014). Success factors for environmentally sustainable product innovation: A systematic literature review. Journal of Cleaner Production, 65, 76-86. 
Michaud, C., \& Llerena, D. (2011). Green consumer behaviour: An experimental analysis of willingness to pay for remanufactured products. Business Strategy and the Environment, 20, 408-420.

Miller, K. M., Hofstetter, R., Krohme, H., \& Zhang, Z. J. (2011). How should consumers' willingness to pay be measured? An empirical comparison of state-of-the-art approaches. Journal of Marketing Research, 48, 172-184.

Miller, N. E. (1944). Experimental studies of conflict. In J. M. Hunt (Ed.), Personality and the behavior disorders (pp. 431-465). New York, NY: Roland.

Mitchell, R. C., \& Carson, R. T. (1989). Using surveys to value public goods: The contingent valuation method. Washington, DC: Resources for the Future.

Munnukka, J. (2008). Customers' purchase intentions as a reflection of price perception. Journal of Product Brand Management, 17, 188-196.

Noble, S. M., Hytko, D. L., \& Phillips, J. (2009). What drives college-age Generation Y consumers? Journal of Business Research, 62, 617-628.

Nocella, G., Boecker, A., Hubbard, L., \& Scarpa, R. (2012). Eliciting consumer preferences for certified animal-friendly foods: Can elements of the theory of planned behavior improve choice experiment analysis? Psychology $\&$ Marketing, 29, 850-868.

Nordlund, A. M., \& Garvill, J. (2002). Value Structures behind Proenvironmental Behavior. Environment and Behavior, 34, 740-756.

nova-Institut (2010). Entwicklung von Förderinstrumenten für die stoffliche Nutzung von nachwachsenden Rohstoffen in Deutschland (Kurzfassung) [The development of instruments to support the material use of renewable raw materials in Germany (Summary)]. Hürth: nova-Institut für politische und ökologische Innovation GmbH.

nova-Institut (2012). Stoffliche Nutzung von Biomasse. Basisdaten für Deutschland, Europa und die Welt [Material use of biomass. Basic data for Germany, Europe and the world]. Retrieved June 18, 2013, from http://www.nova-institut.de/download/Stoffliche_Nutzun g_von_Biomasse_nova

Nuszbaum, M., Voss, A., Klauer, K. C., \& Betsch, T. (2010). Assessing individual differences in the use of haptic information using a German translation of the Need for Touch Scale. Social Psychology, 41, 263-274.

O'Brien, K. A., \& Teisl, M. F. (2004). Eco-information and its effects on consumer values for environmentally certified forest products. Journal of Forest Economics, 10, 75-96.

Onozaka, Y., \& McFadden, D. (2011). Does local labeling complement or compete with other sustainable labels? A conjoint analysis of direct and joint values for fresh produce claims. American Journal of Agricultural Economics, 93, 693-706.

Ortega, D. L., Wang, H. H., Wu, L., \& Olynk, N. J. (2011). Modeling heterogeneity in consumer preferences for select food safety attributes in China. Food Policy, 36, 318-324.

Osburg, V.-S., Strack, M. , \& Toporowski, W. (2014). Choices between wood, plastics, and innovative wood plastic composites: Do consumers accept eco-innovations? In E. Miller, G. Milne \& E. Iyer (Eds.), AMA 2014 Marketing and Public Policy Conference Proceedings, Vol. 24 (pp. 83-84). Chicago, IL: American Marketing Association. 
Osburg, V.-S., Strack, M. \& Toporowski, W. (2015). Consumer acceptance of Wood-Polymer Composites: A conjoint analytical approach with a focus on innovative and environmentally concerned consumers. Journal of Cleaner Production. doi: 10.1016/j.jclepro.2015.0 4.086

Ozaki, R. (2011). Adopting sustainable innovation: What makes consumers sign up to green electricity? Business Strategy and the Environment, 20, 1-17.

Ozanne, L. K., \& Vlosky, R. P. (2003). Certification from the U.S. consumer perspective: A comparison from 1995 and 2000. Forest Products Journal, 53, 13-21.

Pagiaslis, A., \& Krystallis, A. (2014), Green consumption behavior antecedents: Environmental concern, knowledge, and beliefs. Psychology 83 Marketing, 31, 335-348.

Pakarinen, T. J., \& Asikainen, A. T. (2001). Consumer segments for wooden household furniture. European Journal of Wood and Wood Products, 59, 217-227.

Park, J., \& Ha, S. (2012). Understanding pro-environmental behavior: A comparison of sustainable consumers and apathetic consumers. International Journal of Retail $\&$ Distribution Management, 40, 388-403.

Park, S.-J., Choi, S., \& Kim, E.-J. (2012). The relationships between socio-demographic variables and concerns about environmental sustainability. Corporate Social Responsibility and Environmental Management, 19, 343-354.

Peck, J., \& Childers, T. L. (2003). Individual differences in haptic information processing. The "Need for Touch" scale. Journal of Consumer Research, 30, 430-442.

Petchwattana, N., Covavisaruch, S., \& Sanetuntikul, J. (2012). Recycling of wood-plastic composites prepared from poly (vinyl chloride) and wood flour. Construction and Building Materials, 28, 557-560.

Petrescu, I., Ispas, C., \& Mohora, C. (2010). Risk assessment in the implementation of composite materials (Proceedings in Manufacturing Systems No. 5). Retrieved August 10, 2013, from http://icmas.eu/recenzare2010/248-Petrescu.doc

Petty, R. E., \& Cacioppo, J. T. (1986). The Elaboration Likelihood Model of persuasion. In L. Berkowitz (Ed.), Advances in experimental social psychology (Vol. 19, pp. 123-205). New York: Academic Press.

Pieniak, Z., Vanhonacker, F., \& Verbeke, W. (2013). Consumer knowledge and use of information about fish and aquaculture. Food Policy, 40, 25-30.

Pritchard, G. (2004). Two technologies merge: Wood plastic composites. Plastics, Additives and Compounding, 6, 18-21.

Ramirez, E., \& Goldsmith, R. E. (2009). Some antecedents of price sensitivity. Journal of Marketing Theory and Practice, 17, 199-213.

Read, D. L., Brown, R. F., Thorsteinsson, E. B., Morgan, M., \& Price, I. (2013). The theory of planned behaviour as a model for predicting public opposition to wind farm developments. Journal of Environmental Psychology, 36, 70-76.

Reid, L., Sutton, P., \& Hunter, C. (2010). Theorizing the meso level: the household as a crucible of pro-environmental behaviour. Progress in Human Geography, 34, 309-327.

Rex, E., \& Baumann, H. (2007). Beyond ecolabels: What green marketing can learn from conventional marketing. Journal of Cleaner Production, 15, 567-576. 
Rhodes, R. E., Beauchamp, M. R., Conner, M., Bruijn, G.-J. de, Kaushal, N., \& LatimerCheung, A. (2014). Prediction of depot-based specialty recycling behavior using an extended Theory of Planned Behavior. Environment and Behavior, 1-23.

Richetin, J., Perugini, M., Conner, M., Adjali, I., Hurling, R., Sengupta, A., \& Greetham, D. (2012). To reduce and not to reduce resource consumption? That is two questions. Journal of Environmental Psychology, 32, 112-122.

Rijnsoever, F. J. van, Castaldi, C., \& Dijst, M. J. (2012). In what sequence are information sources consulted by involved consumers? The case of automobile pre-purchase search. Journal of Retailing and Consumer Services, 19, 343-352.

Roehrich, G. (2004). Consumer innovativeness. Concepts and measurements. Journal of Business Research, 57, 671-677.

Roos, A., \& Nyrud, A. Q. (2008). Description of green versus environmentally indifferent consumers of wood products in Scandinavia: flooring and decking. Journal of Wood Science, $54,402-407$.

Salaün, Y., \& Flores, K. (2001). Information quality: Meeting the needs of the consumer. International Journal of Information Management, 21, 21-37.

Salazar, J., \& Meil, J. (2009). Prospects for carbon-neutral housing: The influence of greater wood use on the carbon footprint of a single-family residence. Journal of Cleaner Production, 17, 1563-1571.

Satov, D. V. (2008). Additives for wood-polymer composites. In K. Oksman Niska, K. \& M. Sain (Eds.), Wood-polymer composites (pp. 23-40). Cambridge: Woodhead Publishing Limited.

Scarpa, R., \& Willis, K. (2010). Willingness-to-pay for renewable energy: Primary and discretionary choice of British households' for micro-generation technologies. Energy Economics, 32, 129-136.

Scholz, S. W., \& Decker, R. (2007). Measuring the impact of wood species on consumer preferences for wooden furniture by means of the analytic hierarchy process. Forest Products Journal, 57, 23-28.

Schultz, P. (2001). The structure of environmental concern: Concern for self, other people, and the biosphere. Journal of Environmental Psychology, 21, 327-339.

Schwartz, S. H. (1992). Universals in the content and structure of values: Theoretical advances and empirical tests in 20 countries. Advances in Experimental Social Psychology, 25, 1-65.

Schwendemann, D. (2008). Manufacturing technologies for Wood-Polymer Composites. In K. Oksman Niska, \& M. Sain (Eds.), Wood-polymer composites (pp. 72-100). Cambridge: Woodhead Publishing Limited.

Shahi, P., Behravesh, A. H., Daryabari, S. Y., \& Lotfi, M. (2012). Experimental investigation on reprocessing of extruded wood flour/HDPE composites. Polymer Composites, 33, 753-763.

Sheeran, P. (2002). Intention-behavior relations: A conceptual and empirical review. European Review of Social Psychology, 12, 1-36.

Singh, S. C. (2010). Strategies to make the manufacturing processes more environment friendly. Management Insight, VI, 49-58. 
Sirkin, T., \& ten Houten, M. (1994). The cascade chain. A theory and tool for achieving resource sustainability with applications for product design. Resources, Conservation and Recycling, 10, 213-277.

Smith, J. B., \& Bristor, J. M. (1994). Uncertainty orientation: Explaining differences in purchase involvement and external search. Psychology $\&$ Marketing, 11, 587-607.

Sparks, P., \& Shepherd, R. (1992). Self-identity and the theory of planned behavior: Assessing the role of identification with 'Green consumerism'. Social Psychology Quarterly, 55, 388-399.

Stern, P. C. (2000). New environmental theories: Toward a coherent theory of environmentally significant behaviour. Journal of Social Issues, 56, 407-424.

Stern, P. C., Dietz, T., Abel, T., Guagnano, G. A., \& Kalof, L. (1999). A value-belief-norm theory of support for social movements: The case of environmentalism. Human Ecology Review, 6, 81-97.

Suttie, E. (2007). Briefing note for Forestry Commission - an update on Wood Plastic Composites (WPC). Retrieved September 2, 2014, from http://www.forestry.gov.uk/pdf/WoodPl asticComposites_update_june07.pdf/\protect $\backslash \mathrm{T} 1 \backslash$ textdollarFILE/WoodPlasticComposit es_update_june07.pdf

Taylor, S., \& Todd, P. (1995). An integrated model of waste management behaviour: A test of household recycling and composting intentions. Environment and Behavior, 27, 603-630.

Teisl, M. F. (2003). What we may have is a failure to communicate: Labeling environmentally certified forest products. Forest Science, 49, 668-680.

Teuber, L., Osburg, V.-S., Toporowski, W., Militz, H., \& Krause, A. (2015). Wood Polymer Composites and their contribution to cascading utilisation. Journal of Cleaner Production. doi: $10.1016 /$ j.jclepro.2015.04.009

Thompson, D. W., Anderson, R. C., Hansen, E. N., \& Kahle, L. R. (2010). Green segmentation and environmental certification: Insights from forest products. Business Strategy and the Environment, 19, 319-334.

Thompson, D. W., Hansen, E. N., Knowles, C., \& Muszynski, L. (2010). Opportunities for wood plastic composite products in the US highway construction sector. BioResources, 5, 1336-1552.

Thompson, M., Sylvia, G., \& Morrissey, M. T. (2005). Traceability in the United States: Current trends, system design, and potential applications. Reviews in Food Science and Food Safety, 1, 1-7.

Tikir, A., \& Lehmann, B. (2011). Climate change, theory of planned behavior and values: A structural equation model with mediation analysis. A letter. Climate Change, 104, 389-402.

Tseng, S.-C., \& Hung, S.-W. (2013). A framework identifying the gaps between customers' expectations and their perceptions in green products. Journal of Cleaner Production, 59, $174-184$

Tsoumis, G. (2009). Science and Technology of Wood. Structure, Properties, Utilization (reprint of the ed. from 1991). Remagen-Oberwinter: Publishing House Kessel.

Ubilava, D., \& Foster, K. (2009). Quality certification vs. product traceability: Consumer preferences for informational attributes of pork in Georgia. Food Policy, 34, 305-310. 
Upham, P., Dendler, L., \& Bleda, M. (2011). Carbon labelling of grocery products: Public perceptions and potential emissions reductions. Journal of Cleaner Production, 19, 348-355.

Urien, B., \& Kilbourne, W. (2011). Generativity and self-enhancement values in eco-friendly behavioral intentions and environmentally responsible consumption behavior. Psychology Es Marketing, 28, 69-90.

Vanclay, J. K., Shortiss, J., Aulsebrook, S., Gillespie, A. M., Howell, B. C., Johanni, R., ... Yates, J. (2011). Customer response to carbon labelling of groceries. Journal of Consumer Policy, 34, 153-160.

Veisten, K. (2007). Willingness to pay for eco-labelled wood furniture: Choice-based conjoint analysis versus open-ended contingent valuation. Journal of Forest Economics, 13, 29-48.

Verbeke, W. (2005). Agriculture and the food industry in the information age. European Review of Agricultural Economics, 32, 347-368.

Verbeke, W. (2008). Impact of communication on consumers' food choices. Proceedings of the Nutrition Society, 67, 281-288.

Verbruggen, A., \& Al Marchohi, M. (2010). Views on peak oil and its relation to climate change policy. Energy Policy, 38, 5572-5581.

Vermeir, I., \& Verbeke, W. (2008). Sustainable food consumption among young adults in Belgium: Theory of planned behaviour and the role of confidence and values. Ecological Economics, 64, 542-553.

Vidal, J. (2013, May 26). The Sumatran rainforest will mostly disappear within 20 years. The Observer. Retrieved March 10, 2014, from http://www.theguardian.com/world/2013/m ay/26/sumatra-borneo-deforestation-tigers-palm-oil

Vlosky, R. P., Ozanne, L. K., \& Fontenot, R. J. (1999). A conceptual model of US consumer willingness-to-pay for environmentally certified wood products. Journal of Consumer Marketing, 16, 116-136.

Vogt, D., Karus, M., Ortmann, S., Schmidt, C., \& Gahle, C. (2006). Wood-Plastic-Composites (WPC) - Märkte in Nordamerika, Japan und Europa mit Schwerpunkt auf Deutschland: Technische Eigenschaften - Anwendungsgebiete - Preise - Märkte - Akteure [Wood-PlasticComposites (WPC) - Markets in North America, Japan and Europe with emphasis on Germany: Engineering properties - Fields of application - Prices - Markets - Actors]. Retrieved on June 18, 2013, from http://www.nova-institut.de/pdf/06-01_WPC-Studie .pdf(accessed18June2013)

Walker, N., Patel, N., Davis, F., Milledge, S., \& Hulse, J. (2013). Demand-side interventions to reduce deforestation and forest degradation. London: Oldacres Printers.

Wan, C., Shen, G. Q., \& Yu, A. (2014). The moderating effect of perceived policy effectiveness on recycling intention. Journal of Environmental Psychology, 37, 55-60.

Webb, T. L., Benn, Y., \& Chang, B. P. (2014). Antecedents and consequences of monitoring domestic electricity consumption. Journal of Environmental Psychology, 40, 228-238.

Webb, T. L., \& Sheeran, P. (2006). Does changing behavioral intentions engender behavior change? A meta-analysis of the experimental evidence. Psychological Bulletin, 132, 249-268.

Weinfurter, S., \& Eder, A. (2009). Consumer perceptions of innovative wood-polymer composite decking with a focus on environmental aspects. Lenzinger Berichte, 87, 168-178. 
Wiedmann, K.-P., Hennigs, N., Pankalla, L., Kassubek, M., \& Seegebarth, B. (2011). Adoption barriers and resistance to sustainable solutions in the automotive sector. Journal of Business Research, 64, 1201-1206.

World Values Survey (2006). Weltwertestudie 2006. Retrieved October 11, 2013, from http: //www.worldvaluessurvey.org

Yamamoto, Y., Takeuchi, K., \& Shinkuma, T. (2014). Is there a price premium for certified wood? Empirical evidence from log auction data in Japan. Forest Policy and Economics, 38, 168-172.

Yeaton, K. (2008). Recruiting and managing the 'Why?' generation: Gen Y. The CPA Journal, $78,68-72$.

Young, W., Hwang, K., McDonald, S., \& Oates, C. J. (2010). Sustainable consumption: Green consumer behaviour when purchasing products. Sustainable Development, 18, 20-31.

Yue, C., Alfnes, F., \& Jensen, H. H. (2009). Discounting spotted apples: Investigating consumers' willingness to accept cosmetic damage in an organic product. Journal of Agricultural and Applied Economics, 41, 29-46.

Zhao, H.-H., Gao, Q., Wu, Y.-P., Wang, Y., \& Zhu, X.-D. (2014). What affects green consumer behavior in China? A case study from Qingdao. Journal of Cleaner Production, 63, $143-151$. 